Supporting information for

\title{
A straightforward Synthesis of Ynones by Reaction of Dimethylalkynylaluminum Reagents with Acid Chlorides
}

Baomin Wang, Martine Bonin and Laurent Micouin.*

Laboratoire de Chimie Thérapeutique, UMR 8638 associée au CNRS et à l'Université René Descartes, Faculté des Sciences Pharmaceutiques et Biologiques, 4 av de l'Observatoire, 75270 Paris cedex 06 (France)

laurent.micouin@univ-paris5.fr

\section{Table of Contents}

General methods: S2

Experimental data: S3-S7

References: S7

Copy of spectra: S8-S56 


\section{General methods}

Silica gel (230-400 mesh) was used for product purification by flash column chromatography. Solvents were purified and dried by standard techniques, and distilled prior to use. All organic extracts were dried over $\mathrm{MgSO}_{4}$ or $\mathrm{Na}_{2} \mathrm{SO}_{4}$. IR spectra were recorded on a FTIR spectrometer as thin film. ${ }^{1} \mathrm{H}$ and ${ }^{13} \mathrm{C}$ NMR spectra were recorded on a 300 or $400 \mathrm{MHz}$ spectrometer ( $\mathrm{H}$ value) with TMS as internal standard and $\mathrm{CDCl}_{3}$ as solvent. HRMS were determined on a Q Tof spectrometer. 

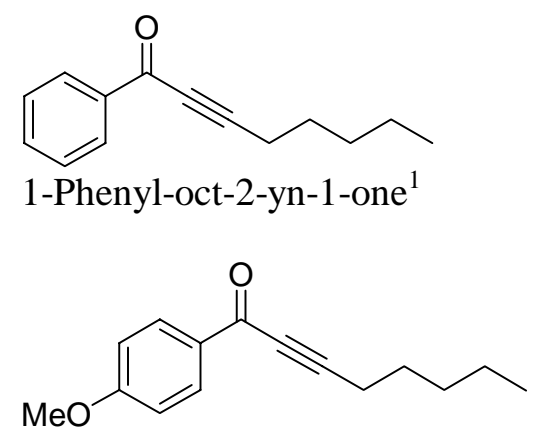

1-(4-Methoxy-phenyl)-oct-2-yn-1one

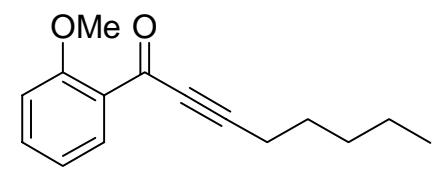

1-(2-Methoxy-phenyl)-oct-2-yn-1one $^{2}$

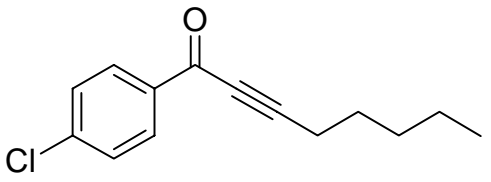

1-(4-Chloro-phenyl)-oct-2-yn-1-one

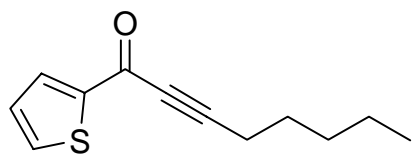

1-Thiophen-2-yl-oct-2-yn-1-one ${ }^{3}$

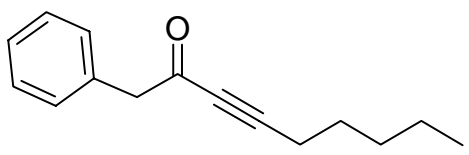

1-Phenyl-non-3-yn-2-one
Oil. ${ }^{1} \mathrm{H}$ NMR $\left(400 \mathrm{MHz}, \mathrm{CDCl}_{3}\right) \delta 8.13(\mathrm{~d}, J=8.25$ $\mathrm{Hz}, 2 \mathrm{H}), 7.59(\mathrm{td}, J=7.6,1.1 \mathrm{~Hz}, 1 \mathrm{H}), 7.4(\mathrm{~m}, 2 \mathrm{H})$, $2.49(\mathrm{t}, J=7.1 \mathrm{~Hz}, 2 \mathrm{H}), 1.68(\mathrm{~m}, 2 \mathrm{H}), 1.34-1.48(\mathrm{~m}$, $4 \mathrm{H}), 0.93$ (t, $J=7.2 \mathrm{~Hz}, 3 \mathrm{H})$.

Oil. ${ }^{1} \mathrm{H}$ NMR (400 MHz, $\left.\mathrm{CDCl}_{3}\right) \delta 8.10(\mathrm{~d}, J=8.9 \mathrm{~Hz}$, $2 \mathrm{H}), 6.94(\mathrm{~d}, J=8.9 \mathrm{~Hz}, 2 \mathrm{H}), 3.88(\mathrm{~s}, 3 \mathrm{H}), 2.48(\mathrm{t}, J=$ $7.1 \mathrm{~Hz}, 2 \mathrm{H}), 1.67(\mathrm{~m}, 2 \mathrm{H}), 1.34-1.47(\mathrm{~m}, 4 \mathrm{H}), 0.93(\mathrm{t}$, $J=7.2 \mathrm{~Hz}, 3 \mathrm{H}) ;{ }^{13} \mathrm{C} \mathrm{NMR}\left(100 \mathrm{MHz}, \mathrm{CDCl}_{3}\right) \delta 177.0$, 164.4, 132.0 (2C), 130.4, 113.8 (2C), 95.1, 79.7, 55.6, $31.2,27.6,22.2,19.2,14.0$; IR $\left(\mathrm{cm}^{-1}\right)$ 2956, 2952, 2237, 2199, 1638, 1597, 1574, 1508, 1257, 1167; HRMS (ES+) for $\mathrm{C}_{15} \mathrm{H}_{18} \mathrm{O}_{2} \mathrm{Na}$ : cald.: 253.1204, found: 253.1194 .

Oil. ${ }^{1} \mathrm{H}$ NMR (400 MHz, $\left.\mathrm{CDCl}_{3}\right) \delta 7.99(\mathrm{dd}, J=7.7$, $1.8 \mathrm{~Hz}, 1 \mathrm{H}), 7.48(\mathrm{ddd}, J=8.3,7.4,1.8 \mathrm{~Hz}, 1 \mathrm{H}), 6.97$ $(\mathrm{m} \mathrm{2H}), 3.89(\mathrm{~s}, 3 \mathrm{H}), 2.43(\mathrm{t}, J=7.1 \mathrm{~Hz}, 2 \mathrm{H}), 1.62(\mathrm{~m}$ 2H), 1.30-1.44 (m, 4H), $0.90(\mathrm{t}, J=7.2 \mathrm{~Hz}, 3 \mathrm{H}) ;{ }^{13} \mathrm{C}$ NMR $\left(100 \mathrm{MHz}, \mathrm{CDCl}_{3}\right) \delta 177.3,159.7,134.8,133.0$, $126.9,120.2,112.2,95.5,81.9,55.9,31.2,27.6,22.2$, 19.3, 14.0.

Oil. ${ }^{1} \mathrm{H}$ NMR $\left(400 \mathrm{MHz}, \mathrm{CDCl}_{3}\right) \delta 8.08(\mathrm{~d}, J=8.6 \mathrm{~Hz}$, $2 \mathrm{H}), 7.45(\mathrm{~d}, J=8.6 \mathrm{~Hz}, 2 \mathrm{H}), 2.50(\mathrm{t}, J=7.1 \mathrm{~Hz}, 2 \mathrm{H})$, $1.68(\mathrm{~m}, 2 \mathrm{H}), 1.34-1.47(\mathrm{~m}, 4 \mathrm{H}), 0.93(\mathrm{t}, J=7.2 \mathrm{~Hz}$, $3 \mathrm{H}) ;{ }^{13} \mathrm{C} \mathrm{NMR}\left(100 \mathrm{MHz}, \mathrm{CDCl}_{3}\right) \delta 177.0,140.5$, 135.5, 131.0 (2C), 128.9 (2C), 97.6, 79.5, 31.2, 27.6, 22.2, 19.3, 14.0; IR $\left(\mathrm{cm}^{-1}\right) 2956,2931,2860,2237$, 2201, 1648, 1586, 1262; HRMS (ES+) for $\mathrm{C}_{14} \mathrm{H}_{15} \mathrm{ONaCl}$ : cald.: 257.0709, found: 257.0707.

Oil. ${ }^{1} \mathrm{H}$ NMR $\left(400 \mathrm{MHz}, \mathrm{CDCl}_{3}\right) \delta 7.88(\mathrm{dd}, J=3.8$, $1.0 \mathrm{~Hz}, 1 \mathrm{H}), 7.67(\mathrm{dd}, J=4.9,1.0 \mathrm{~Hz}, 1 \mathrm{H}), 7.14(\mathrm{t}, J=$ $3.9 \mathrm{~Hz}, 1 \mathrm{H}), 2.46(\mathrm{t}, J=7.1 \mathrm{~Hz}, 2 \mathrm{H}), 1.66(\mathrm{~m}, 2 \mathrm{H})$, $1.33-1.46(\mathrm{~m}, 4 \mathrm{H}), 0.92(\mathrm{t}, J=7.2 \mathrm{~Hz}, 3 \mathrm{H}) ;{ }^{13} \mathrm{C} \mathrm{NMR}$ $\left(100 \mathrm{MHz}, \mathrm{CDCl}_{3}\right) \delta 170.2,145.2,135.0(2 \mathrm{C}), 128.3$, 95.6, 79.4, 31.2, 27.5, 22.2, 19.2, 14.0.

Amorphous solid. ${ }^{1} \mathrm{H}$ NMR $\left(400 \mathrm{MHz}, \mathrm{CDCl}_{3}\right) \delta 7.25-$ $7.36(\mathrm{~m}, 5 \mathrm{H}), 3.82(\mathrm{~s}, 2 \mathrm{H}), 2.31(\mathrm{t}, J=7.1 \mathrm{~Hz}, 2 \mathrm{H})$, $1.51(\mathrm{~m}, 2 \mathrm{H}), 1.30(\mathrm{~m}, 4 \mathrm{H}), 0.90(\mathrm{t}, J=7.1 \mathrm{~Hz}, 3 \mathrm{H})$; ${ }^{13} \mathrm{C}$ NMR $\left(100 \mathrm{MHz}, \mathrm{CDCl}_{3}\right) \delta 185.5,133.4,129.9$ (2C), 128.7 (2C), 127.4, 96.7, 80.8, 52.3, 31.0, 27.4, 22.2, 19.1, 14.0; IR $\left(\mathrm{cm}^{-1}\right)$ 2957, 2236, 1700, 1285; HRMS (ES+) for $\mathrm{C}_{15} \mathrm{H}_{18} \mathrm{ONa}$ : cald.: 237.1255, found: 237.1249 . 


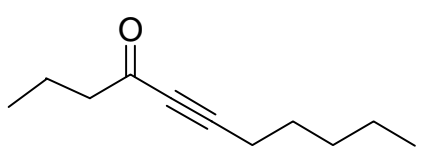

Undec-5-yn-4-one ${ }^{4}$

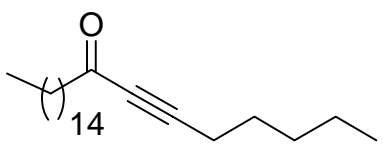

Tricos-6-yn-8-one

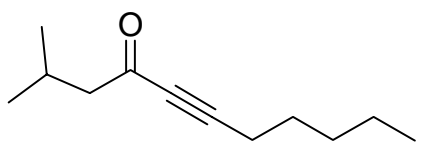

2-Methyl-undec-5-yn-4-one ${ }^{5}$

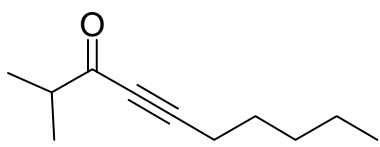

2-Methyl-dec-4-yn-3-one ${ }^{6}$

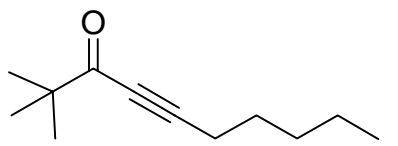

2,2-Dimethyl-dec-4-yn-3-one ${ }^{6}$

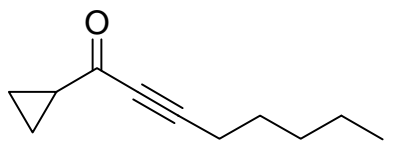

1-Cyclopropyl-oct-2-yn-1-one

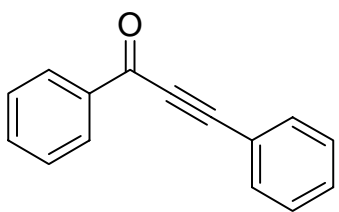

1,3-Diphenyl-propynone ${ }^{7}$
Oil. ${ }^{1} \mathrm{H}$ NMR $\left(400 \mathrm{MHz}, \mathrm{CDCl}_{3}\right) \delta 2.49(\mathrm{t}, J=7.3 \mathrm{~Hz}$, $2 \mathrm{H}), 2.34(\mathrm{t}, J=7.1 \mathrm{~Hz}, 2 \mathrm{H}), 1.67(\mathrm{~m}, 2 \mathrm{H}), 1.56(\mathrm{~m}$, 2H), 1.31-1.41 (m, 4H), $0.93(\mathrm{~m}, 6 \mathrm{H}) ;{ }^{13} \mathrm{C}$ NMR (100 $\left.\mathrm{MHz}, \mathrm{CDCl}_{3}\right) \delta 188.5,94.3,81.0,47.5,31.1,27.5$, $22.2,19.0,17.7,13.9,13.6$.

Oil. ${ }^{1} \mathrm{H}$ NMR $\left(400 \mathrm{MHz}, \mathrm{CDCl}_{3}\right) \delta 2.51(\mathrm{t}, J=7.4 \mathrm{~Hz}$, $2 \mathrm{H}), 2.35(\mathrm{t}, J=7.1 \mathrm{~Hz}, 2 \mathrm{H}), 1.56-1.66(\mathrm{~m}, 4 \mathrm{H}), 1.25-$ $1.40(\mathrm{~m}, 28 \mathrm{H}), 0.89(\mathrm{~m}, 6 \mathrm{H}) ;{ }^{13} \mathrm{C}$ NMR $(100 \mathrm{MHz}$, $\left.\mathrm{CDCl}_{3}\right) \delta 188.7,94.3,81.0,45.6,32.0,31.1,29.8$, $29.5,29.1,27.5,24.3,22.8,19.0,14.2,14.0 ;$ IR $\left(\mathrm{cm}^{-1}\right)$ 2925, 2853, 2361, 2212, 1676, 1465; HRMS (ES+) for $\mathrm{C}_{23} \mathrm{H}_{42} \mathrm{ONa}$ : cald.: 357.3133 , found: 357.3135 .

Oil. ${ }^{1} \mathrm{H}$ NMR (400 MHz, $\left.\mathrm{CDCl}_{3}\right) \delta 2.40(\mathrm{~d}, J=7.0 \mathrm{~Hz}$, $2 \mathrm{H}), 2.34(\mathrm{t}, J=7.1 \mathrm{~Hz}, 2 \mathrm{H}), 2.23(\mathrm{~m}, 1 \mathrm{H}), 1.57(\mathrm{~m}$, 2H), 1.29-1.41 (m, 4H), $0.95(\mathrm{~d}, J=6.6 \mathrm{~Hz}, 6 \mathrm{H}), 0.89$ $(\mathrm{t}, J=7.0 \mathrm{~Hz}, 3 \mathrm{H}) ;{ }^{13} \mathrm{C}$ NMR $\left(100 \mathrm{MHz}, \mathrm{CDCl}_{3}\right) \delta$ $188.4,94.3,81.2,54.6,31.1,27.5,25.3,22.5$ (2C), $22.2,19.0,14.0$.

Oil. ${ }^{1} \mathrm{H}$ NMR $\left(400 \mathrm{MHz}, \mathrm{CDCl}_{3}\right) \delta 2.61$ (hept, $J=7.0$ $\mathrm{Hz}, 1 \mathrm{H}), 2.37(\mathrm{t}, J=7.1 \mathrm{~Hz}, 2 \mathrm{H}), 1.59(\mathrm{~m}, 2 \mathrm{H}), 1.30-$ $1.42(\mathrm{~m}, 4 \mathrm{H}), 1.18(\mathrm{~d}, J=7.0 \mathrm{~Hz}, 6 \mathrm{H}), 0.90(\mathrm{t}, J=7.1$ $\mathrm{Hz}, 3 \mathrm{H}) ;{ }^{13} \mathrm{C}$ NMR $\left(100 \mathrm{MHz}, \mathrm{CDCl}_{3}\right) \delta 192.7,95.4$, 79.9, 43.1, 31.1, 27.3, 22.2, 19.0, 18.1 (2C), 14.0.

Oil. ${ }^{1} \mathrm{H}$ NMR $\left(400 \mathrm{MHz}, \mathrm{CDCl}_{3}\right) \delta 2.38(\mathrm{~d}, J=7.1$ $\mathrm{Hz}, 2 \mathrm{H}), 1.60$ (m, 2H), 1.31-1.42 (m, 4H), 1.19 (s, 9H), 0.91 (t, $J=7.1 \mathrm{~Hz}, 3 \mathrm{H}) ;{ }^{13} \mathrm{C}$ NMR $(100 \mathrm{MHz}$, $\left.\mathrm{CDCl}_{3}\right) \delta 194.6,95.9,78.9,44.7,31.1,27.6,26.2$ (3C), 22.2, 19.0, 14.0 .

Oil. ${ }^{1} \mathrm{H}$ NMR (400 MHz, $\left.\mathrm{CDCl}_{3}\right) \delta 2.34(\mathrm{t}, J=7.1$ $\mathrm{Hz}, 2 \mathrm{H}), 2.01(\mathrm{~m} 1 \mathrm{H}), 1.57(\mathrm{~m}, 2 \mathrm{H}), 1.29-1.39(\mathrm{~m}$, $4 \mathrm{H}), 1.20(\mathrm{~m}, 2 \mathrm{H}), 1.01(\mathrm{~m}, 2 \mathrm{H}), 0.90(\mathrm{t}, J=7.1 \mathrm{~Hz}$, $3 \mathrm{H}) ;{ }^{13} \mathrm{C}$ NMR $\left(100 \mathrm{MHz}, \mathrm{CDCl}_{3}\right) \delta 188.9,94.1$, 78.9, 31.1, 27.5, 24.5, 22.2, 18.9, 14.0, 10.8 (2C); IR $\left(\mathrm{cm}^{-1}\right)$ 2933, 2861, 2217, 1658, 1377, 1261, 1173; HRMS (ES+) for $\mathrm{C}_{11} \mathrm{H}_{16} \mathrm{ONa}$ : cald.: 187.1099 , found: 187.1092.

Oil. ${ }^{1} \mathrm{H}$ NMR (400 MHz, $\left.\mathrm{CDCl}_{3}\right) \delta 8.23(\mathrm{dd}, J=8.5$, $1.3 \mathrm{~Hz}, 2 \mathrm{H}), 7.69(\mathrm{dd}, J=8.5,1.5 \mathrm{~Hz}, \mathrm{H}), 7.65(\mathrm{t}, J=$ $7.4 \mathrm{~Hz}, 1 \mathrm{H}), 7.42-7.55(\mathrm{~m}, 5 \mathrm{H}) ;{ }^{13} \mathrm{C}$ NMR $(100 \mathrm{MHz}$, $\left.\mathrm{CDCl}_{3}\right) \delta 178.2,137.0,134.3,133.2,130.9,129.7$, 128.8, 120.2, 93.2, 87.0. 
<smiles>O=C(C#Cc1ccccc1)C1CC1</smiles>

1-Cyclopropyl-3-phenyl-propynone

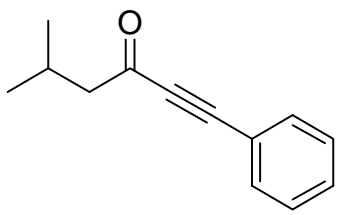

5-Methyl-1-phenyl-hex-1-yn-3-one ${ }^{8}$<smiles>O=C(C#CCCCCl)c1ccccc1</smiles>

6-Chloro-1-phenyl-hex-2-yn-1-one

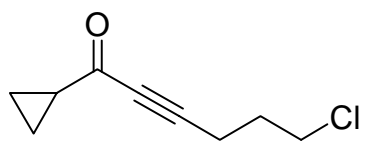

6-Chloro-1-cyclopropyl-hex-2-yn1-one

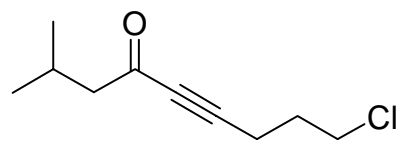

9-Chloro-2-methyl-non-5-yn-4-one

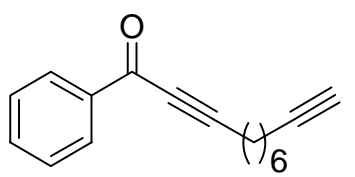

1-Phenyl-undeca-2,10-diyn-1-one
Oil. ${ }^{1} \mathrm{H}$ NMR (400 MHz, $\left.\mathrm{CDCl}_{3}\right) \delta 7.56(\mathrm{~m}, 2 \mathrm{H})$, 7.35-7.44 (m, 3H), $2.16(\mathrm{~m}, 1 \mathrm{H}), 1.32(\mathrm{~m}, 2 \mathrm{H}), 1.10$ $(\mathrm{m}, 2 \mathrm{H}) ;{ }^{13} \mathrm{C}$ NMR $\left(100 \mathrm{MHz}, \mathrm{CDCl}_{3}\right) \delta 188.5,133.1$ (2C), 130.7, 128.7 (2C), 120.1, 90.5, 86.3, 24.7, 11.3 (2C); IR ( $\left.\mathrm{cm}^{-1}\right) 3058,3011,2205,1654,1489,1079$; HRMS (ES+) for $\mathrm{C}_{12} \mathrm{H}_{10} \mathrm{ONa}$ : cald.: 193.0629, found: 193.0626 .

Oil. ${ }^{1} \mathrm{H}$ NMR (400 MHz, $\left.\mathrm{CDCl}_{3}\right) \delta 7.57$ (m 2H), 7.36-7.44 (m, 3H), 2.55 (d, $J=7.1 \mathrm{~Hz}, 2 \mathrm{H}), 2.33$ (m, $1 \mathrm{H}), 1.01(\mathrm{~d}, J=6.7 \mathrm{~Hz}, 6 \mathrm{H}) ;{ }^{13} \mathrm{C}$ NMR $(100 \mathrm{MHz}$, $\left.\mathrm{CDCl}_{3}\right) \delta 188.0,133.1$ (2C), 130.8, 128.7 (2C), $120.1,90.5,88.2,54.6,25.4,22.6(2 \mathrm{C})$.

Oil. ${ }^{1} \mathrm{H}$ NMR $\left(400 \mathrm{MHz}, \mathrm{CDCl}_{3}\right) \delta 8.12(\mathrm{~m}, 2 \mathrm{H})$, $7.60(\mathrm{~m}, 1 \mathrm{H}), 7.48(\mathrm{~m}, 2 \mathrm{H}), 3.71(\mathrm{t}, J=6.2 \mathrm{~Hz}, 2 \mathrm{H})$, $2.72(\mathrm{t}, J=6.9 \mathrm{~Hz}, 2 \mathrm{H}), 2.13(\mathrm{~m}, 2 \mathrm{H}) ;{ }^{13} \mathrm{C}$ NMR $(100$ $\left.\mathrm{MHz}, \mathrm{CDCl}_{3}\right) \delta 178.1,136.8,134.2,129.7(2 \mathrm{C})$, 128.7 (2C), 94.3, 80.3, 43.5, 30.6, 16.7; IR $\left(\mathrm{cm}^{-1}\right)$ 2960, 2235, 2202, 1644, 1597, 1449, 1312, 1265; HRMS (ES+) for $\mathrm{C}_{12} \mathrm{H}_{11} \mathrm{ONaCl}$ : cald.: 229.0396, found: 229.0398.

Oil. ${ }^{1} \mathrm{H}$ NMR $\left(400 \mathrm{MHz}, \mathrm{CDCl}_{3}\right) \delta 3.62(\mathrm{t}, J=6.2$ $\mathrm{Hz}, 2 \mathrm{H}), 2.54(\mathrm{t}, J=6.9 \mathrm{~Hz}, 2 \mathrm{H}), 2.00(\mathrm{~m}, 3 \mathrm{H}), 1.18$ $(\mathrm{m}, 2 \mathrm{H}), 1.00(\mathrm{~m}, 2 \mathrm{H}) ;{ }^{13} \mathrm{C} \mathrm{NMR}\left(100 \mathrm{MHz}, \mathrm{CDCl}_{3}\right)$ $\delta 188.4,91.4,79.6,43.4,30.5,245,16.4,11.0(2 \mathrm{C})$; IR $\left(\mathrm{cm}^{-1}\right)$ 3012, 2963, 2220, 1655, 1379, 1262, 1174; HRMS (ES+) for $\mathrm{C}_{9} \mathrm{H}_{11} \mathrm{ONaCl}$ : cald.: 193.0396, found: 193.0394.

Oil. ${ }^{1} \mathrm{H}$ NMR (400 MHz, $\left.\mathrm{CDCl}_{3}\right) \delta 3.63(\mathrm{t}, J=6.2$ $\mathrm{Hz}, 2 \mathrm{H}), 2.56(\mathrm{t}, J=6.9 \mathrm{~Hz}, 2 \mathrm{H}), 2.39(\mathrm{~d}, J=7.1 \mathrm{~Hz}$, $2 \mathrm{H}), 2.22(\mathrm{~m}, 1 \mathrm{H}), 2.02,(\mathrm{~m}, 2 \mathrm{H}), 0.95(\mathrm{~d}, J=6.7 \mathrm{~Hz}$, $6 \mathrm{H}) ;{ }^{13} \mathrm{C} \mathrm{NMR}\left(100 \mathrm{MHz}, \mathrm{CDCl}_{3}\right) \delta 187.9,91.5$, 81.8, 54.5, 43.4, 30.5, 25.2, 22.5 (2C), 16.4; IR $\left(\mathrm{cm}^{-1}\right)$ 2959, 2214, 1672; HRMS (ES+) for $\mathrm{C}_{10} \mathrm{H}_{16} \mathrm{OCl}$ : cald.: 187.0890 , found: 187.0889 .

Oil. ${ }^{1} \mathrm{H}$ NMR (400 MHz, $\left.\mathrm{CDCl}_{3}\right) \delta 8.13(\mathrm{~m}, 2 \mathrm{H})$, 7.46-7.61 (m, 3H), $2.51(\mathrm{t}, J=7.1 \mathrm{~Hz}, 2 \mathrm{H}), 2.20(\mathrm{td}$, $J=6.9,2.6 \mathrm{~Hz}, 2 \mathrm{H}), 1.95(\mathrm{t}, J=2.6 \mathrm{~Hz}, 1 \mathrm{H}), 1.70$ $(\mathrm{m}, 2 \mathrm{H}), 1.48-1.58(\mathrm{~m}, 6 \mathrm{H}) ;{ }^{13} \mathrm{C}$ NMR $(100 \mathrm{MHz}$, $\left.\mathrm{CDCl}_{3}\right) \delta 178.3,137.0,134.0,129.7$ (2C), 128.6 (2C), 96.7, 84.5, 79.9, 68.5, 28.5, 28.3, 28.2, 27.8, 19.3, 18.4; IR ( $\left.\mathrm{cm}^{-1}\right) 3299,2936,2859,2234,2201$, 1643, 1265; HRMS (ES+) for $\mathrm{C}_{17} \mathrm{H}_{18} \mathrm{ONa}$ : cald.: 261.1255, found: 261.1259 . 
<smiles>C#CC#CC(=O)c1ccc(OC)cc1</smiles>

1-(4-Methoxy-phenyl)-undeca2,10-diyn-1-one

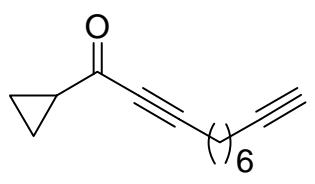

1-Cyclopropyl-undeca-2,10-diyn-1one

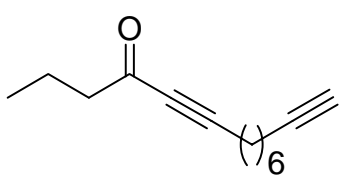

Tetradeca-5,13-diyn-4-one

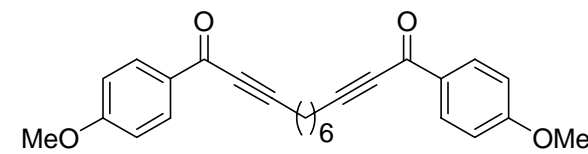

1,12-Bis-(4-methoxy-phenyl)dodeca-2,10-diyne-1,12-dione

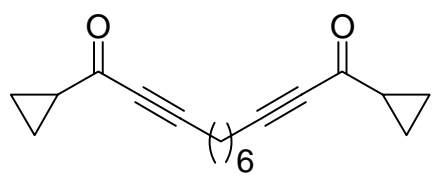

1,12-Dicyclopropyl-dodeca-2,10diyne-1,12-dione
Oil. ${ }^{1} \mathrm{H}$ NMR $\left(400 \mathrm{MHz}, \mathrm{CDCl}_{3}\right) \delta 8.10(\mathrm{~d}, J=8.9$ $\mathrm{Hz}, 2 \mathrm{H}), 6.94(\mathrm{~d}, J=8.9 \mathrm{~Hz}, 2 \mathrm{H}), 3.87(\mathrm{~s}, 3 \mathrm{H}), 2.48$ $(\mathrm{t}, J=7.1 \mathrm{~Hz}, 2 \mathrm{H}), 2.19(\mathrm{td}, J=6.8,2.6 \mathrm{~Hz}, 2 \mathrm{H})$, $1.94(\mathrm{t}, J=2.6 \mathrm{~Hz}, 1 \mathrm{H}), 1.67(\mathrm{~m}, 2 \mathrm{H}), 1.46-1.56(\mathrm{~m}$, $6 \mathrm{H}) ;{ }^{13} \mathrm{C}$ NMR $\left(100 \mathrm{MHz}, \mathrm{CDCl}_{3}\right) \delta 177.0,164.4$, 132.0 (2C), 130.4, 113.8 (2C), 95.8, 84.5, 79.8, 68.5, $55.7,28.5,28.3,28.2,27.8,19.2,18.4 ; \mathrm{IR}\left(\mathrm{cm}^{-1}\right)$ 3296, 2937, 2859, 2236, 2199, 1637, 1597, 1508, 1258, 1167; HRMS (ES+) for $\mathrm{C}_{18} \mathrm{H}_{21} \mathrm{O}_{2}$ : cald.: 269.1542, found: 269.1539 .

Oil. ${ }^{1} \mathrm{H}$ NMR $\left(400 \mathrm{MHz}, \mathrm{CDCl}_{3}\right) \delta 2.34(\mathrm{t}, J=7.0$ $\mathrm{Hz}, 2 \mathrm{H}), 2.17(\mathrm{td}, J=6.9,2.6 \mathrm{~Hz}, 2 \mathrm{H}), 2.00(\mathrm{~m}, 1 \mathrm{H})$, $1.93(\mathrm{t}, J=2.6 \mathrm{~Hz}, 1 \mathrm{H}), 1.49-1.58(\mathrm{~m}, 4 \mathrm{H}), 1.41(\mathrm{~m}$, $4 \mathrm{H}), 1.18(\mathrm{~m}, 2 \mathrm{H}), 1.00(\mathrm{~m}, 2 \mathrm{H}) ;{ }^{13} \mathrm{C}$ NMR (100 $\left.\mathrm{MHz}, \mathrm{CDCl}_{3}\right) \delta 188.7,93.8,84.5,79.0,68.4,28.4$, $28.3,28.1,27.7,24.5,18.9,18.4,10.8(2 \mathrm{C})$; IR $\left(\mathrm{cm}^{-1}\right)$ 3295, 2937, 2860, 2217, 1655, 1377, 1262, 1174; HRMS (ES+) for $\mathrm{C}_{14} \mathrm{H}_{18} \mathrm{ONa}$ : cald.: 225.1255, found: 225.1266 .

Oil. ${ }^{1} \mathrm{H}$ NMR $\left(400 \mathrm{MHz}, \mathrm{CDCl}_{3}\right) \delta 2.50(\mathrm{t}, J=7.3$ $\mathrm{Hz}, 2 \mathrm{H}), 2.36(\mathrm{t}, J=7.1 \mathrm{~Hz}, 2 \mathrm{H}), 2.19$ (td, $J=6.9$, $2.6 \mathrm{~Hz}, 2 \mathrm{H}), 1.94(\mathrm{t}, J=2.6 \mathrm{~Hz}, 1 \mathrm{H}), 1.69(\mathrm{~m}, 2 \mathrm{H})$, $1.55(\mathrm{~m}, 4 \mathrm{H}), 1.43(\mathrm{~m}, 4 \mathrm{H}), 0.94(\mathrm{t}, J=7.4 \mathrm{~Hz}, 3 \mathrm{H})$; ${ }^{13} \mathrm{C}$ NMR $\left(100 \mathrm{MHz}, \mathrm{CDCl}_{3}\right) \delta 188.5,94.1,84.5$, $81.1,68.4,47.5,28.4,28.3,28.2,27.7,19.0,18.4$, 17.7, 13.6; IR $\left(\mathrm{cm}^{-1}\right)$ 3301, 2936, 2861, 2211, 1673; HRMS (ES+) for $\mathrm{C}_{14} \mathrm{H}_{20} \mathrm{ONa}$ : cald.: 227.1412, found: 227.1414.

Amorphous solid. ${ }^{1} \mathrm{H}$ NMR (400 MHz, $\left.\mathrm{CDCl}_{3}\right) \delta$ $8.10(\mathrm{~d}, J=8.9 \mathrm{~Hz}, 4 \mathrm{H}), 6.94(\mathrm{~d}, J=8.9 \mathrm{~Hz}, 4 \mathrm{H})$, $3.87(\mathrm{~s}, 6 \mathrm{H}), 2.50(\mathrm{t}, J=7.0 \mathrm{~Hz}, 4 \mathrm{H}), 1.70(\mathrm{~m}, 4 \mathrm{H})$, $1.54(\mathrm{~m}, 4 \mathrm{H}) ;{ }^{13} \mathrm{C}$ NMR $\left(100 \mathrm{MHz}, \mathrm{CDCl}_{3}\right) \delta 177.0$, $164.4,132.0,130.4,113.9,95.6,79.9,55.7,28.5$, 27.8, 19.2; IR $\left(\mathrm{cm}^{-1}\right)$ 3054, 2940, 2364, 2225, 2199, 1636, 1597, 1265; HRMS (ES+) for $\mathrm{C}_{26} \mathrm{H}_{27} \mathrm{O}_{4}$ : cald.: 403.1909, found: 403.1904 .

Oil. ${ }^{1} \mathrm{H}$ NMR $\left(400 \mathrm{MHz}, \mathrm{CDCl}_{3}\right) \delta 2.34(\mathrm{t}, J=7.0$ $\mathrm{Hz}, 4 \mathrm{H}), 2.00(\mathrm{~m}, 2 \mathrm{H}), 1.57(\mathrm{~m}, 4 \mathrm{H}), 1.41(\mathrm{~m}, 4 \mathrm{H})$, $1.19(\mathrm{~m}, 4 \mathrm{H}), 1.00(\mathrm{~m}, 4 \mathrm{H}) ;{ }^{13} \mathrm{C}$ NMR $(100 \mathrm{MHz}$, $\left.\mathrm{CDCl}_{3}\right) \delta 188.7,93.6,79.1,28.3,27.6,24.5,18.9$, 10.9; IR ( $\left.\mathrm{cm}^{-1}\right)$ 2937, 2860, 2217, 1655, 1377, 1262, 1174; HRMS (ES+) for $\mathrm{C}_{18} \mathrm{H}_{23} \mathrm{O}_{2}$ : cald.: 271.1698, found: 271.1693 . 


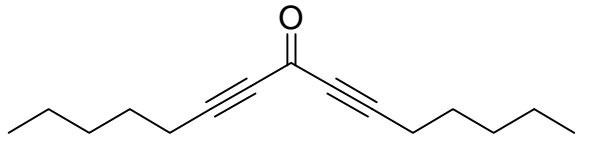

pentadeca-6,9-diyn-8-one
Oil. ${ }^{1} \mathrm{H}$ NMR $\left(400 \mathrm{MHz}, \mathrm{CDCl}_{3}\right) \delta 2.39(\mathrm{t}, J=7.1$ $\mathrm{Hz}, 4 \mathrm{H}), 1.60(\mathrm{~m}, 4 \mathrm{H}), 1.30-1.43(\mathrm{~m}, 8 \mathrm{H}), 0.91(\mathrm{t}, J=$ $7.1 \mathrm{~Hz}, 6 \mathrm{H}) ;{ }^{13} \mathrm{C}$ NMR $\left(100 \mathrm{MHz}, \mathrm{CDCl}_{3}\right) \delta 161.6$, $94.9,82.4,31.1,27.3,22.2,19.2,14.0 ; \operatorname{IR}\left(\mathrm{cm}^{-1}\right)$ 2937, 2861, 2207, 1628, 1244; HRMS (ES+) for $\mathrm{C}_{15} \mathrm{H}_{23} \mathrm{O}$ : cald.: 219.1749, found: 219.1758 .

References:

1) Bourgain, M.; Normand, J. F. Bull. Soc. Chim. Fr. 1973, 6, 2137.

2) Lin, C.-F.; Duh, T.-H.; Lu, W.-D.; Lee, J.-L.; Lee, C.-Y.; Chen, C.-C.; Wu, M.-J. J. Chin. Chem. Soc. 2004, 51, 183.

3) Nakhmanovich, A. S.; Deryagina, E. N.; Elokhina, V. N. Khim. Geterotsikl. Soedin. 1971, 3,45 .

4) Yamagushi, M.; Shibato, K.; Fujiwara, S.; Hirao, I. Synthesis, 1986, 421.

5) Glazunova, N. P.; Kirillova, L. P.; Yashina, O. G.; Vereshchagin, L. I. Khim-Farm. Zh. 1974, 8, 18.

6) Shergina, S. I.; Sokolov, I. E.; Anaina, A. S. Medeleev Commun. 1994, 6, 207

7) Chen, L.; Li, C.-J. Org. Lett. 2004, 6, 3151.

8) Vereshchagin, L. I.; Yashina, O. G.; Zarva, T. V. Biol. Aktiv. Soedin. 1968, 58. 


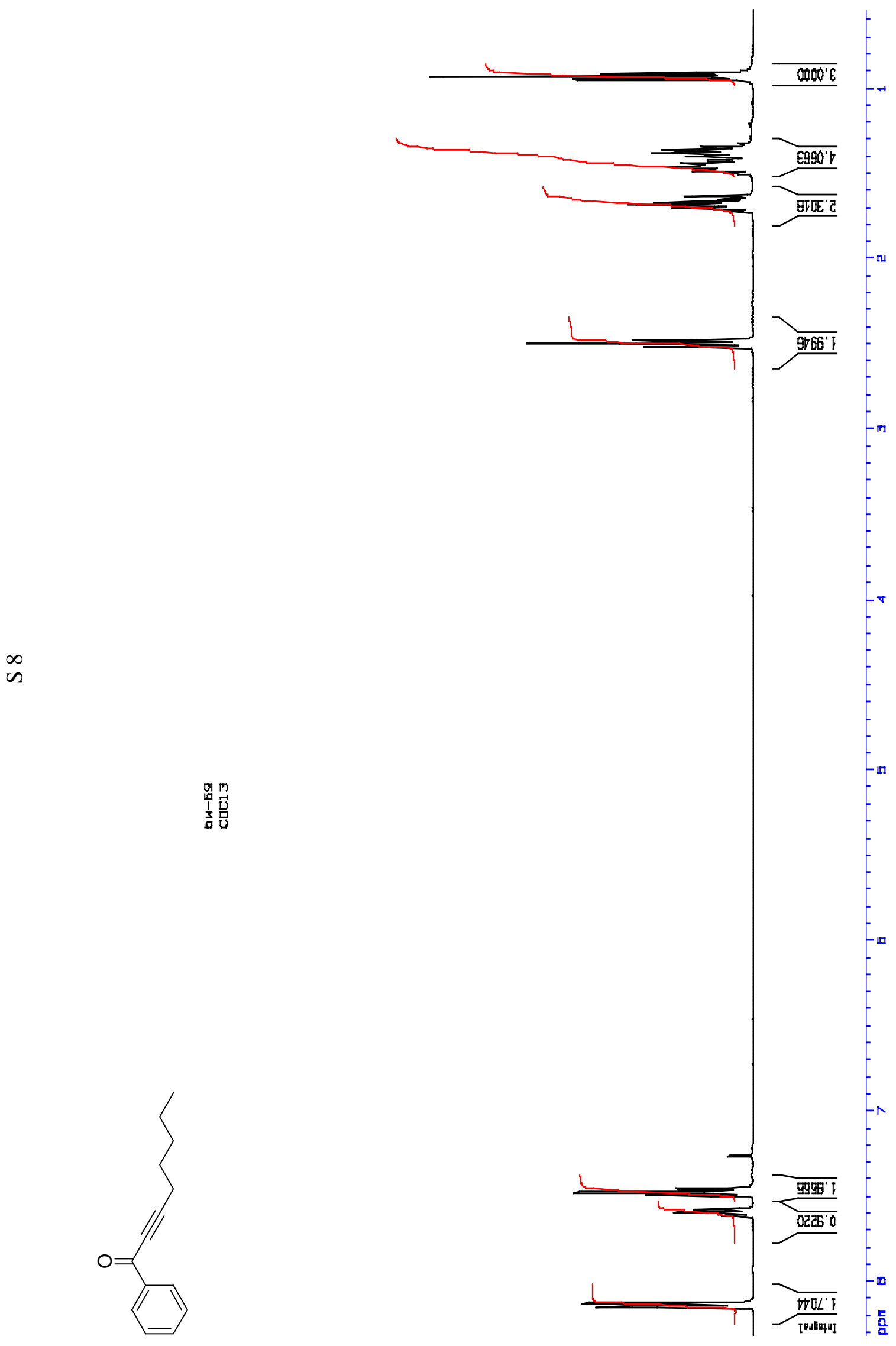




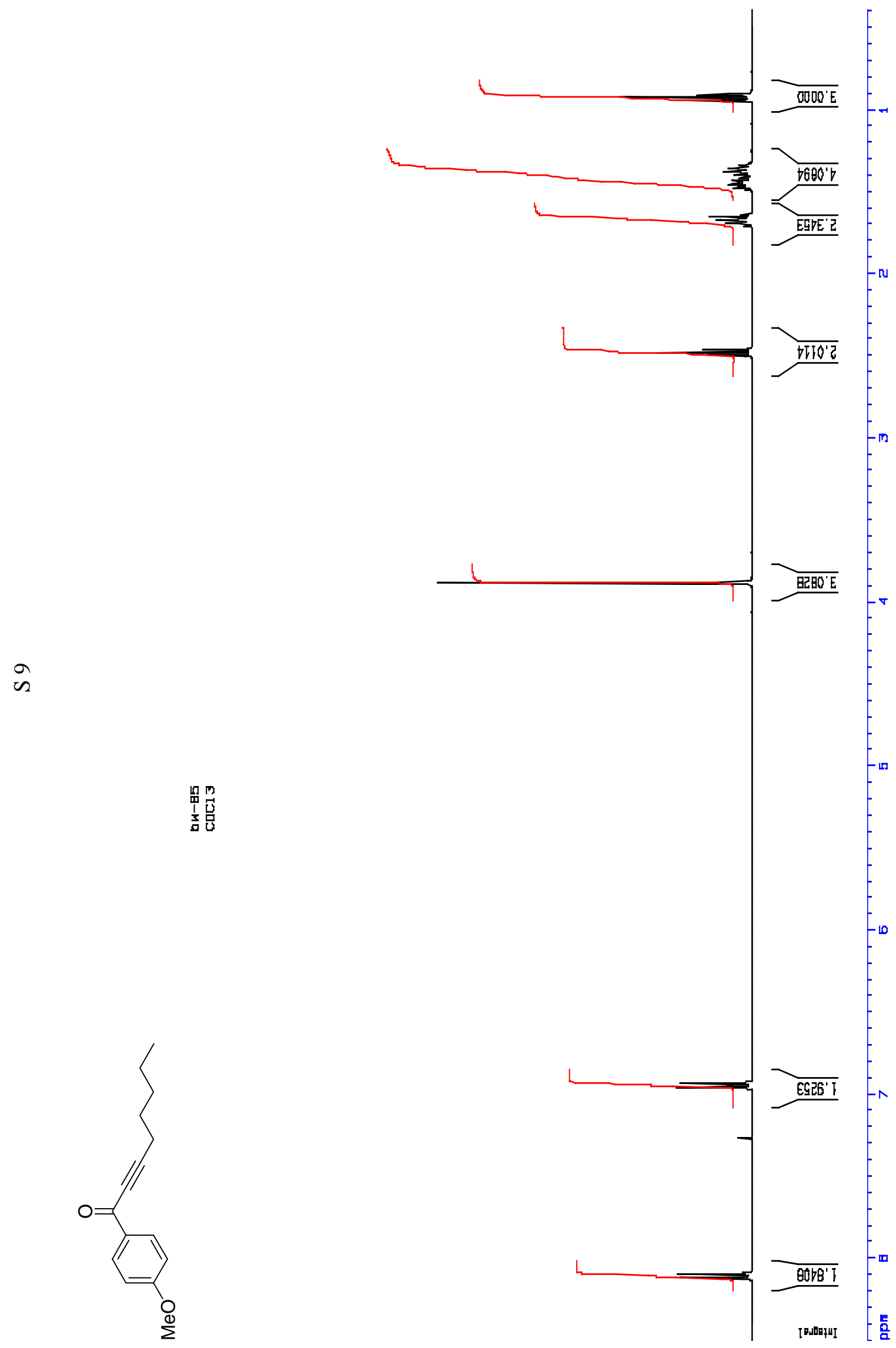



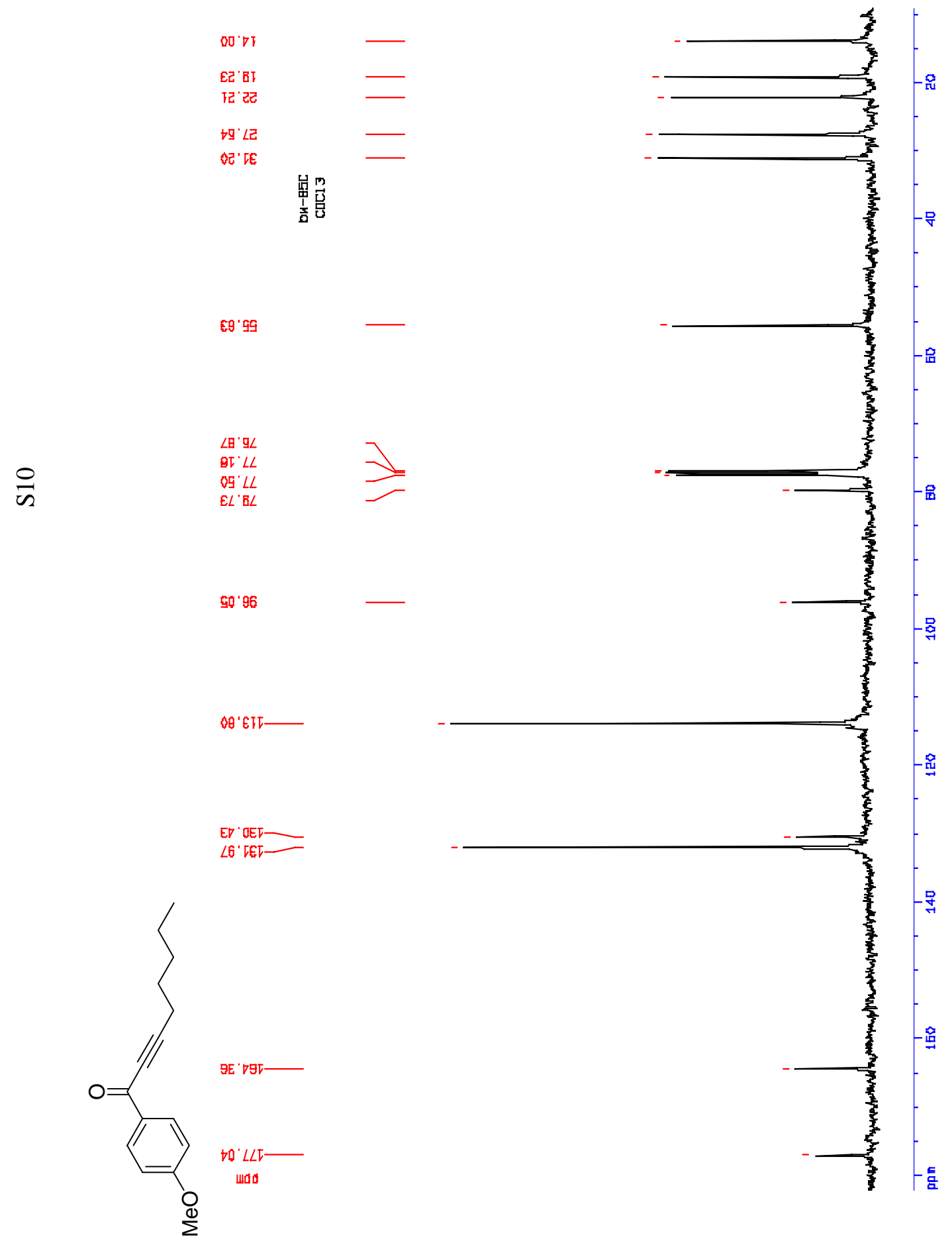


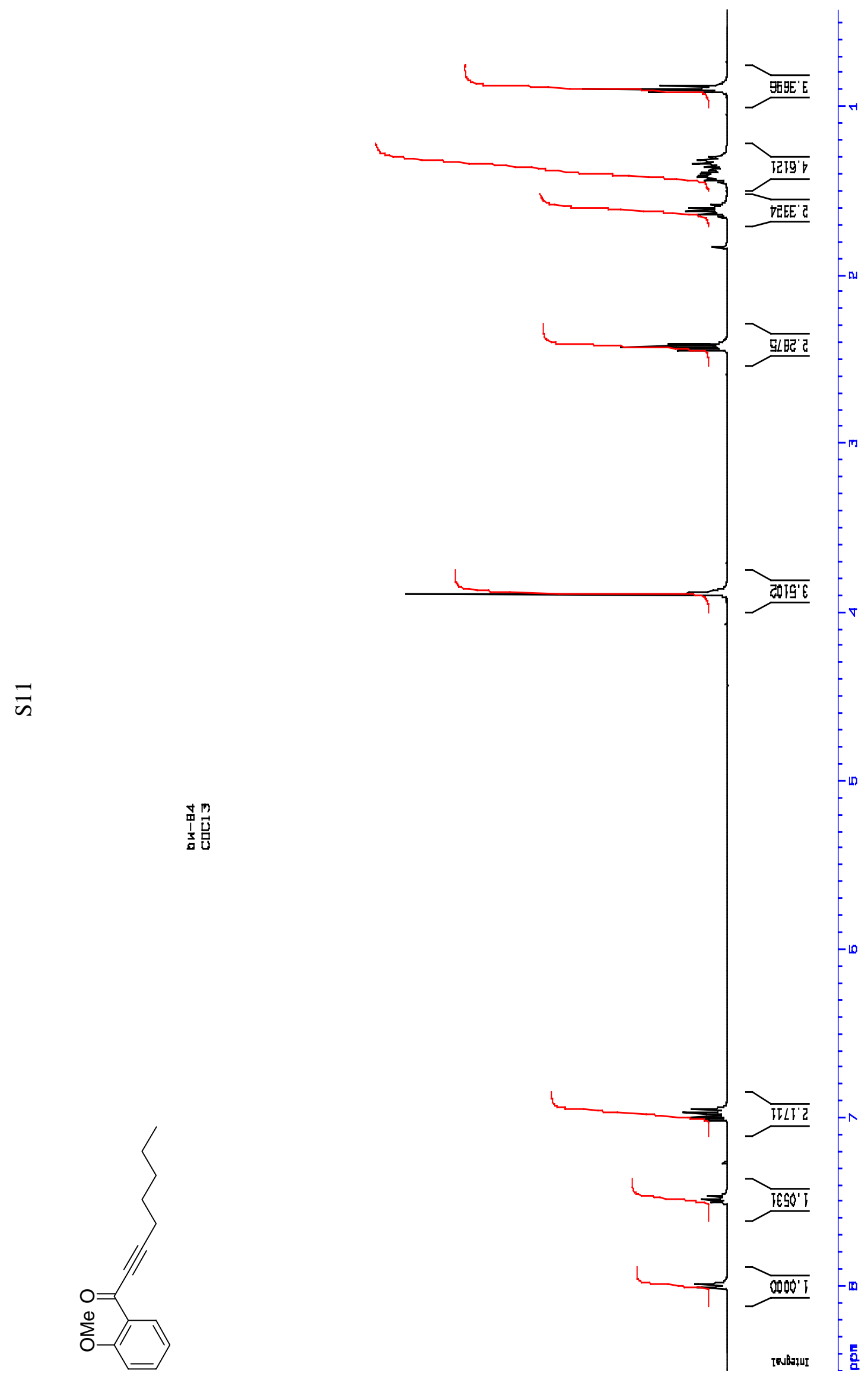



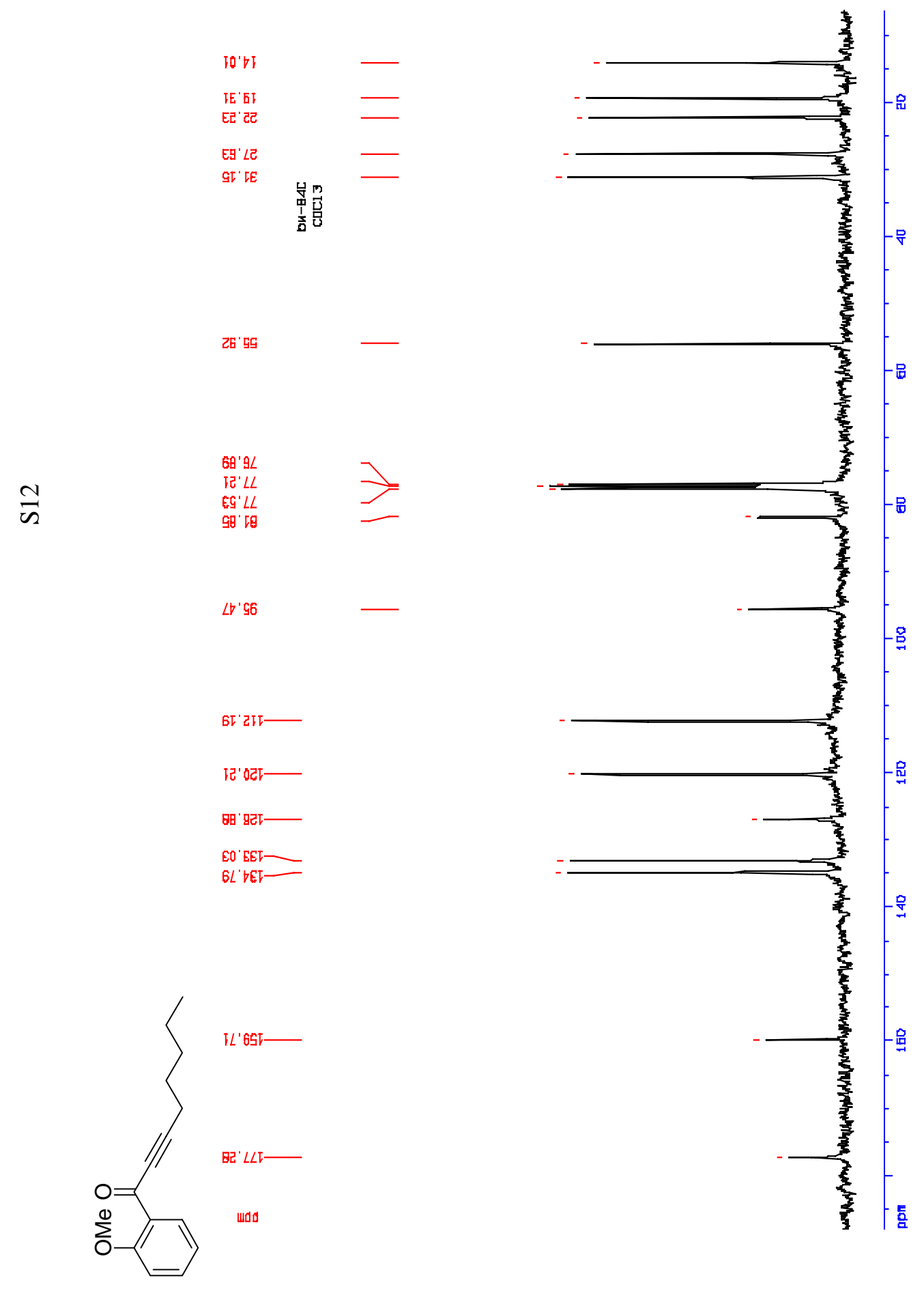


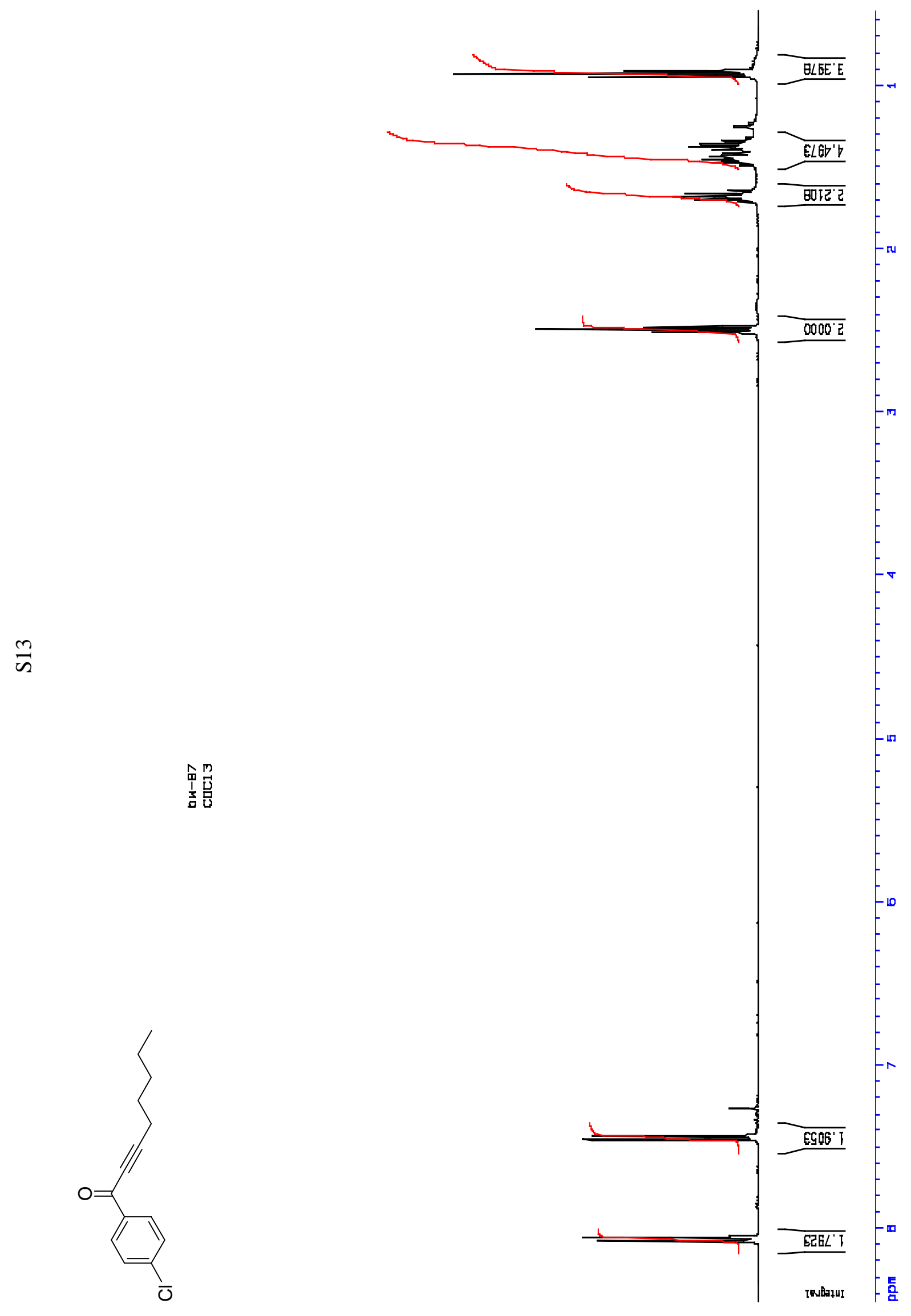




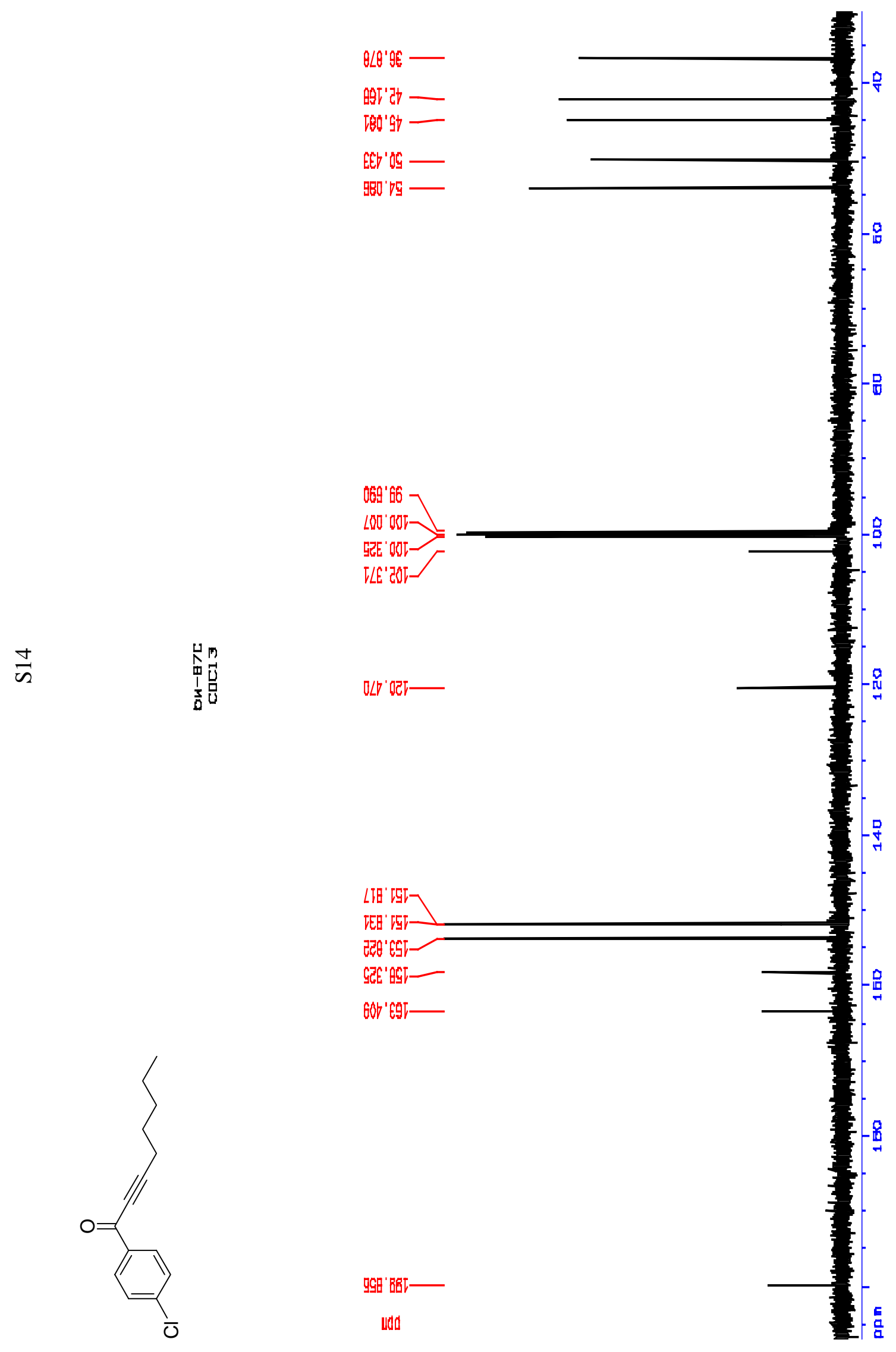




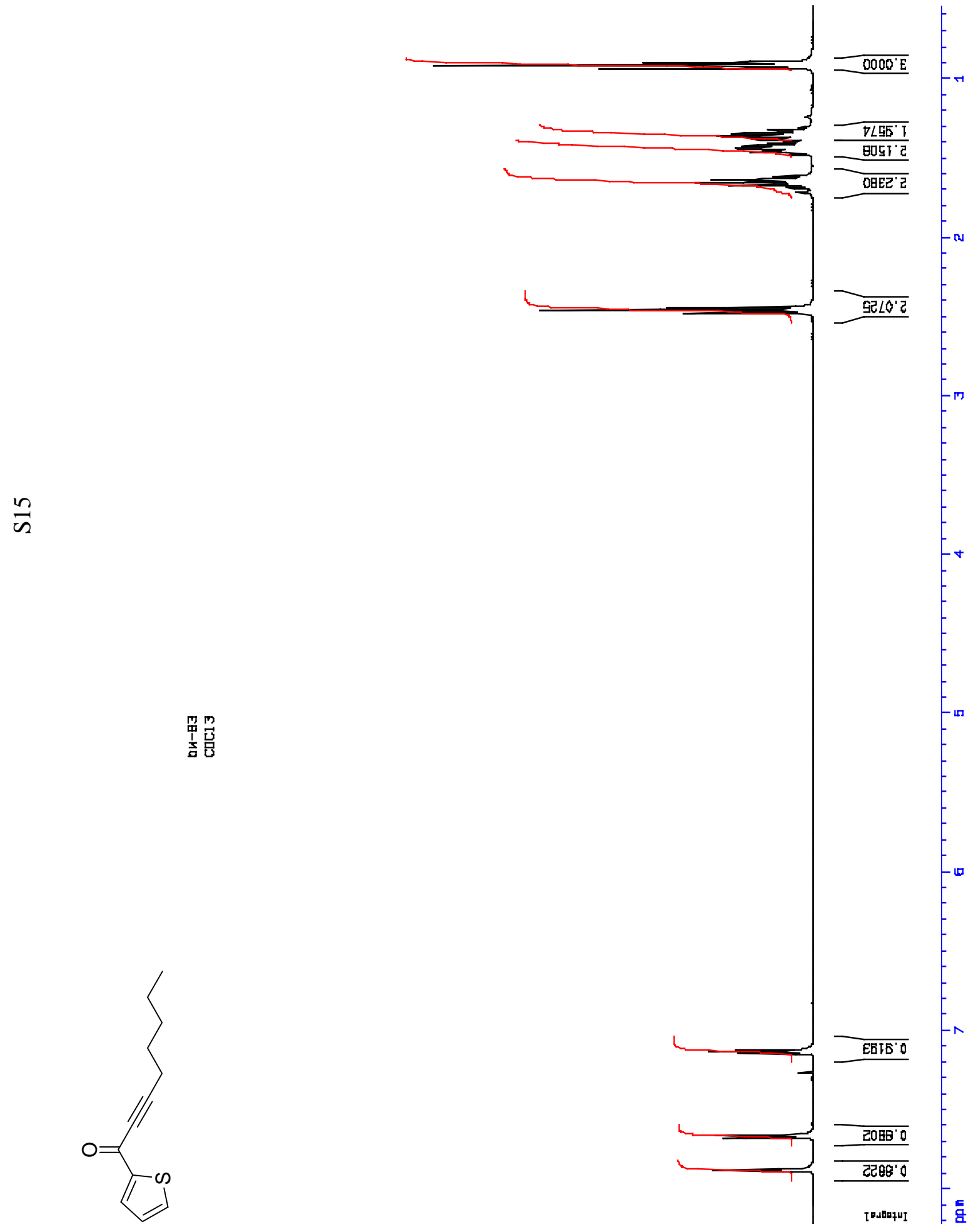



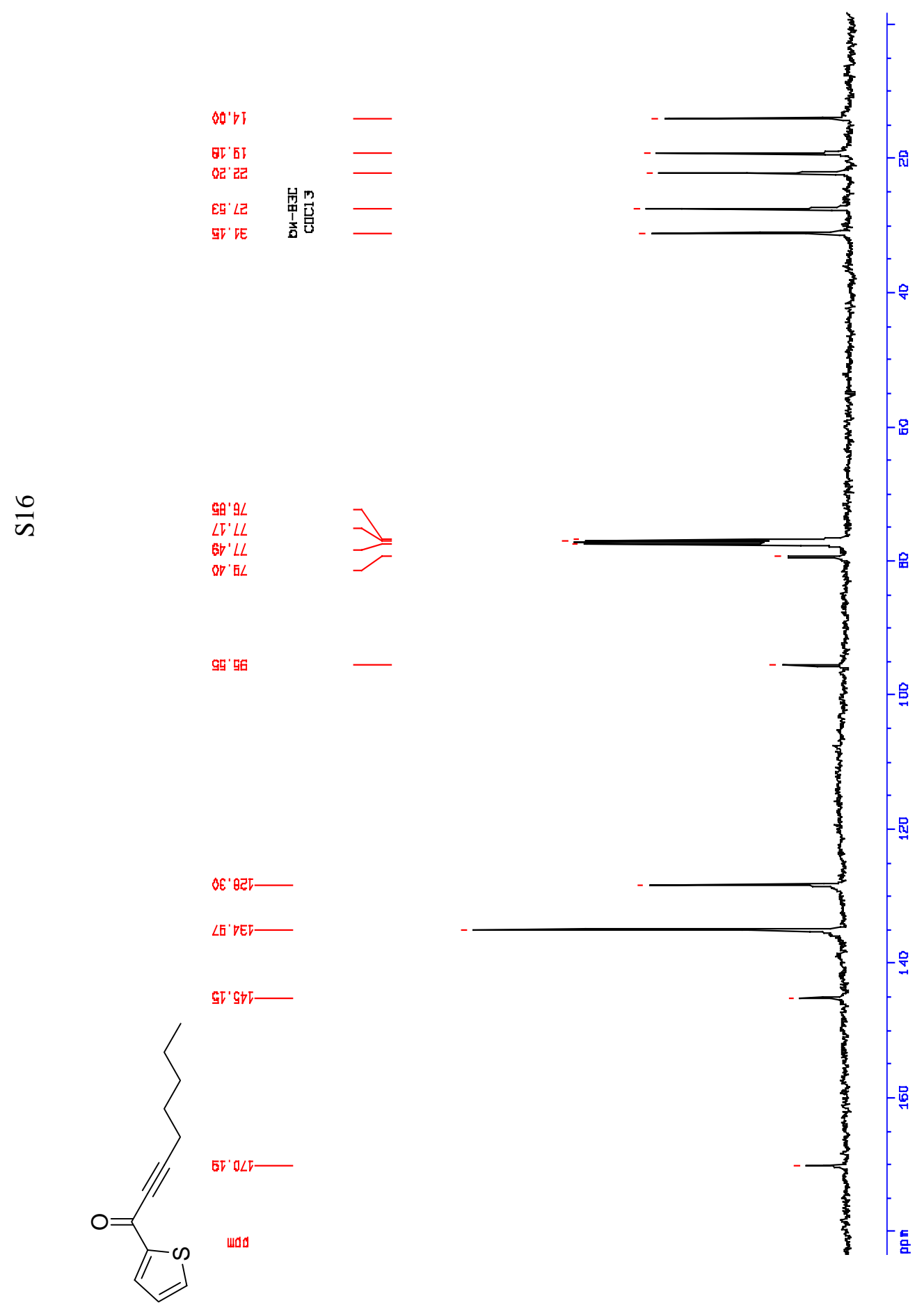


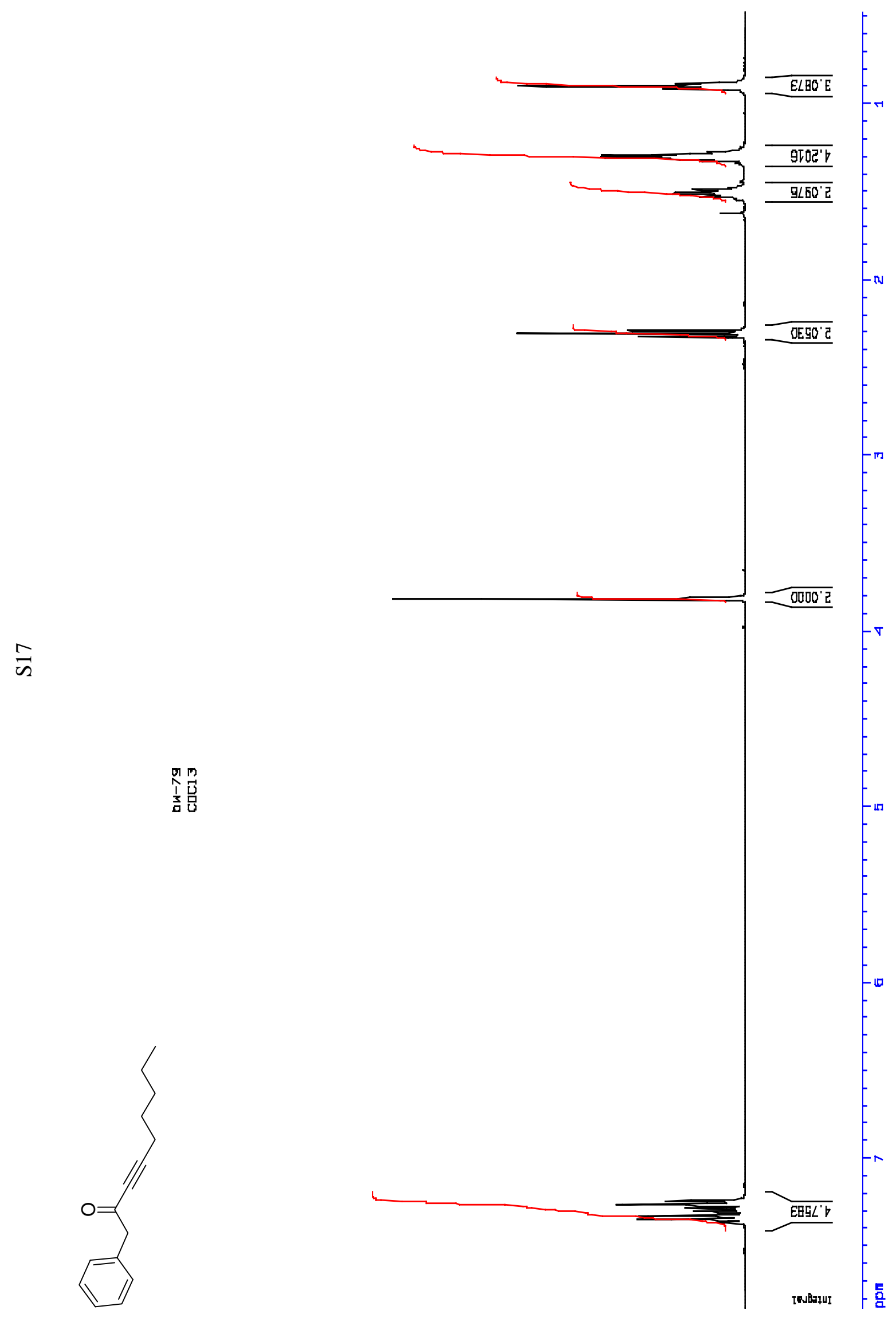




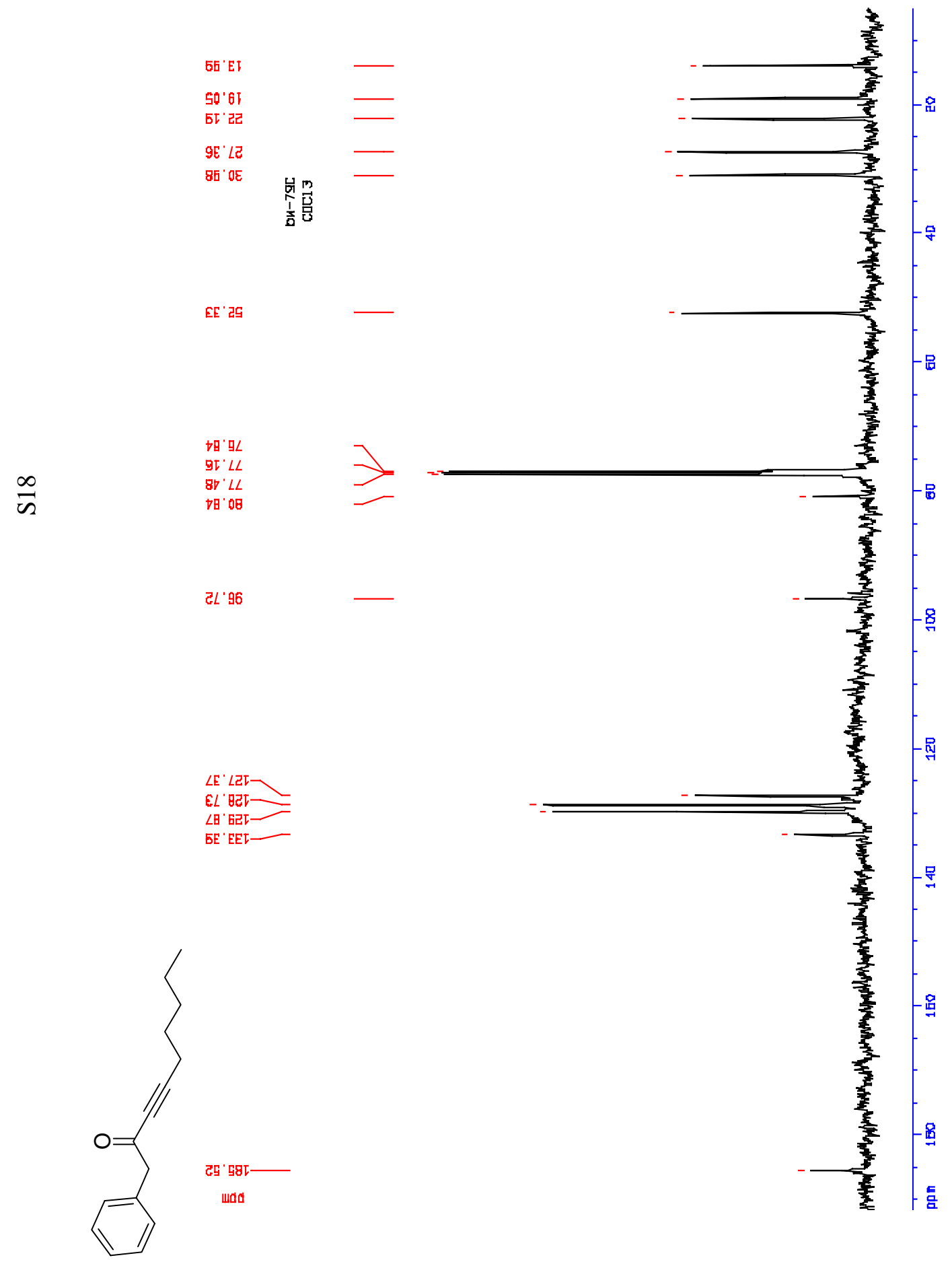




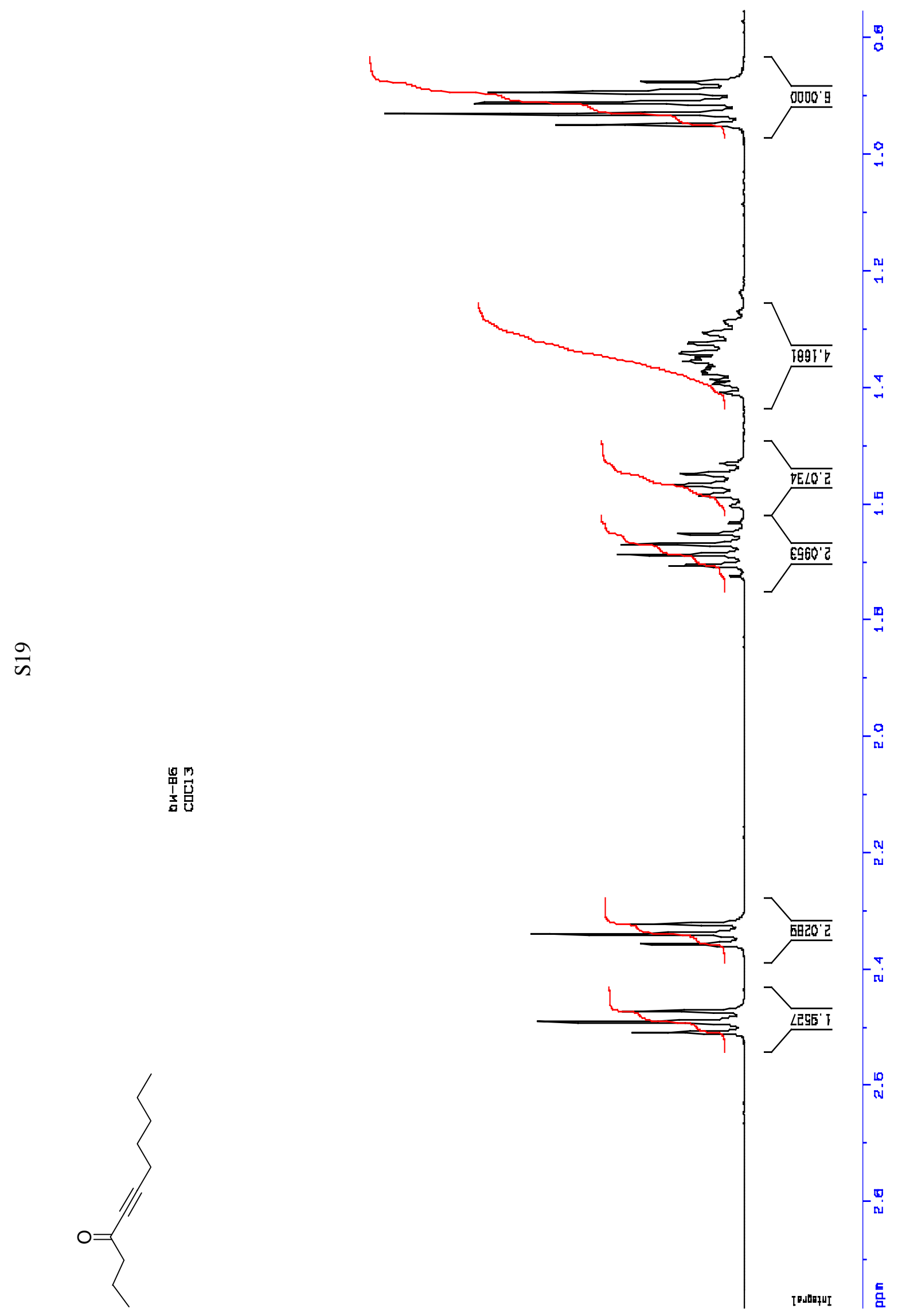




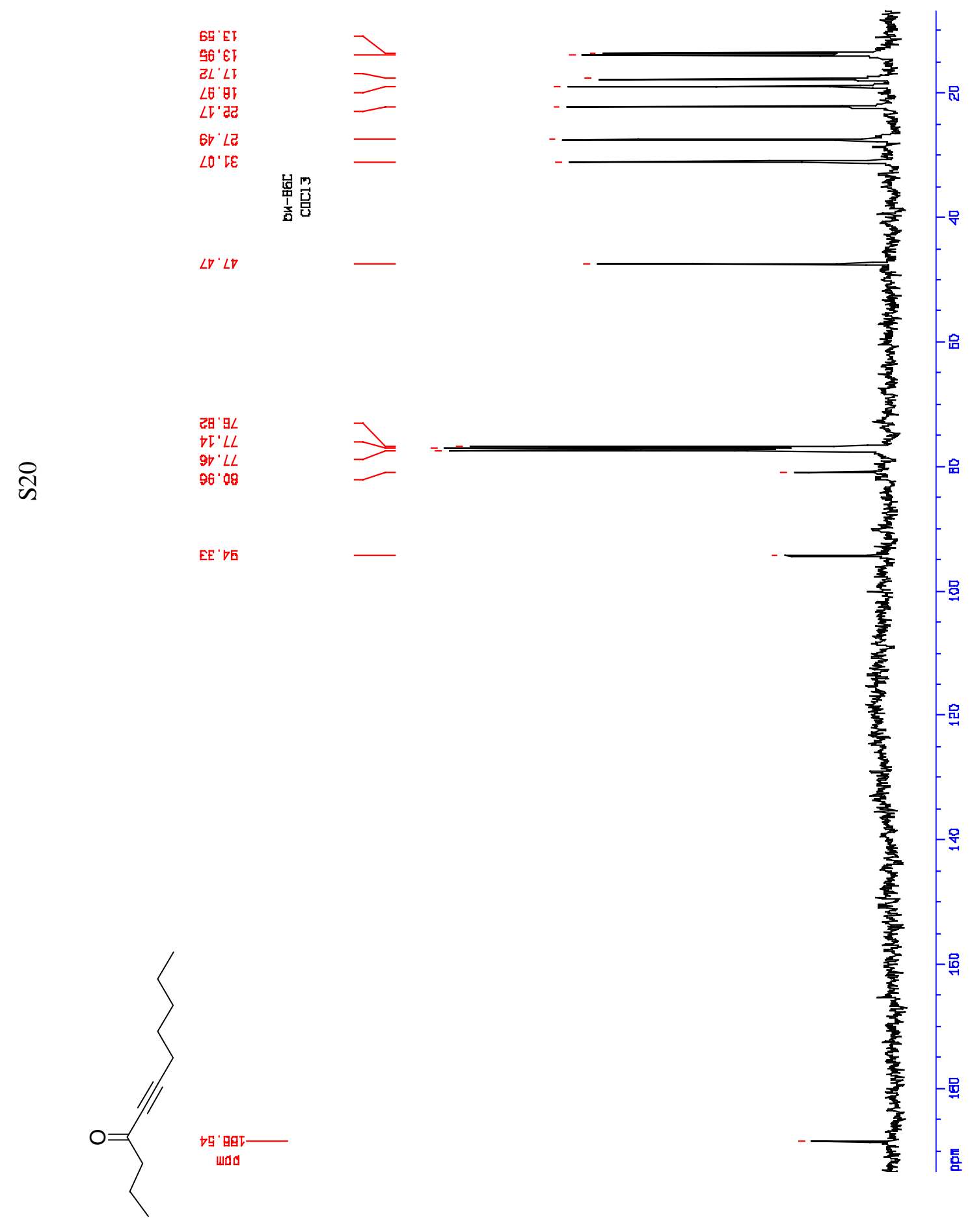




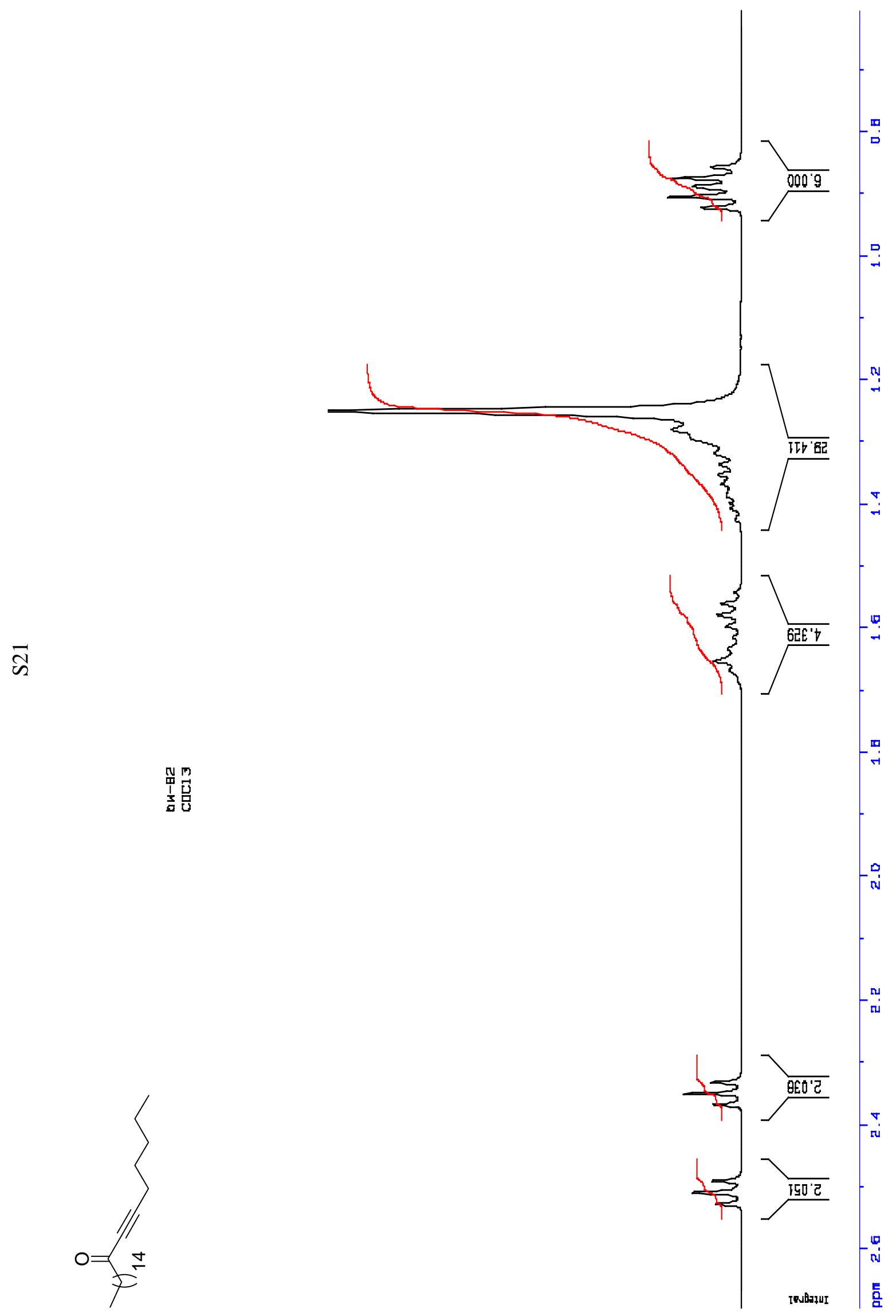




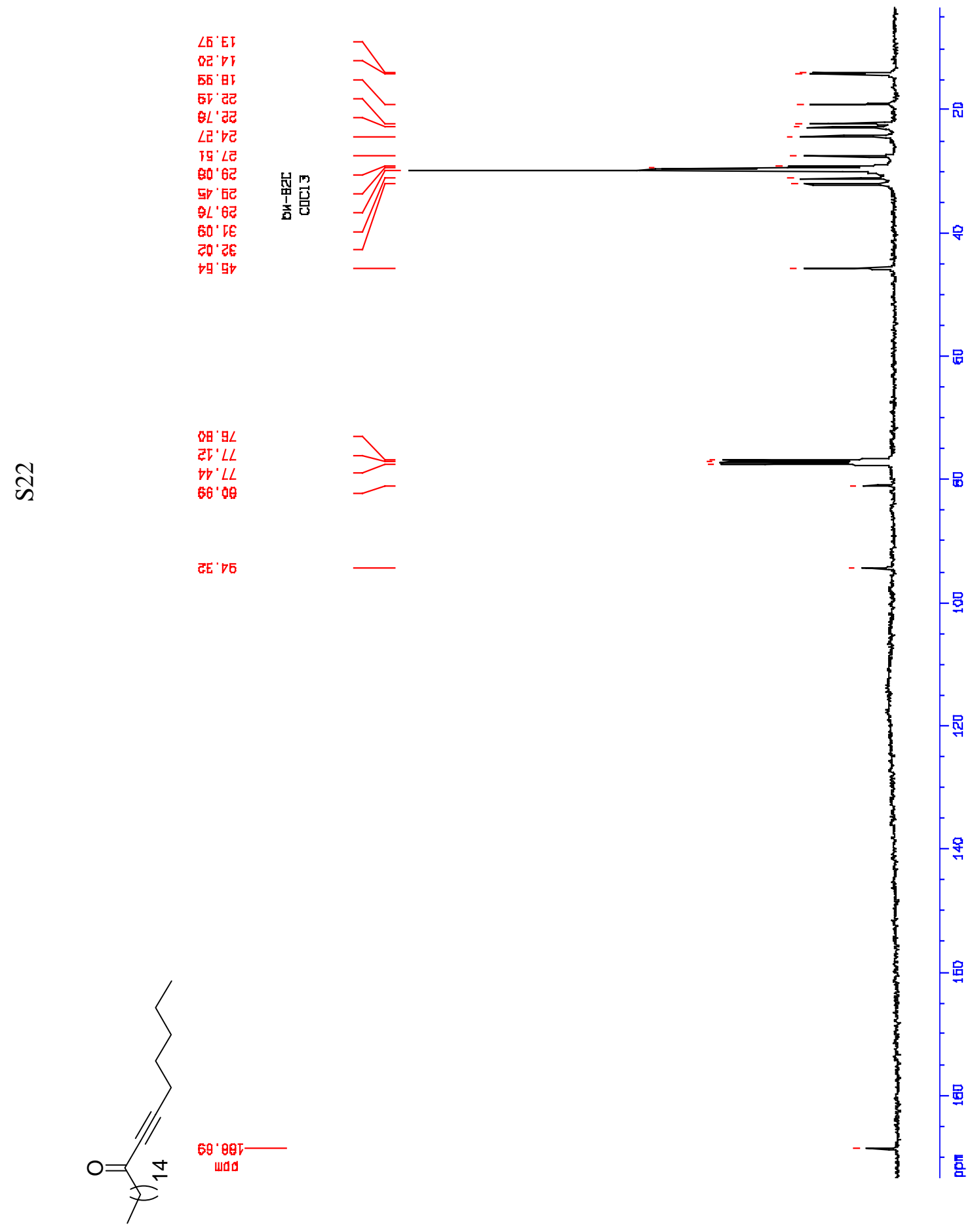




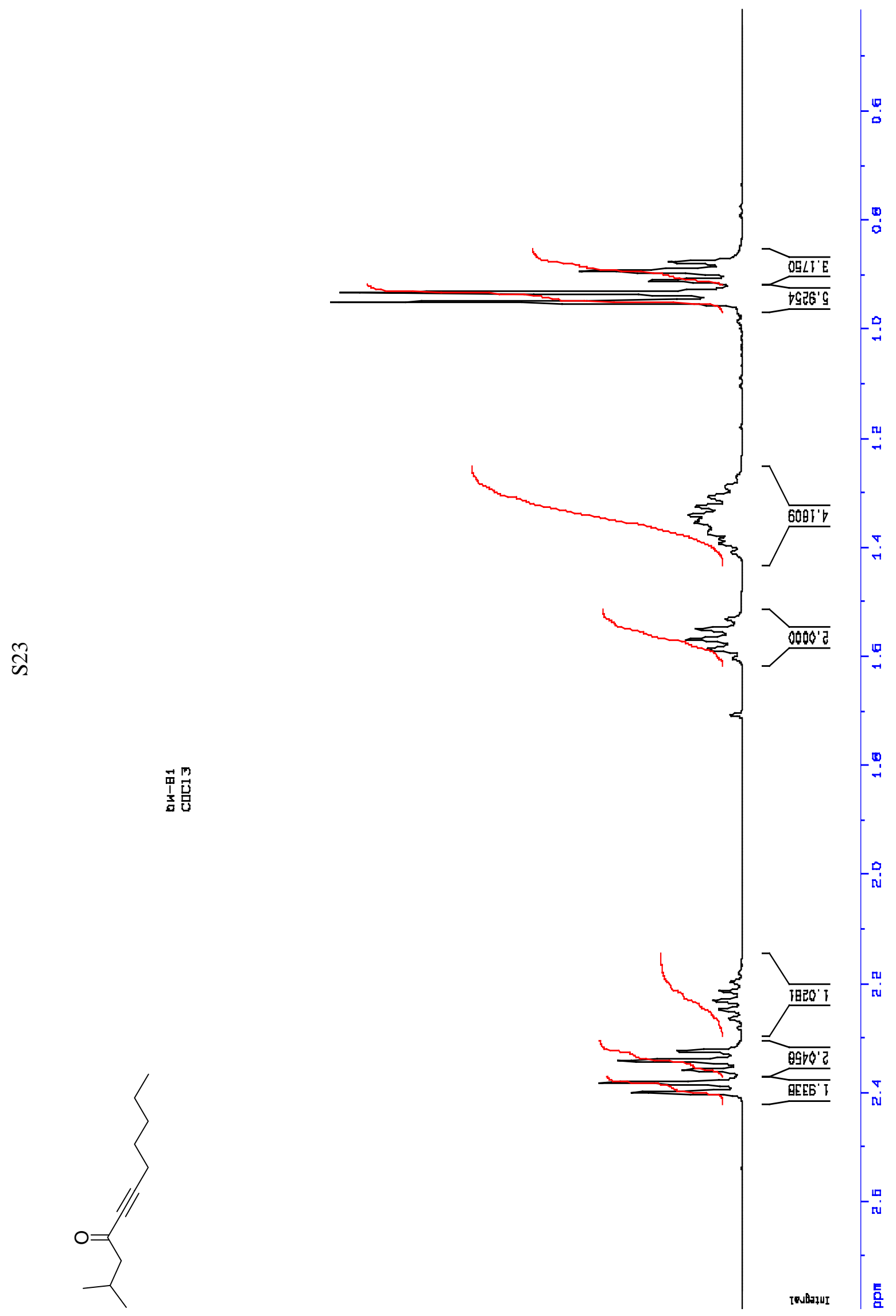



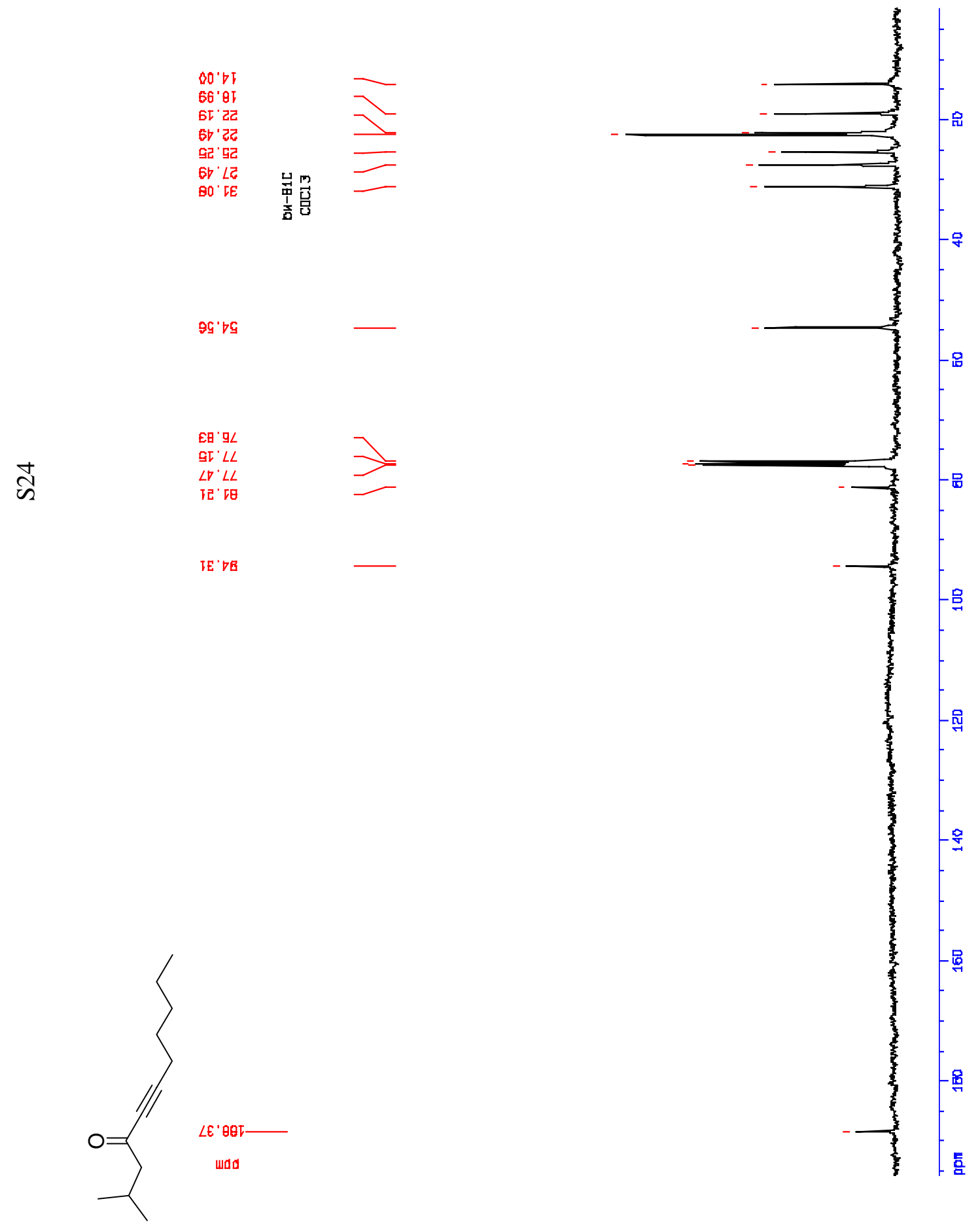


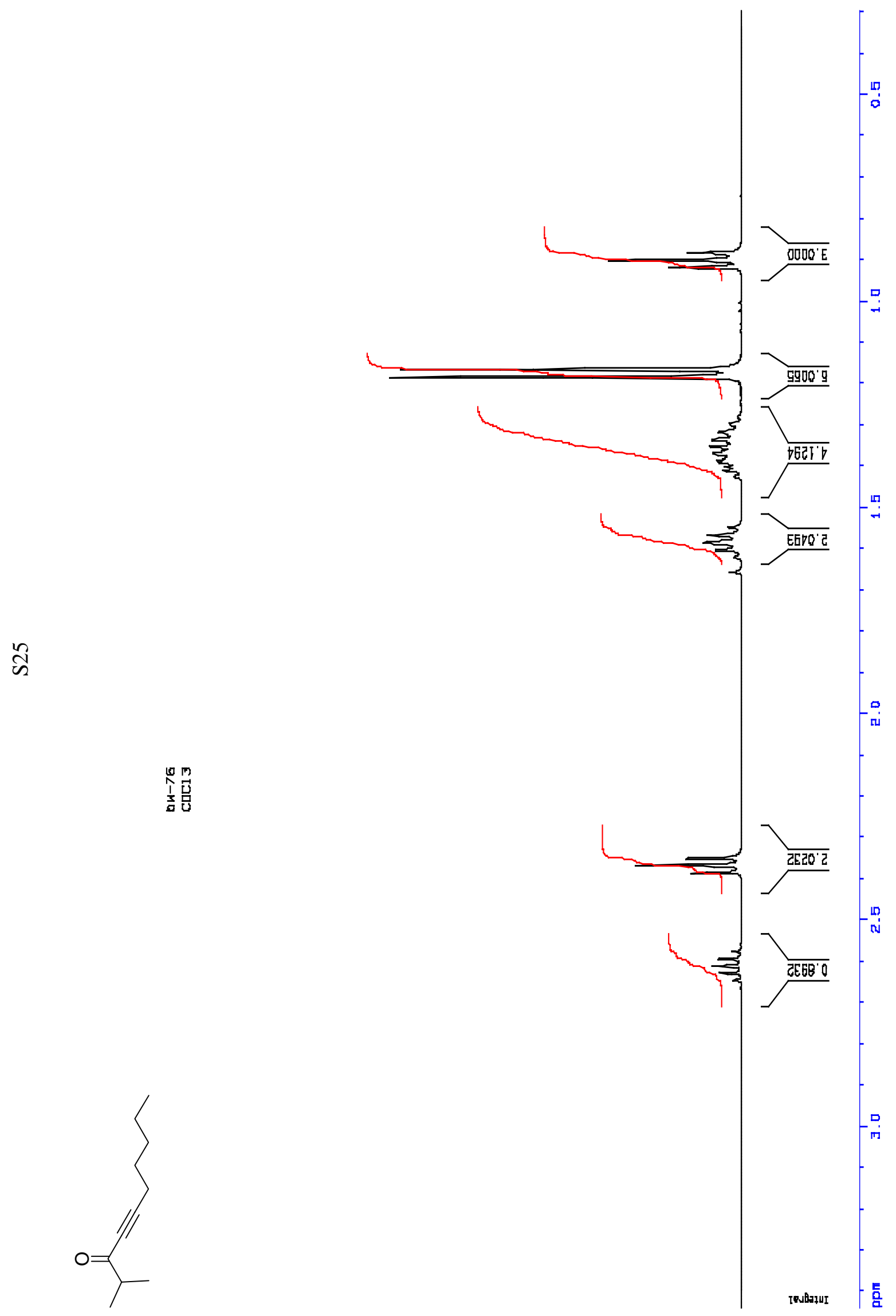



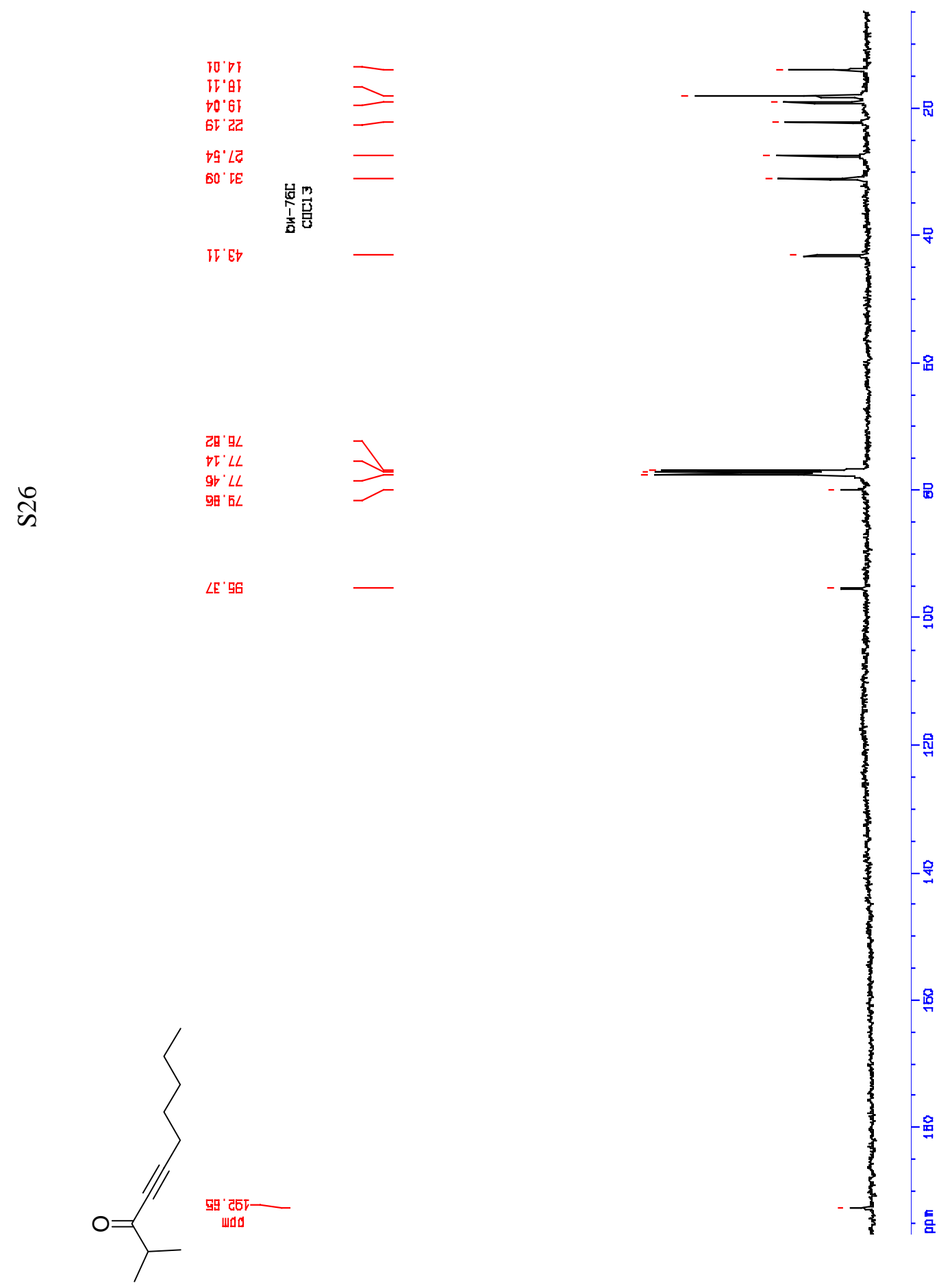


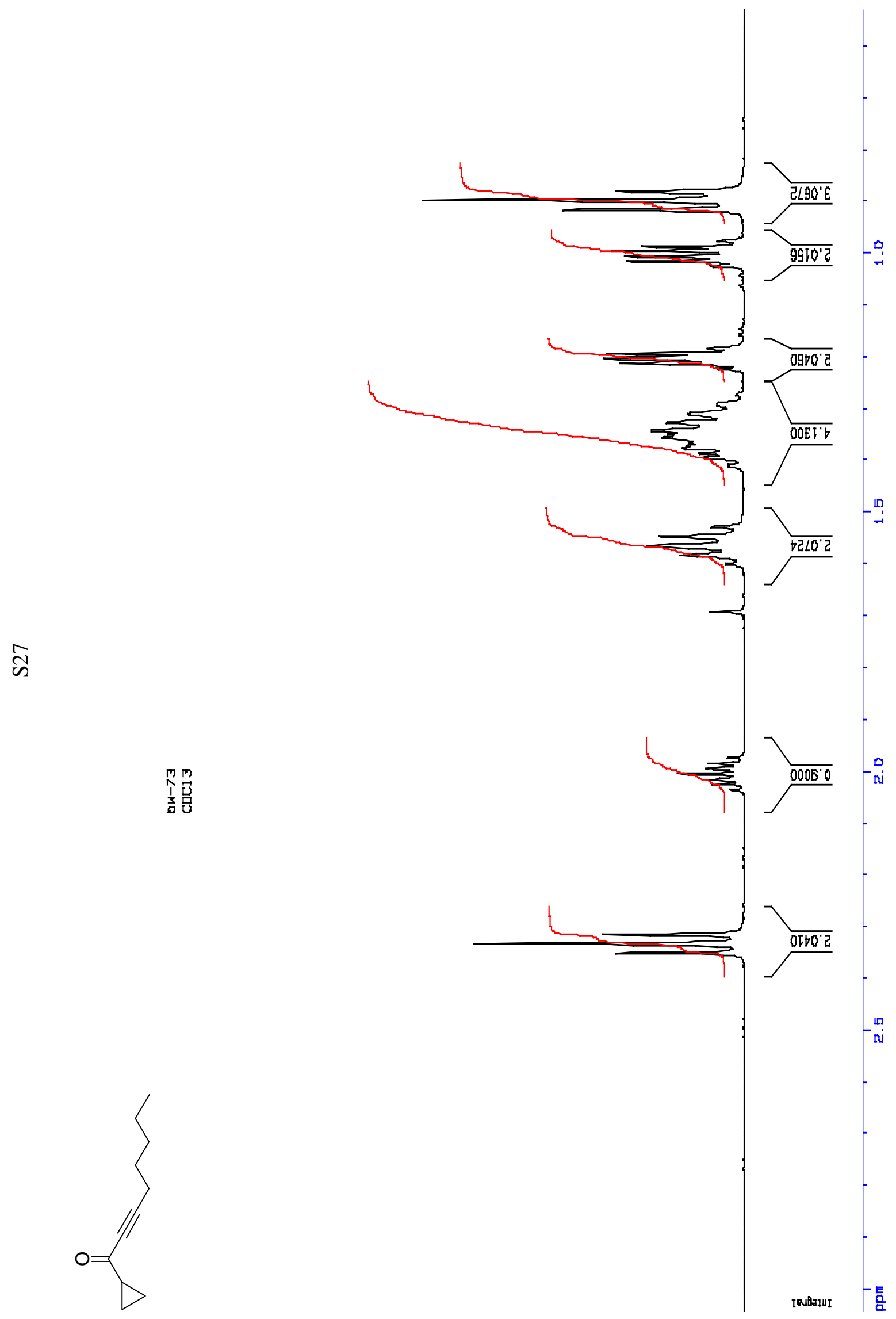



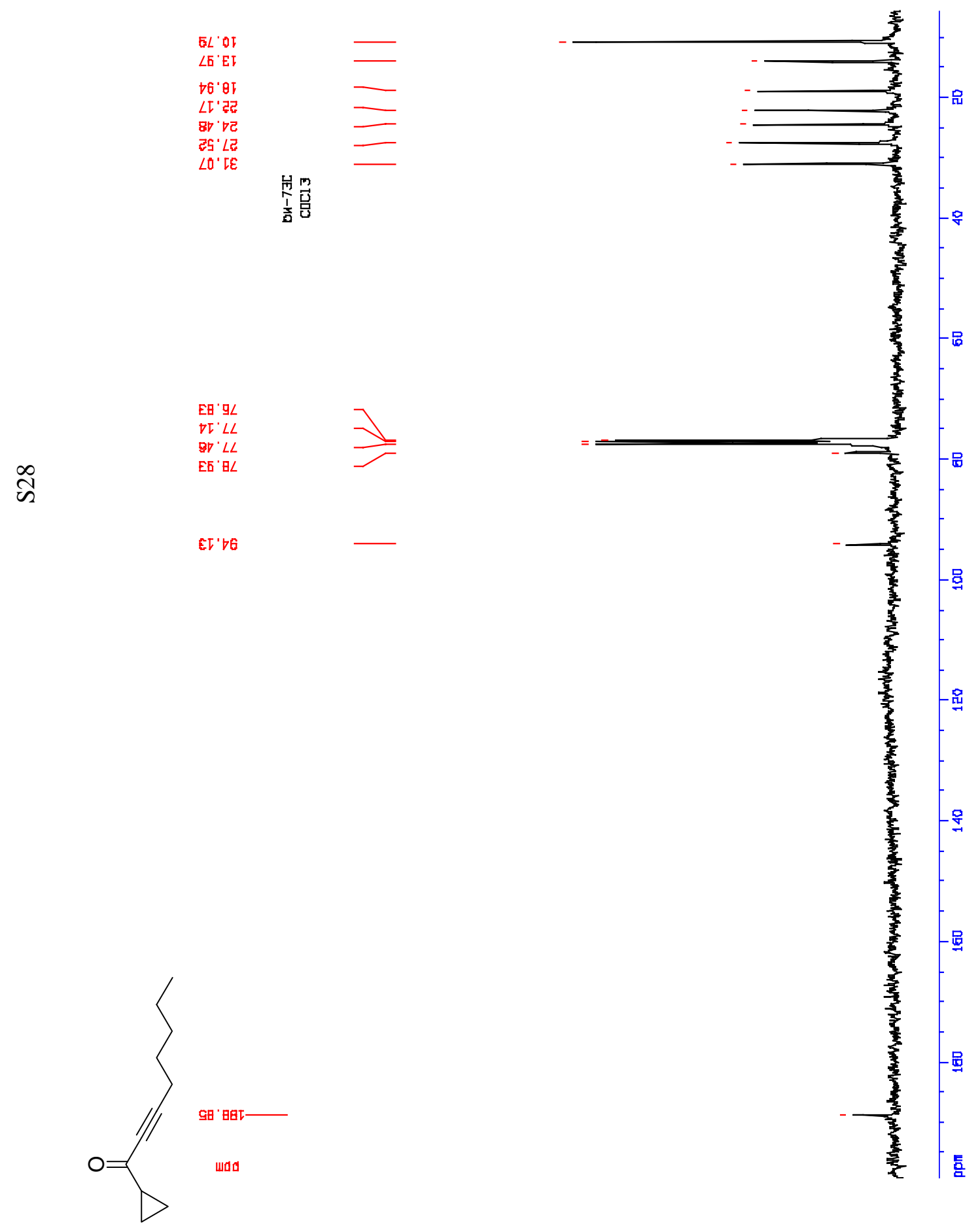
ถิ

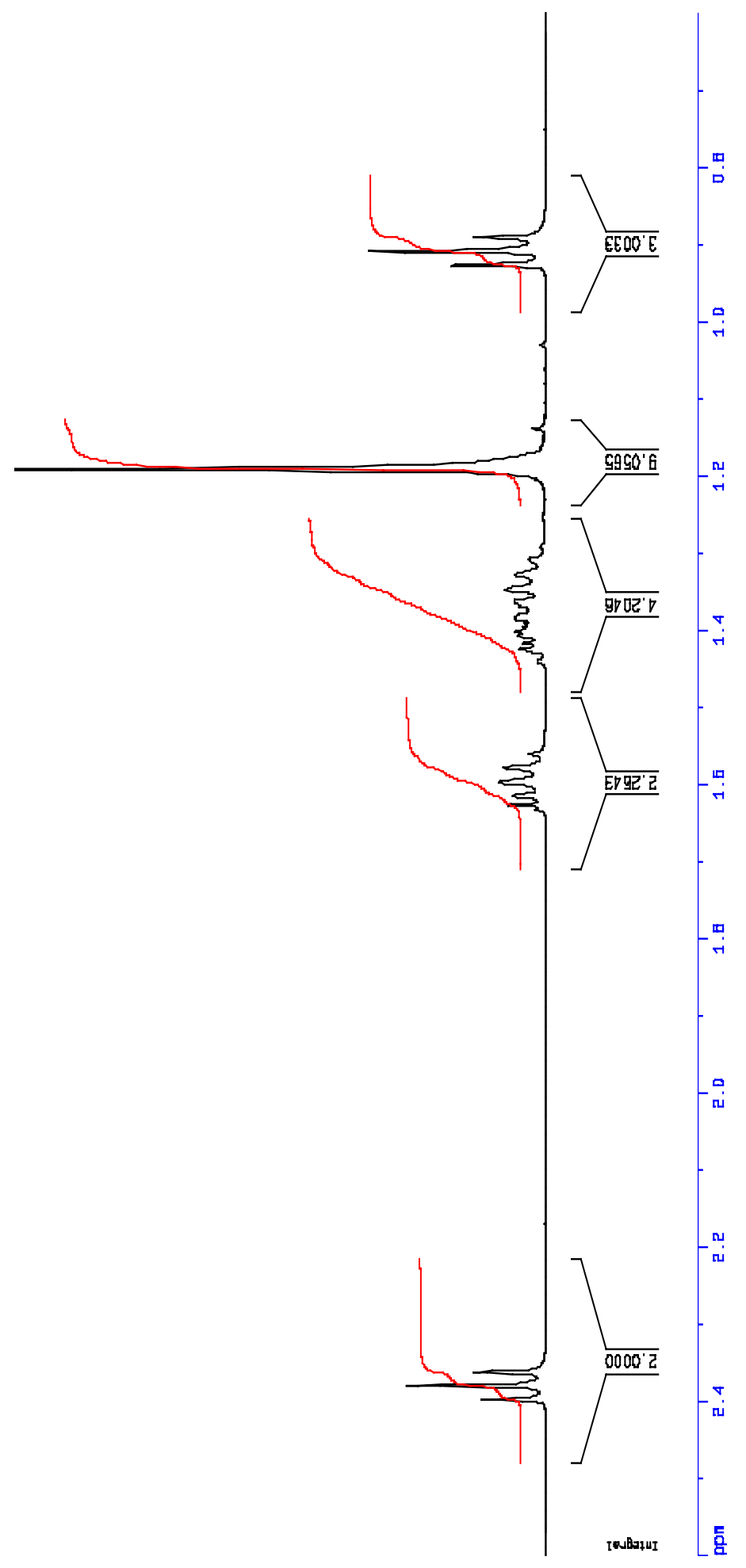




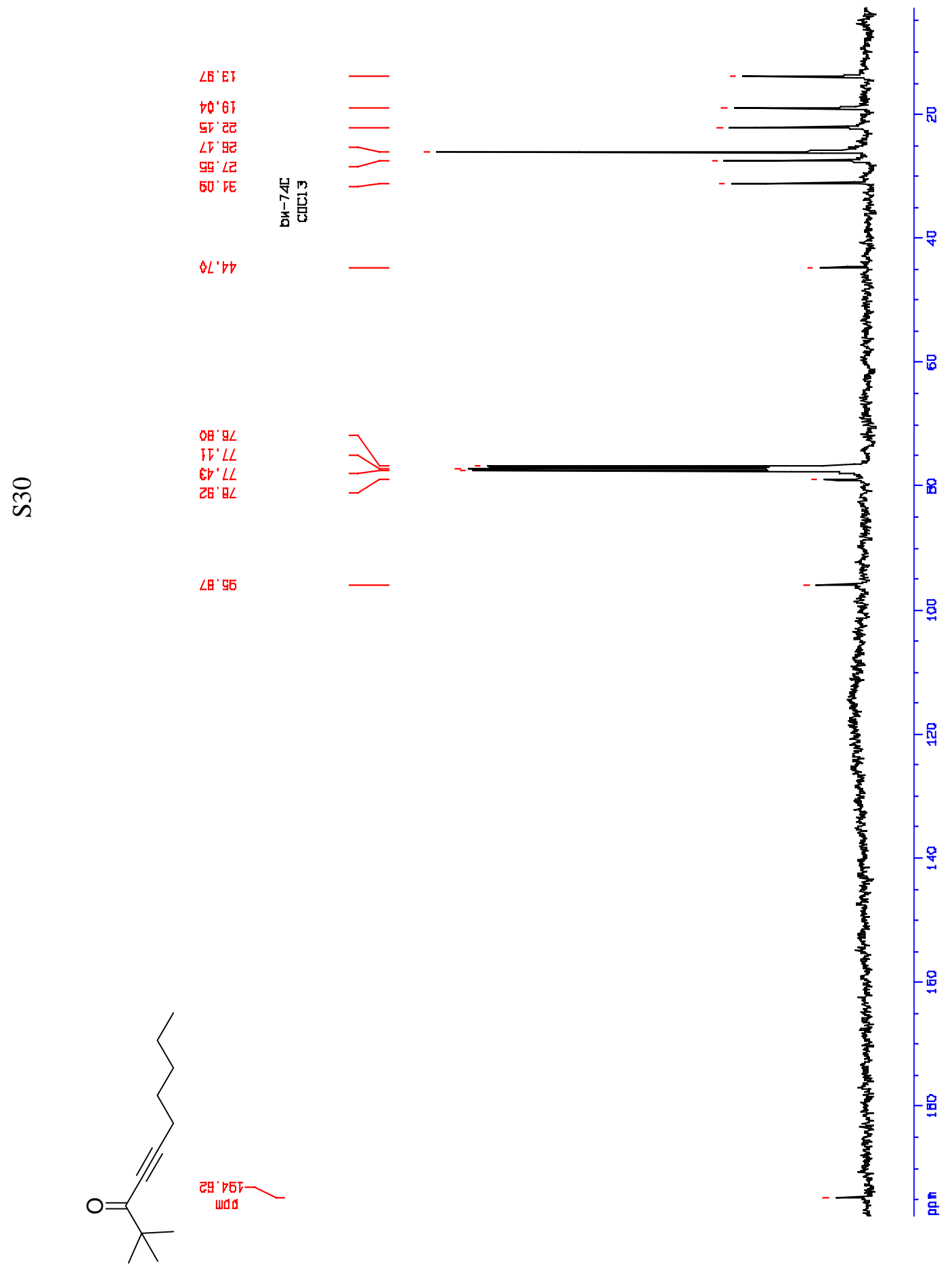




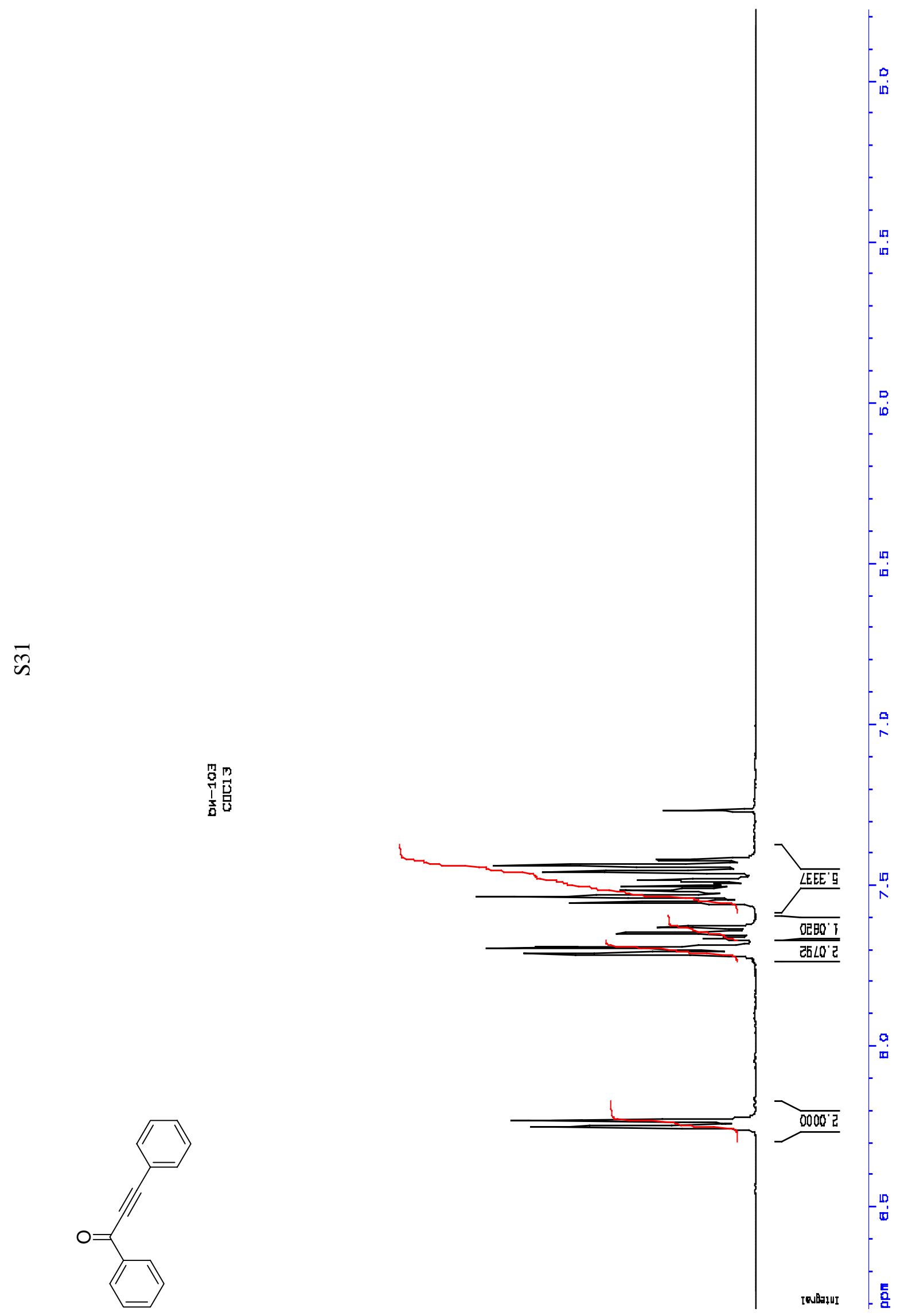




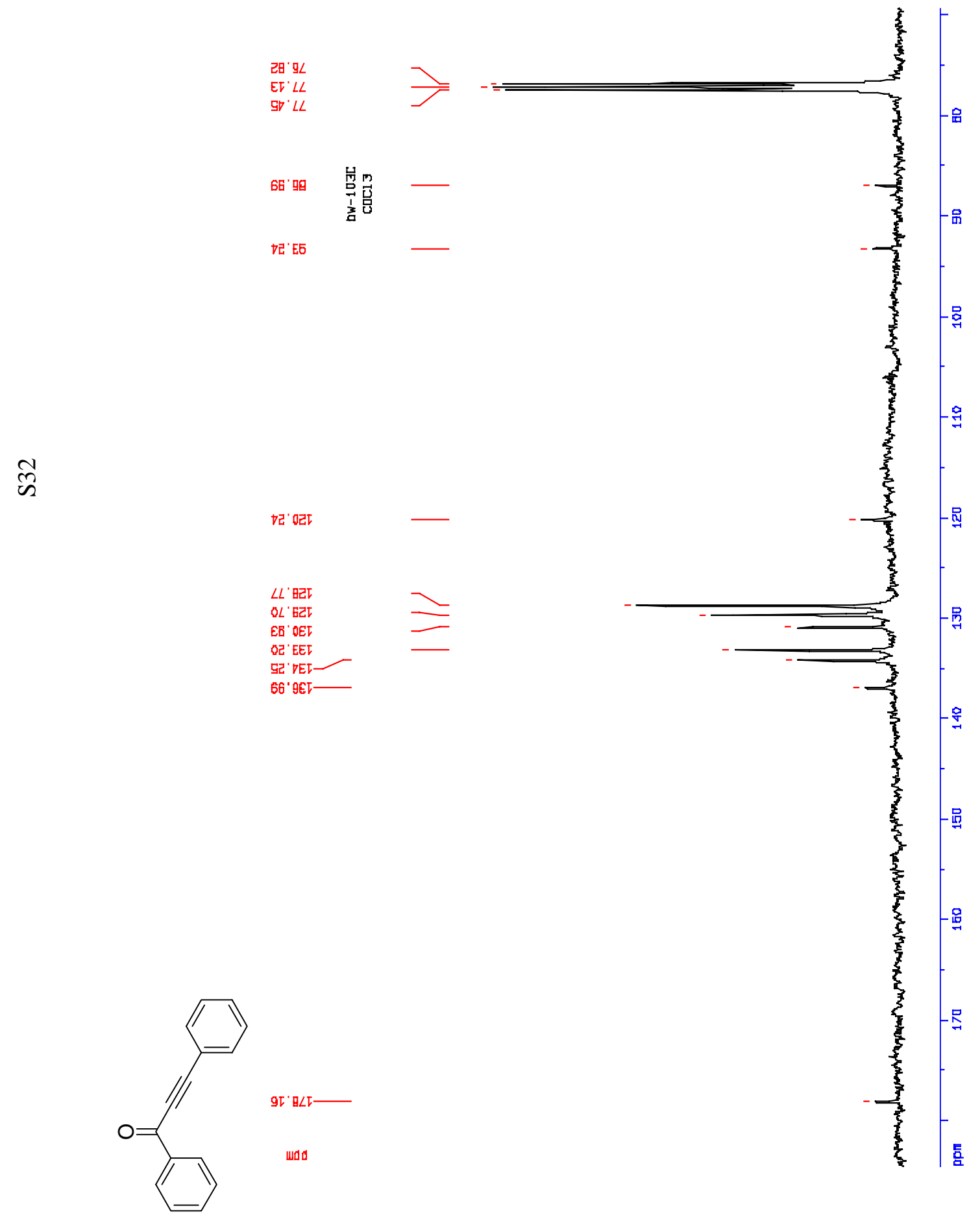


釆

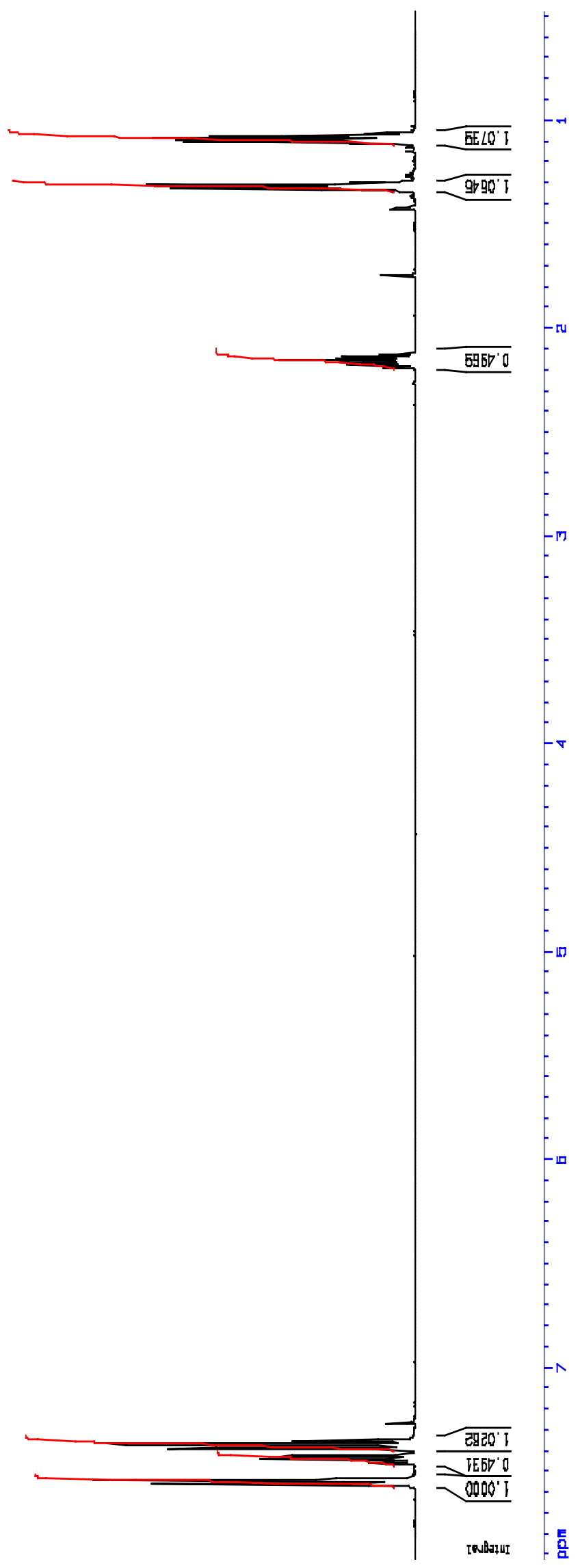




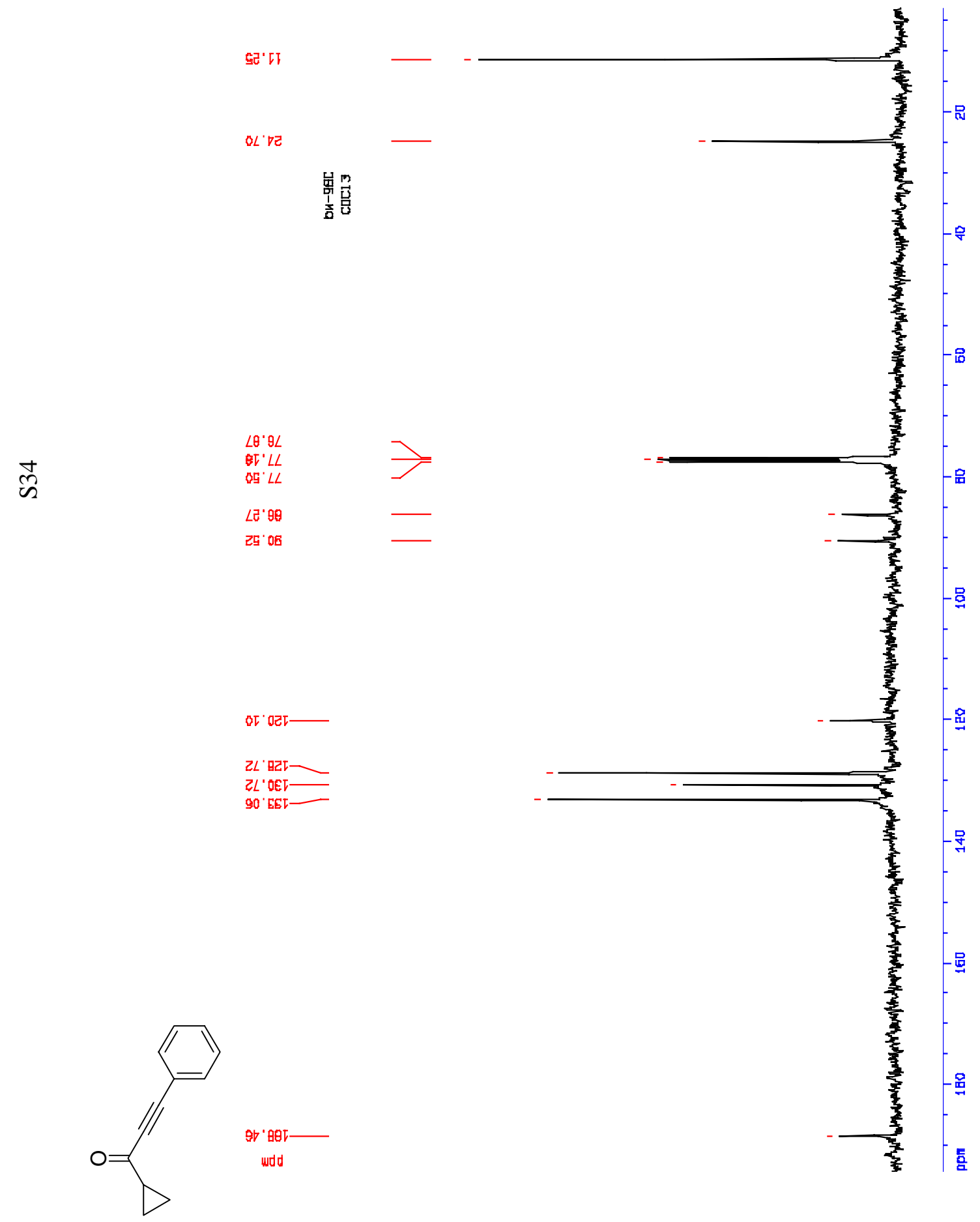




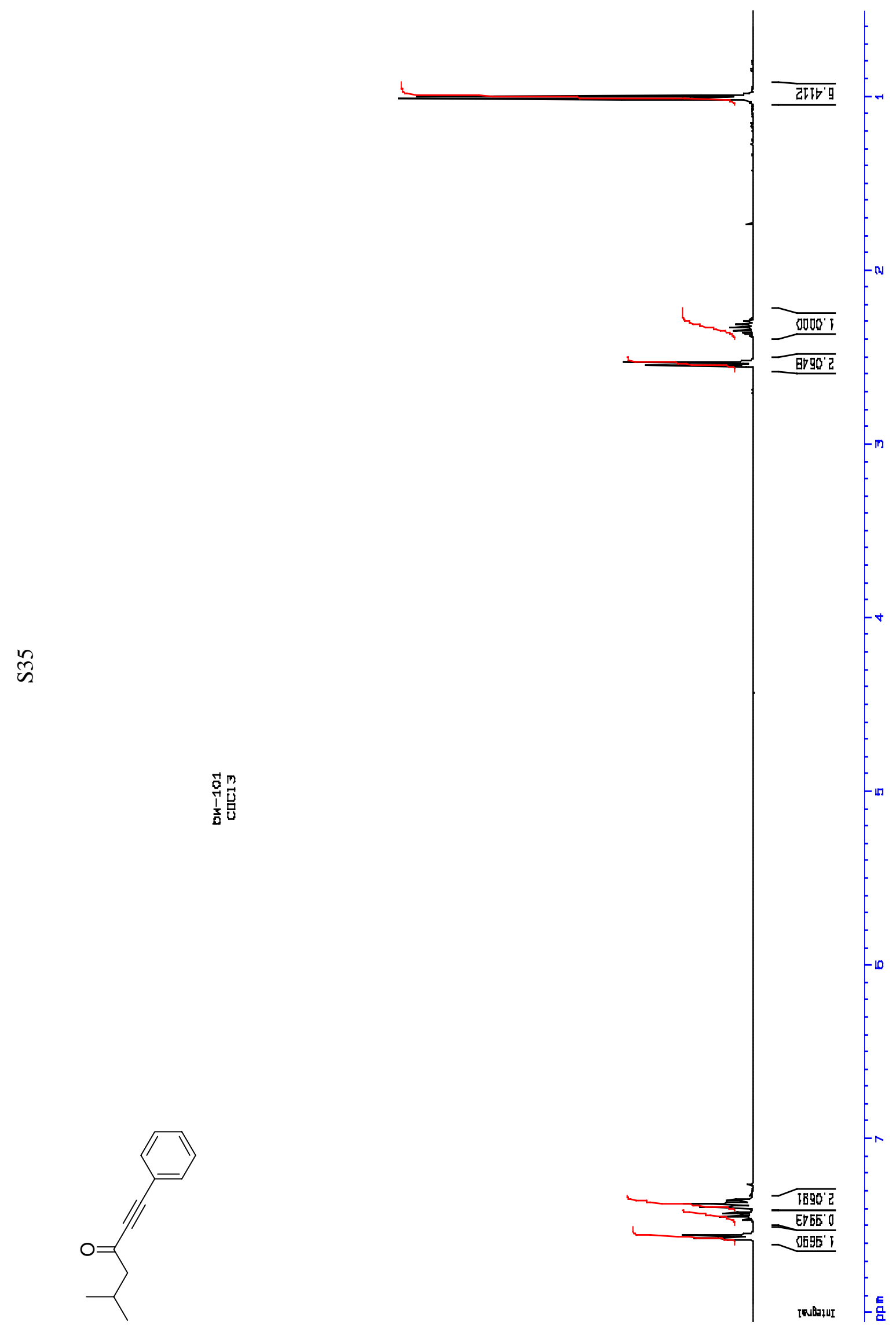




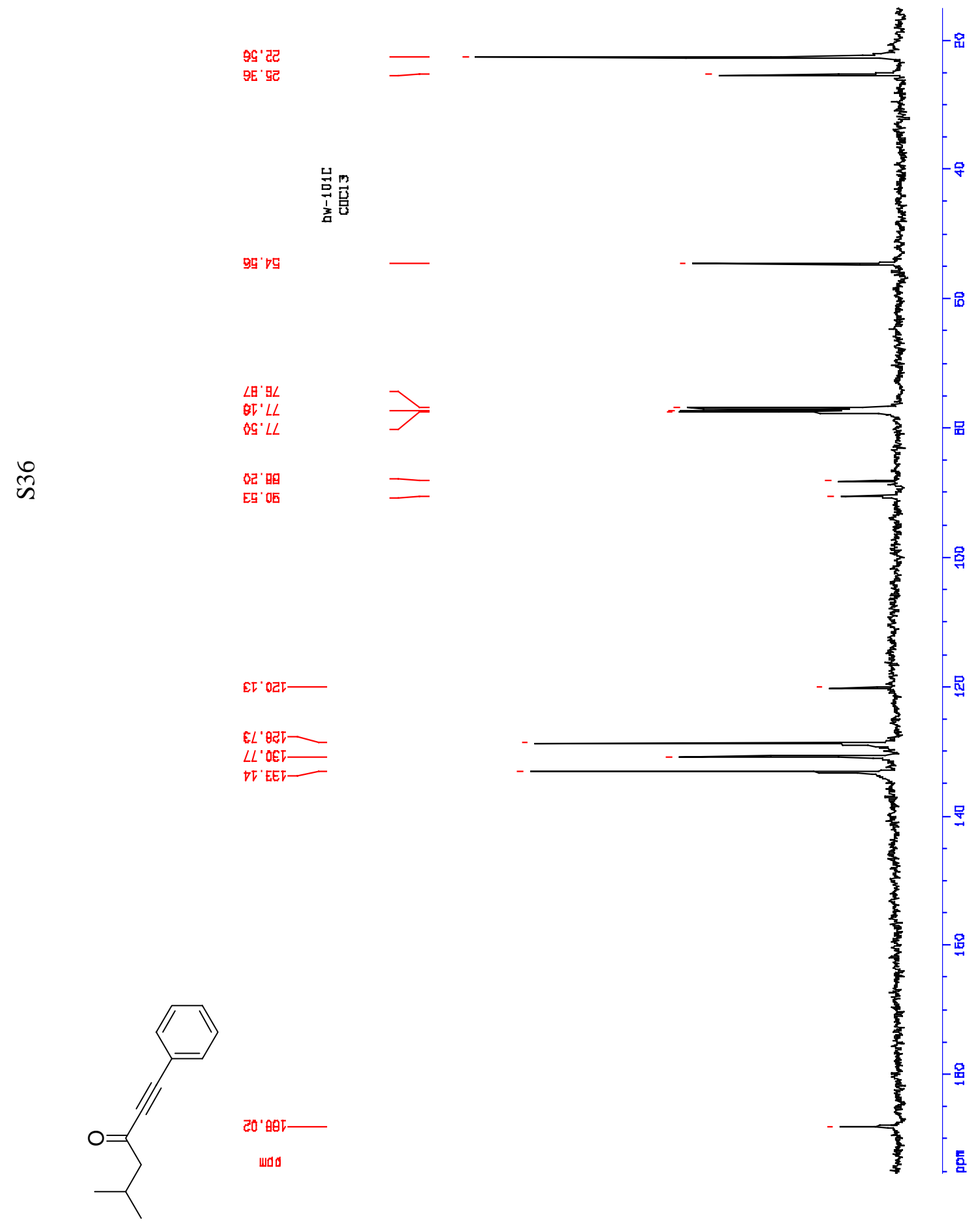




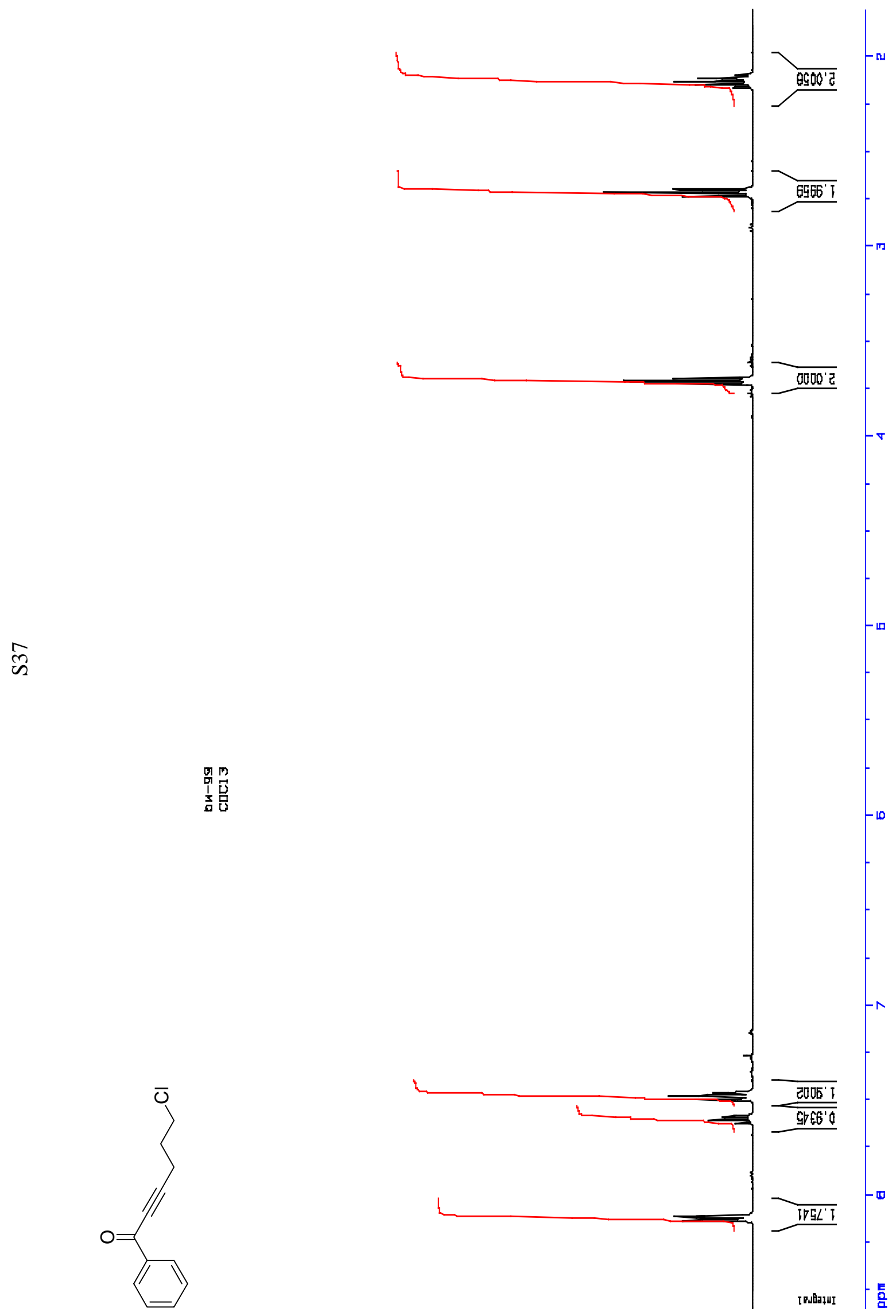


IS Et

$\stackrel{\infty}{n}$

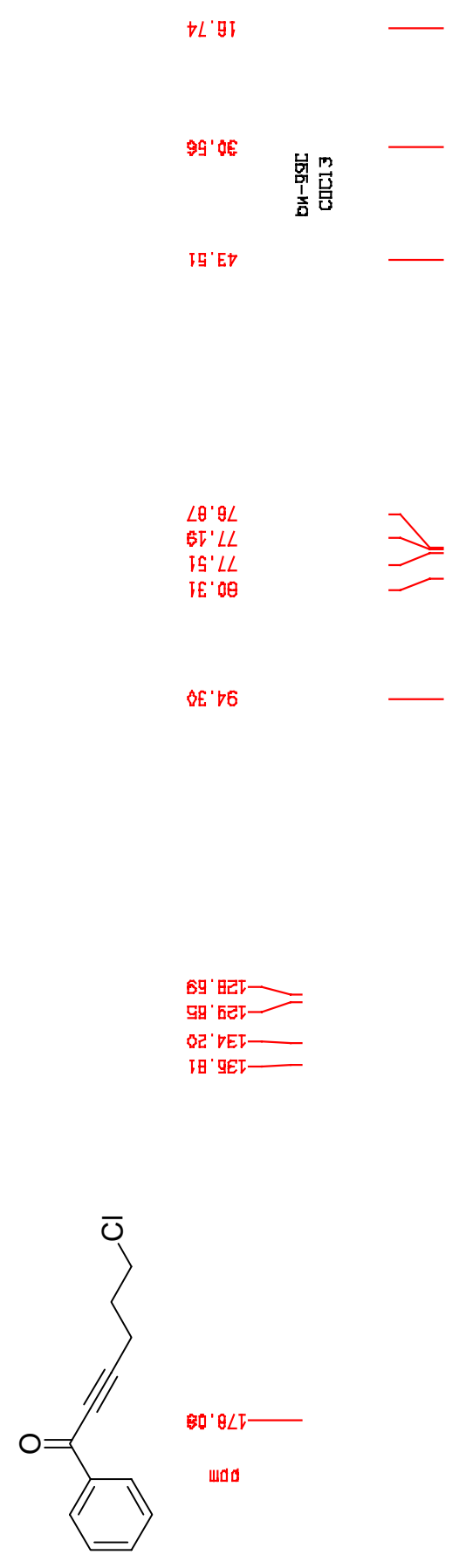

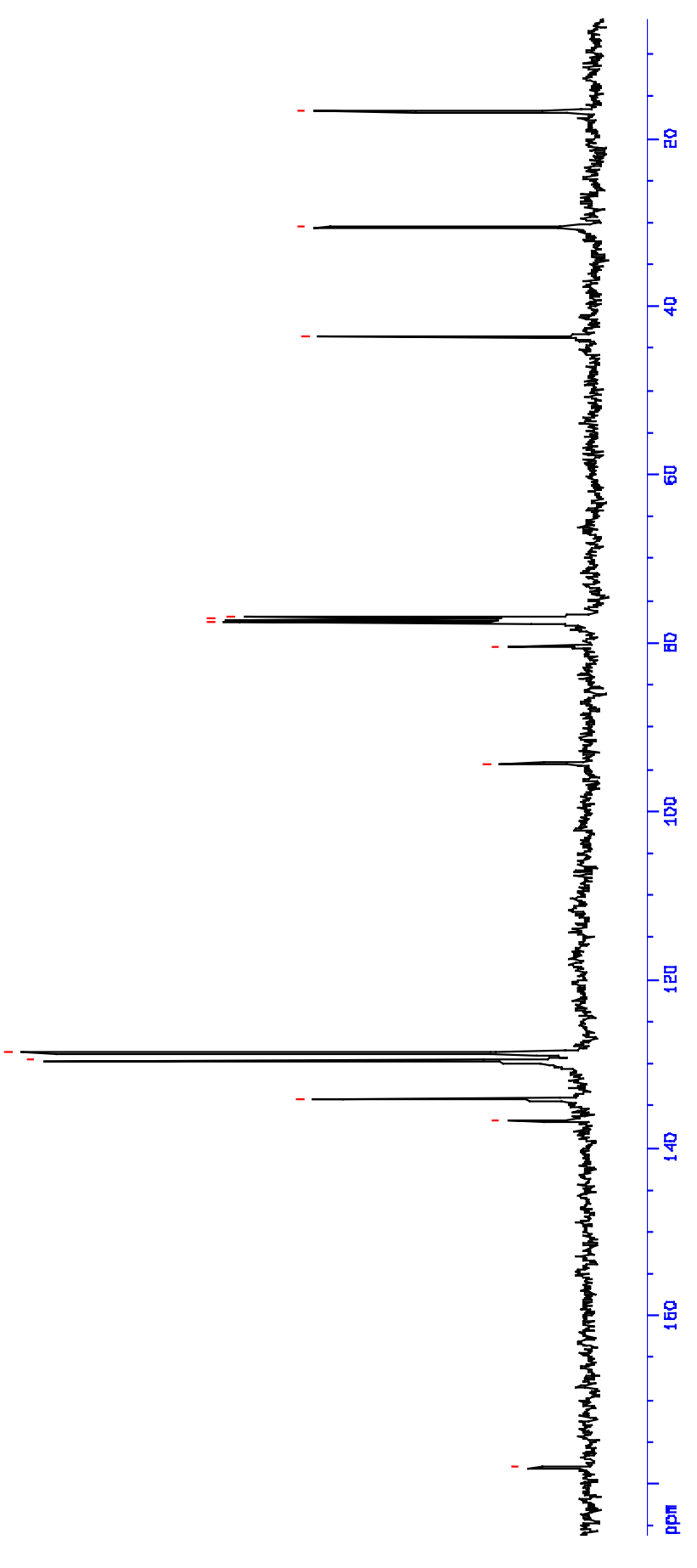




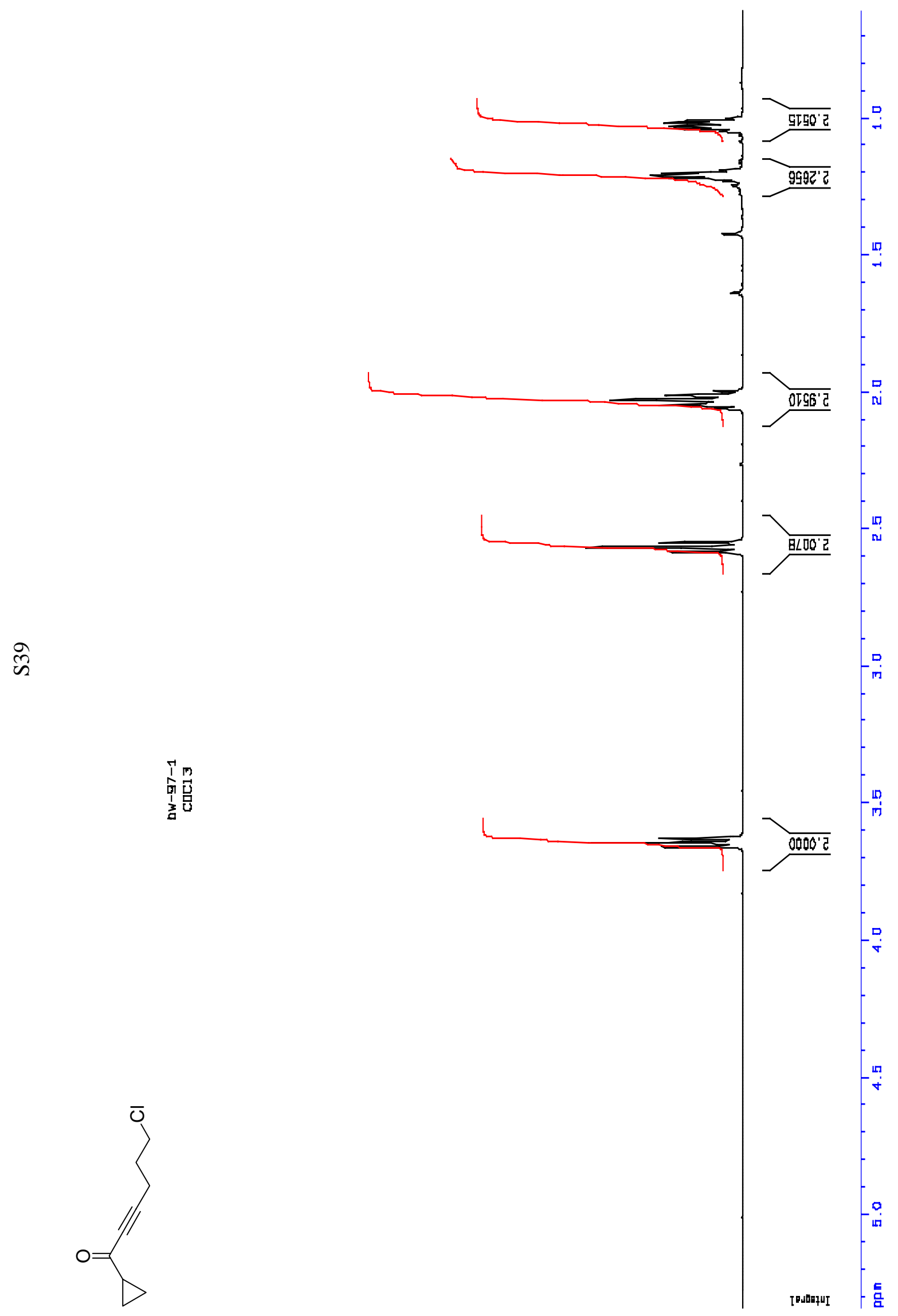




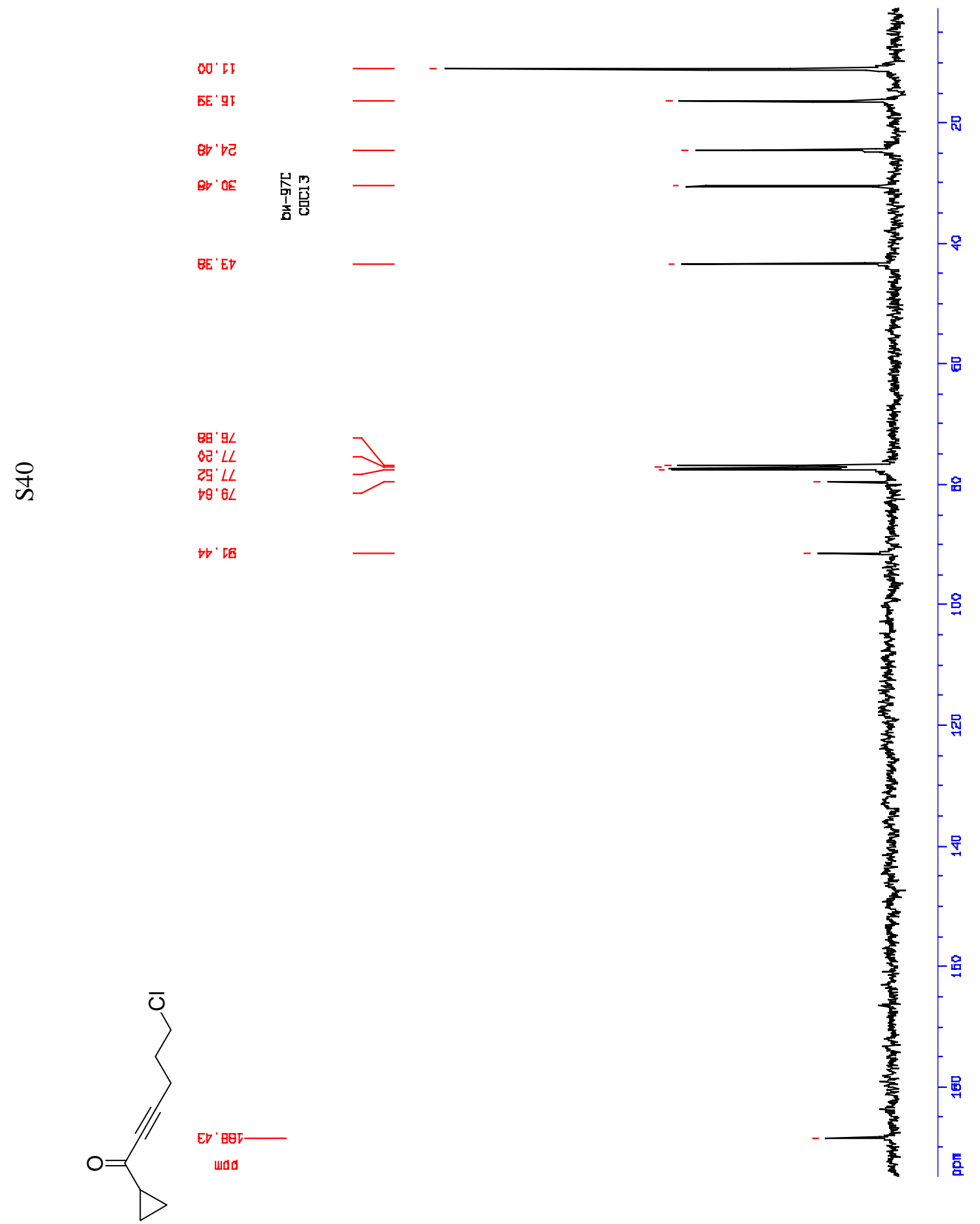




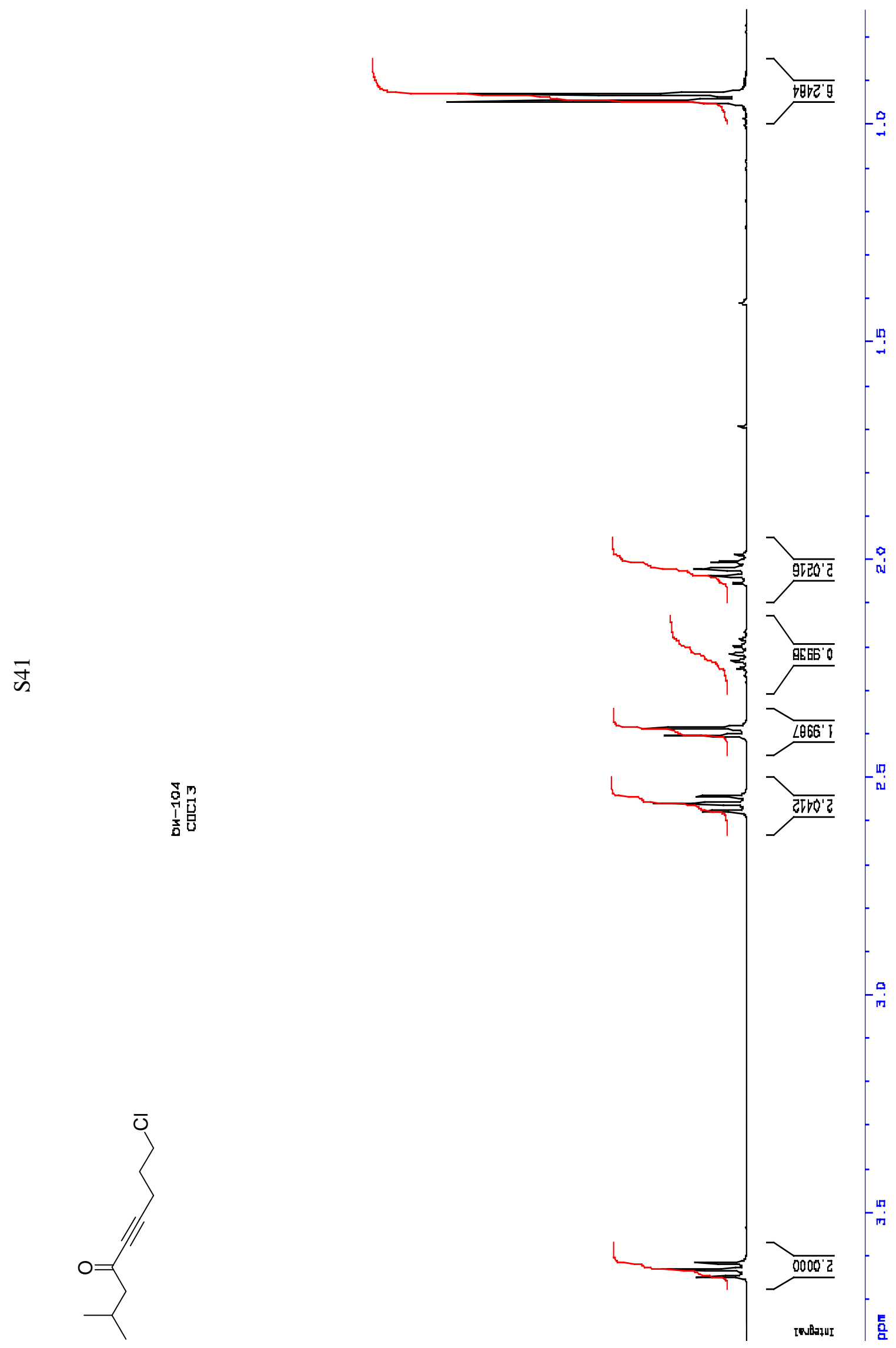




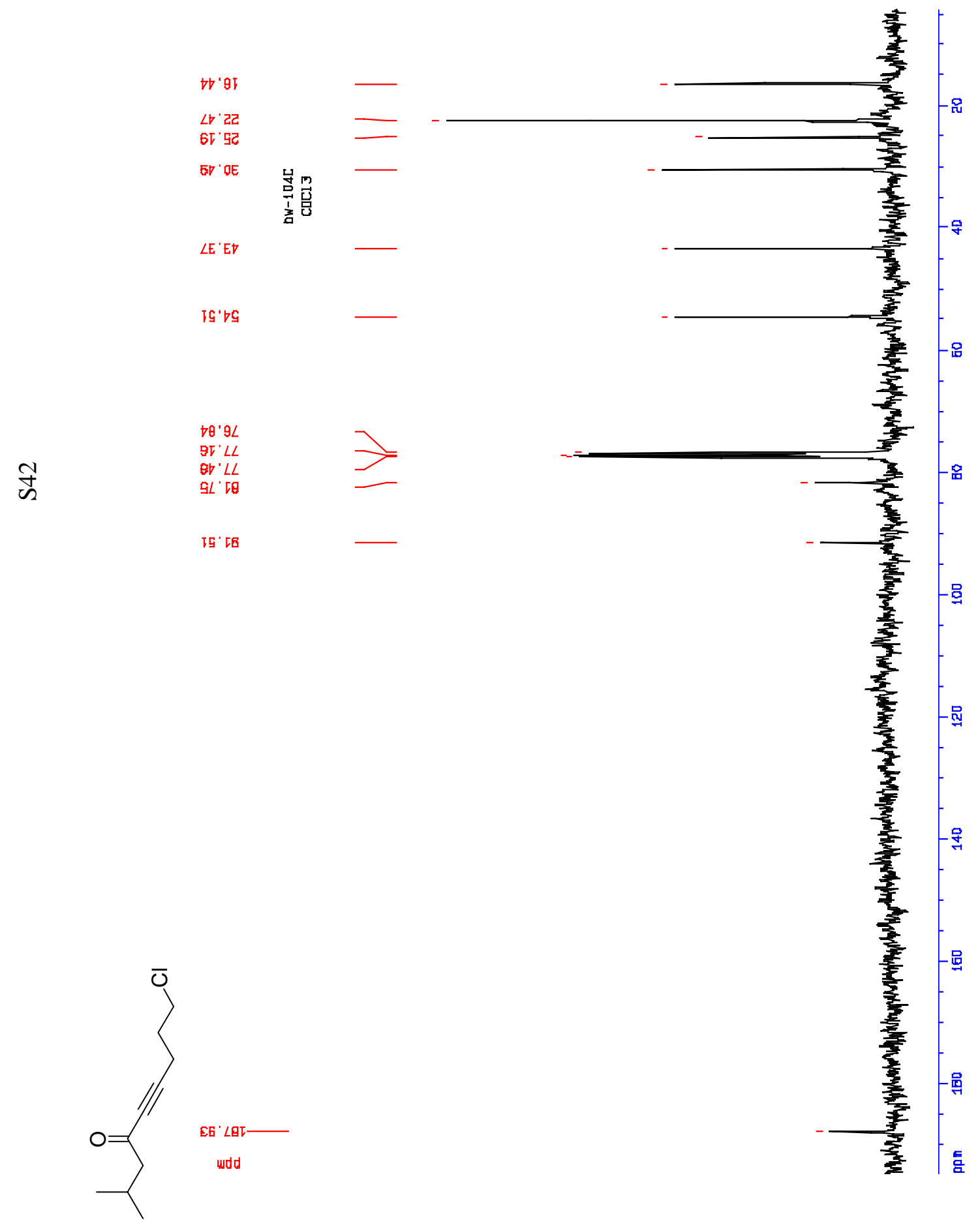




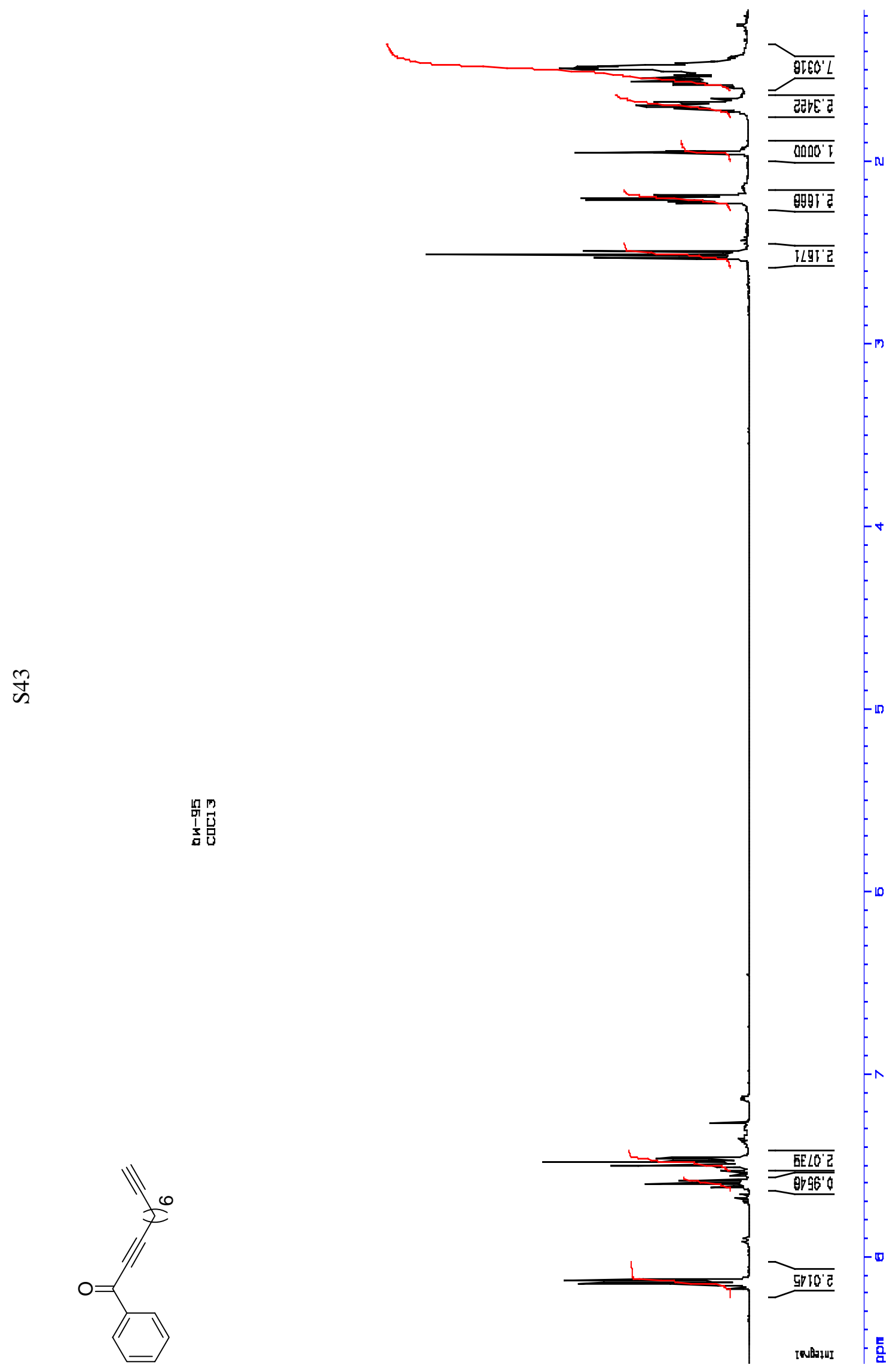



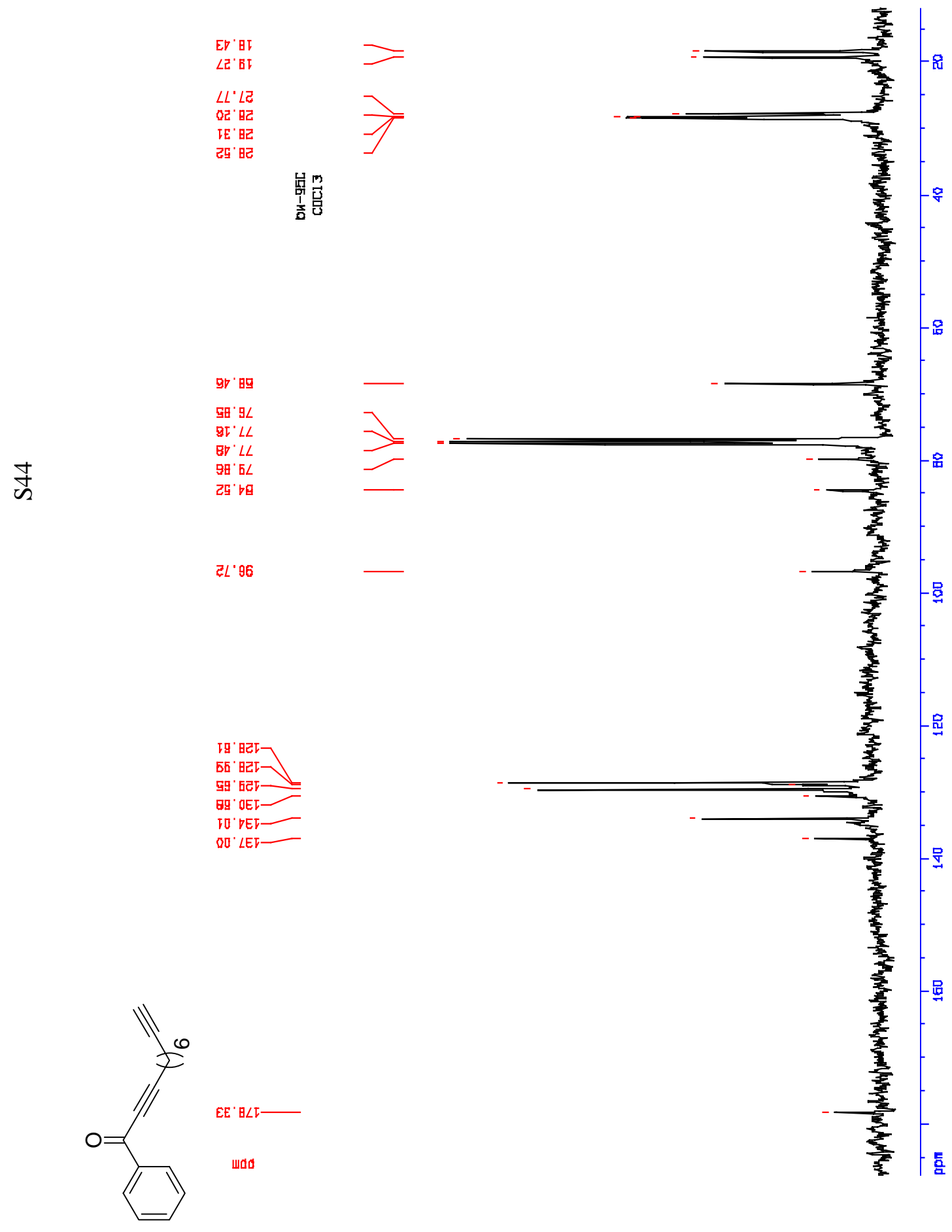


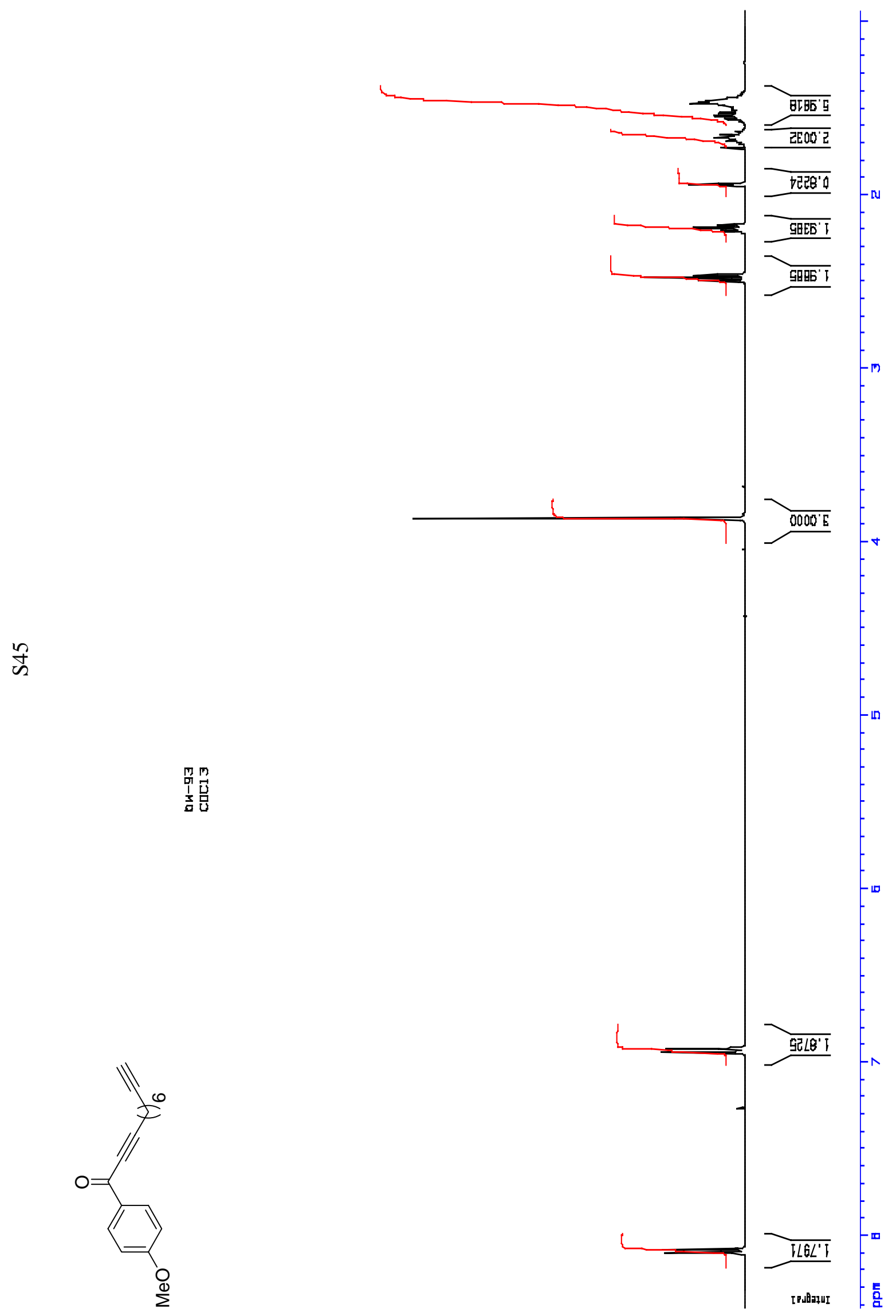




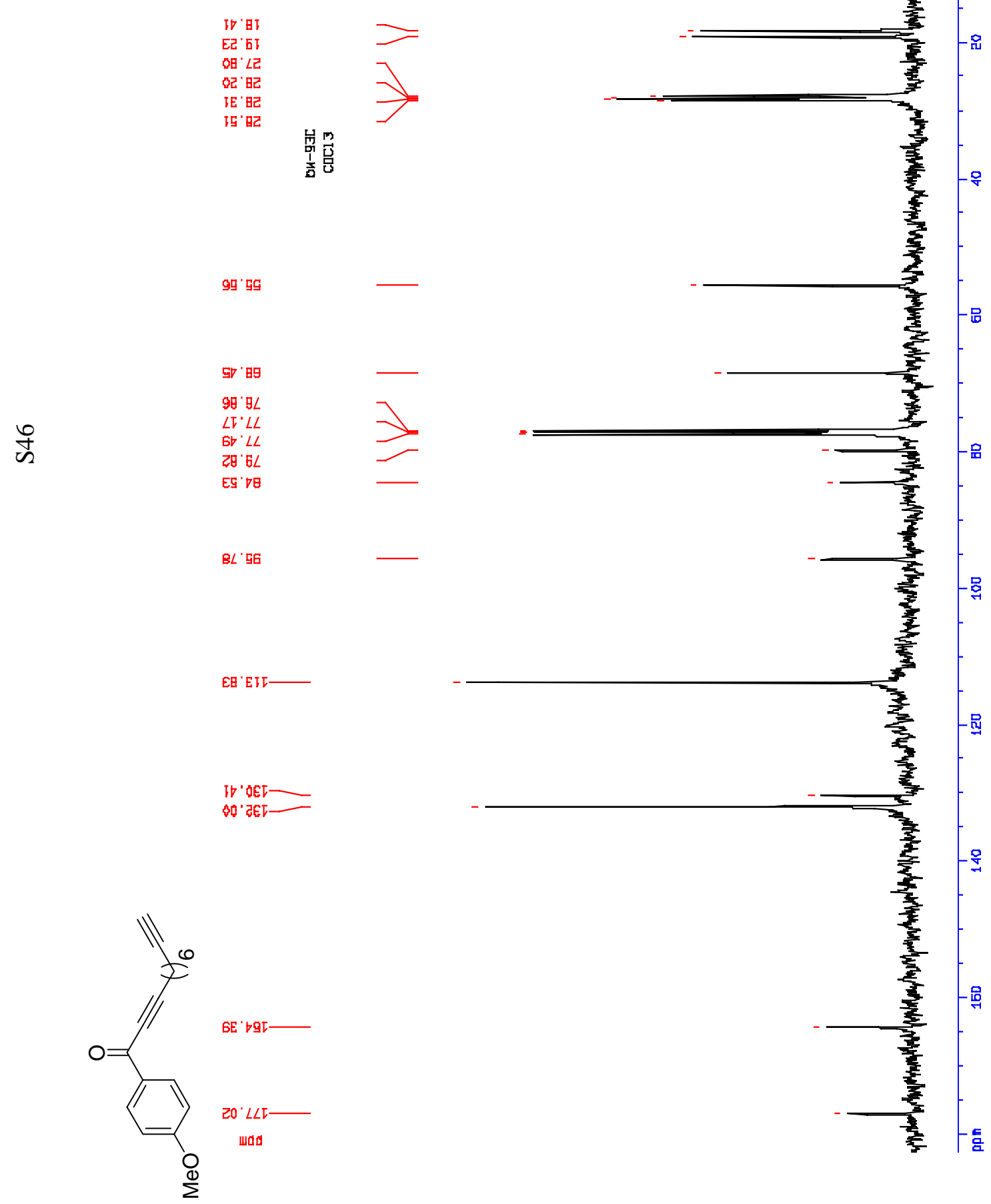




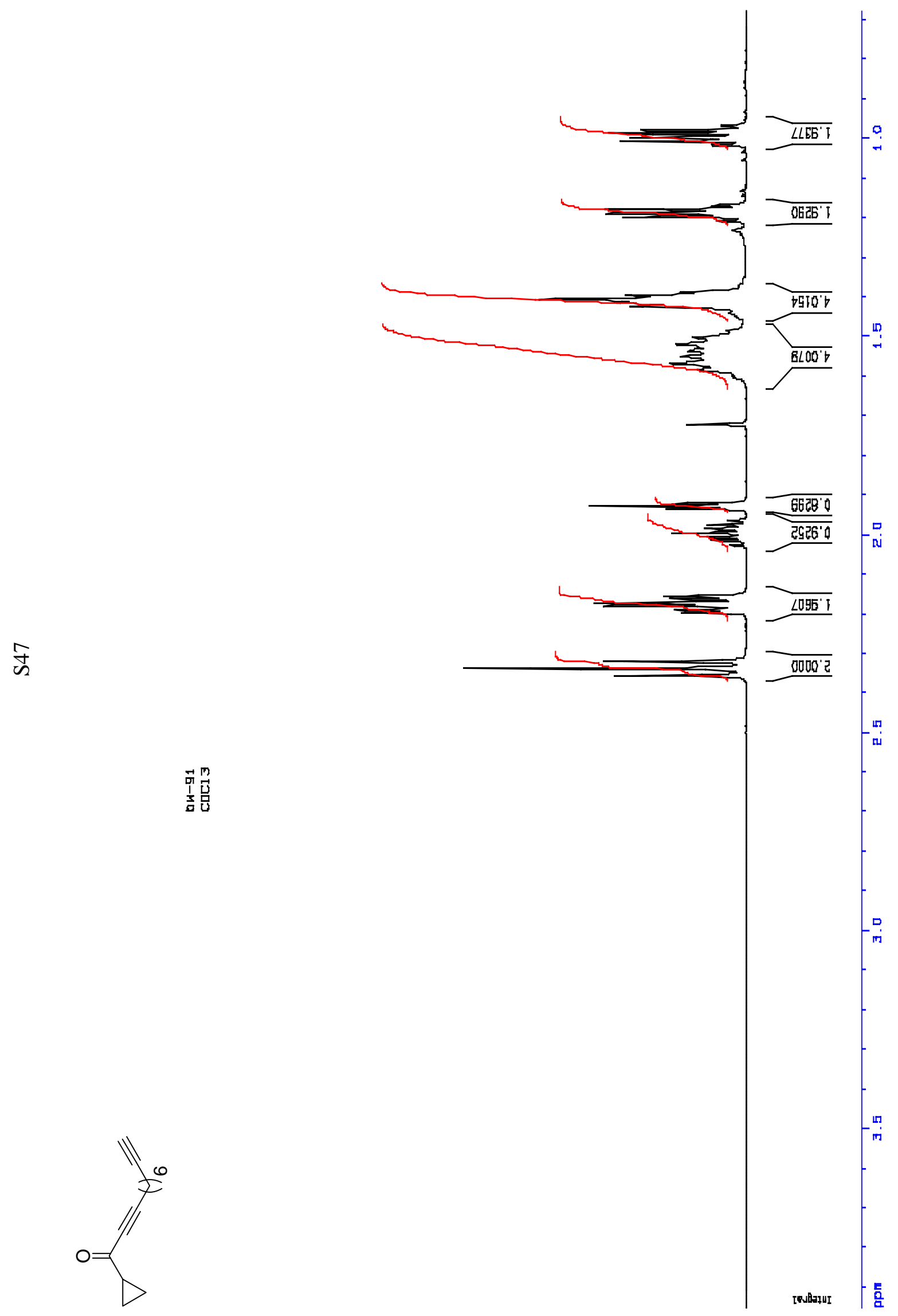



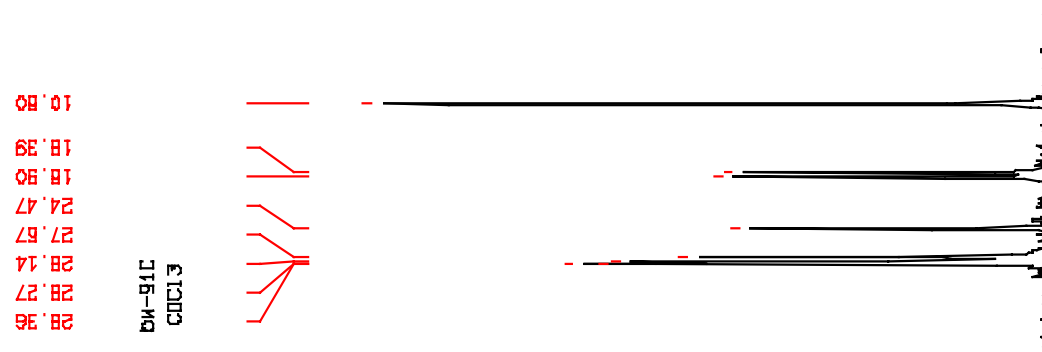

tb' 99
$5 \theta^{\prime} 9 L$
9t $L L$
gb $L L$
t0 $6 L$
gb 69

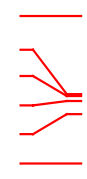

$18^{\prime} E 6$

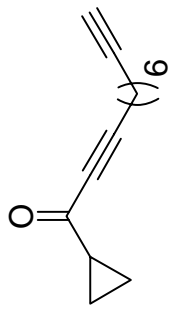

$\nabla L^{\prime} \theta \theta$
wd

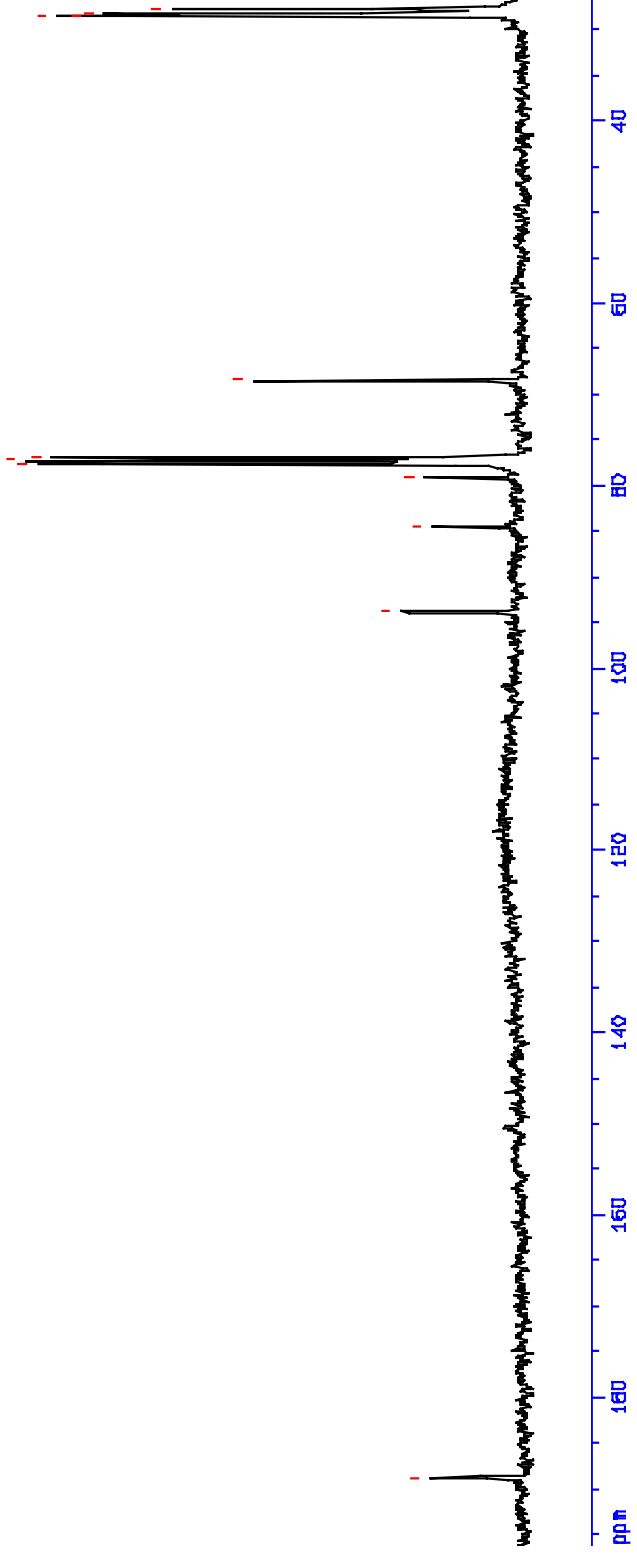




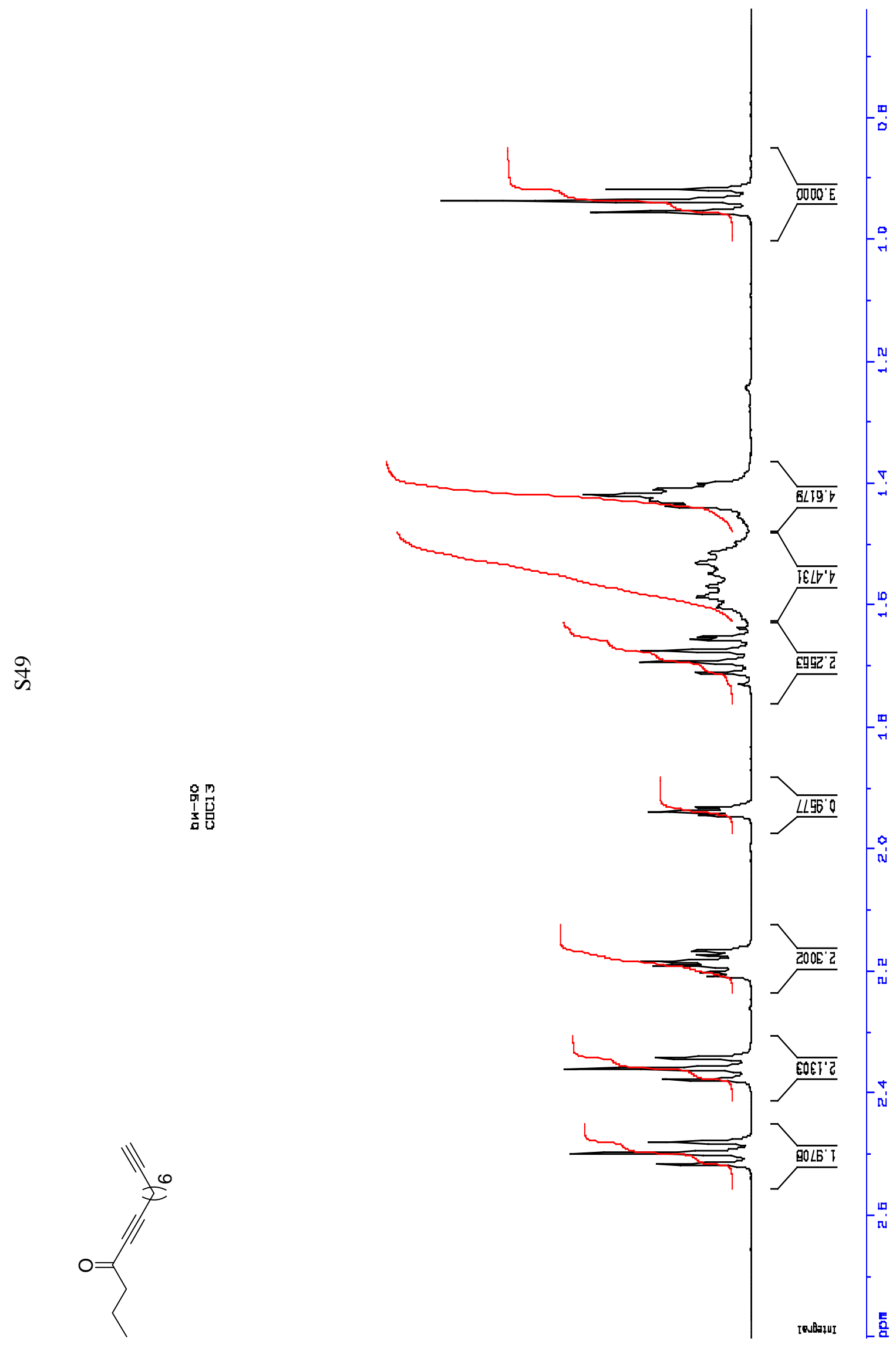




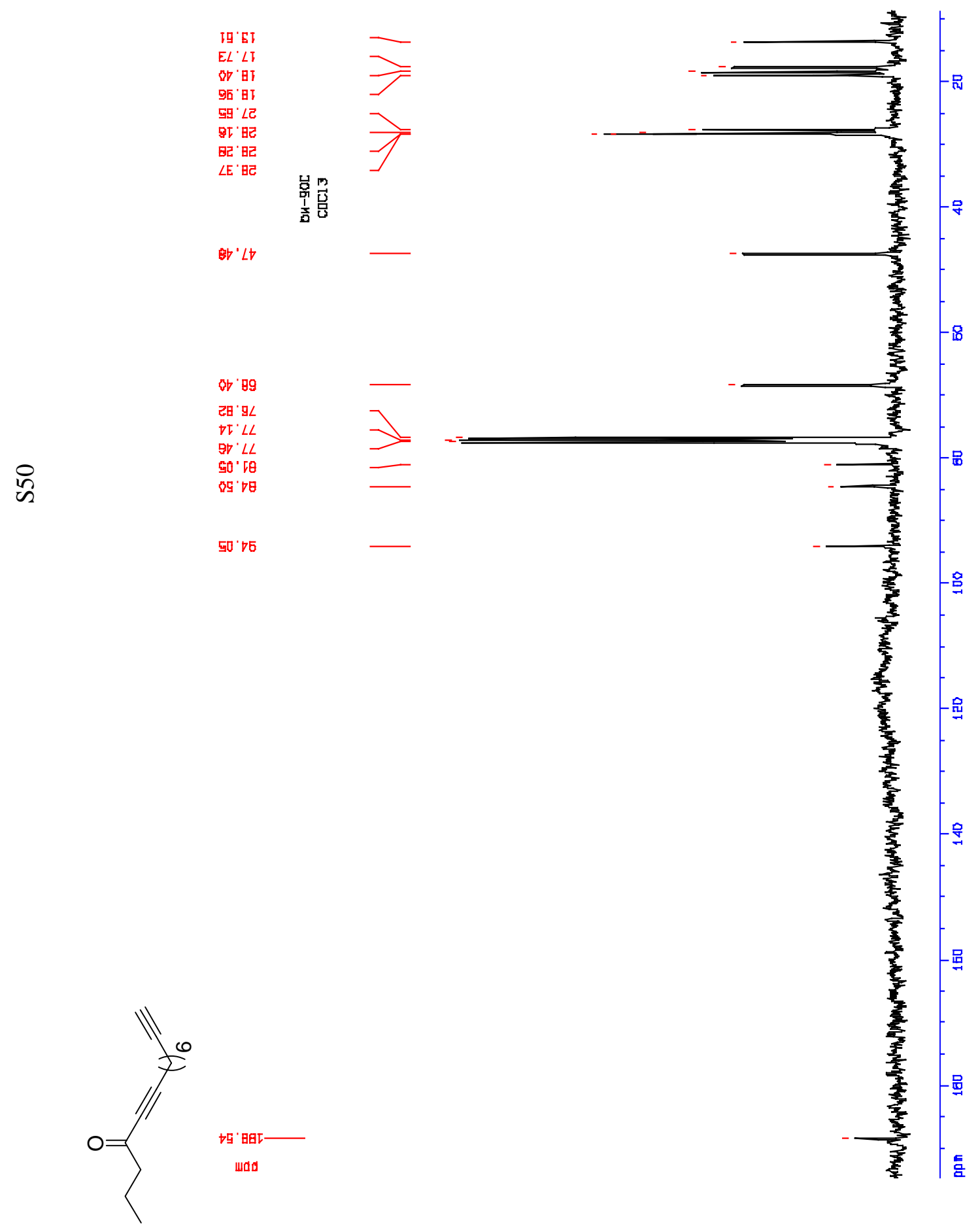




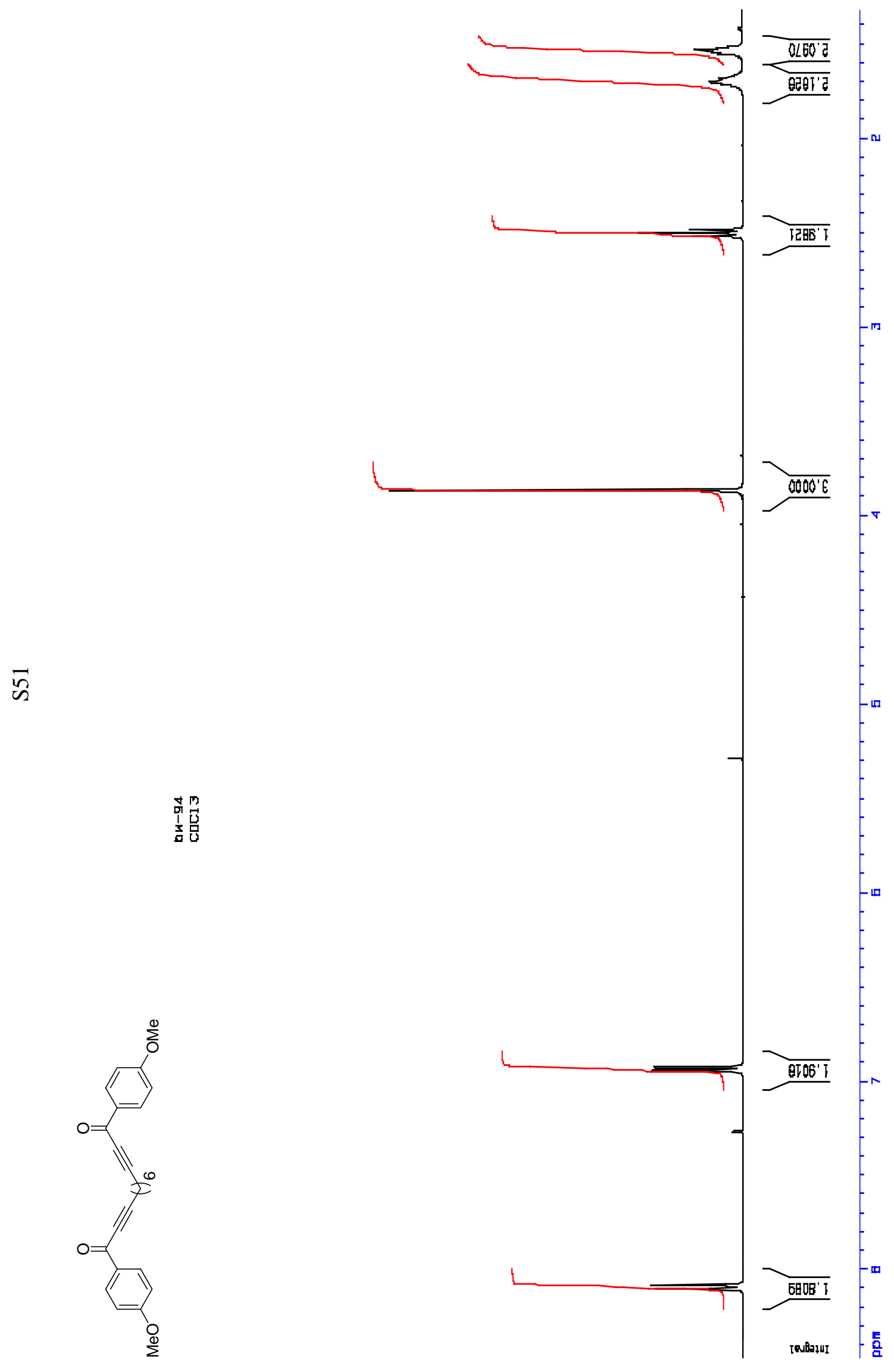




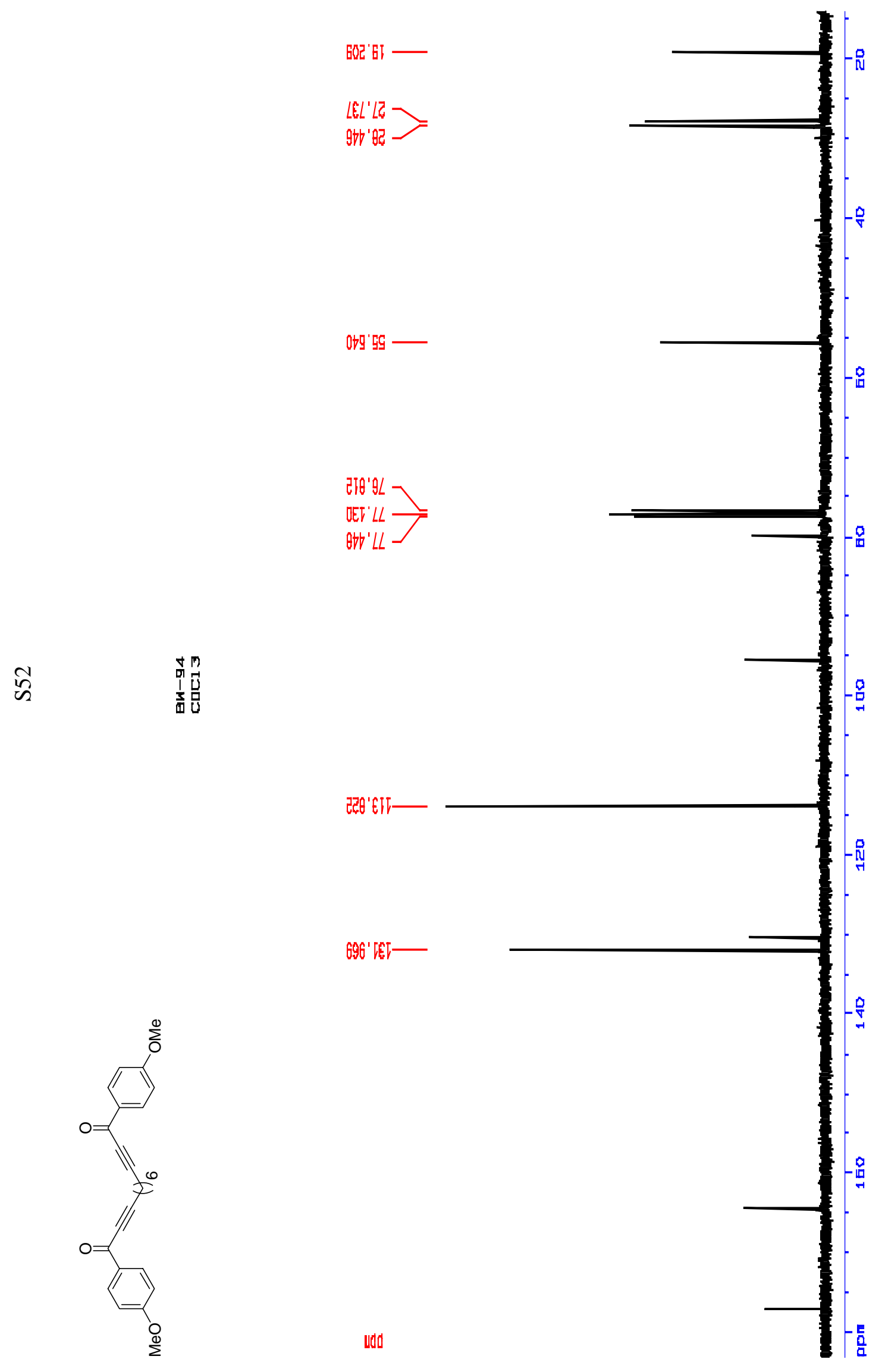




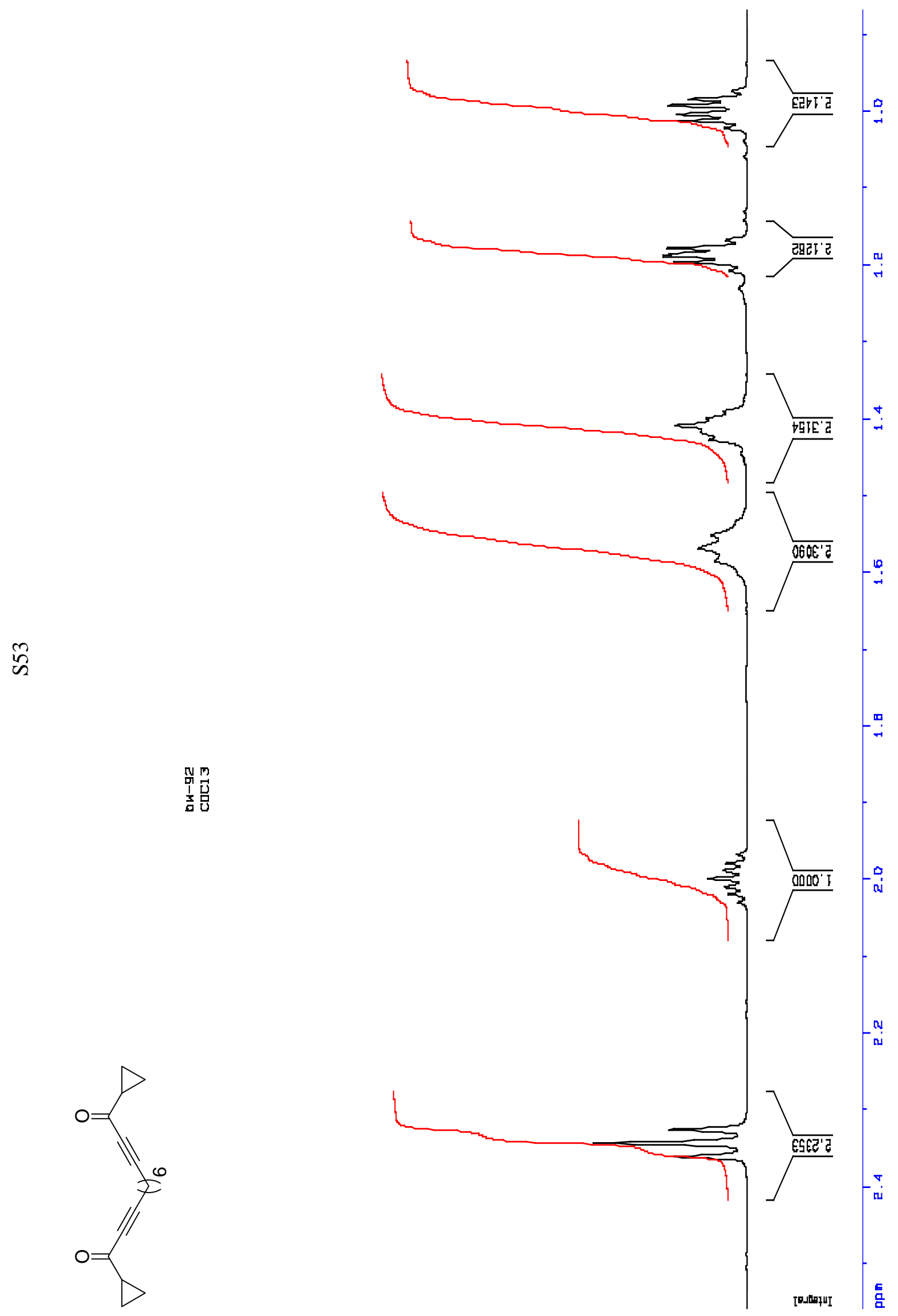




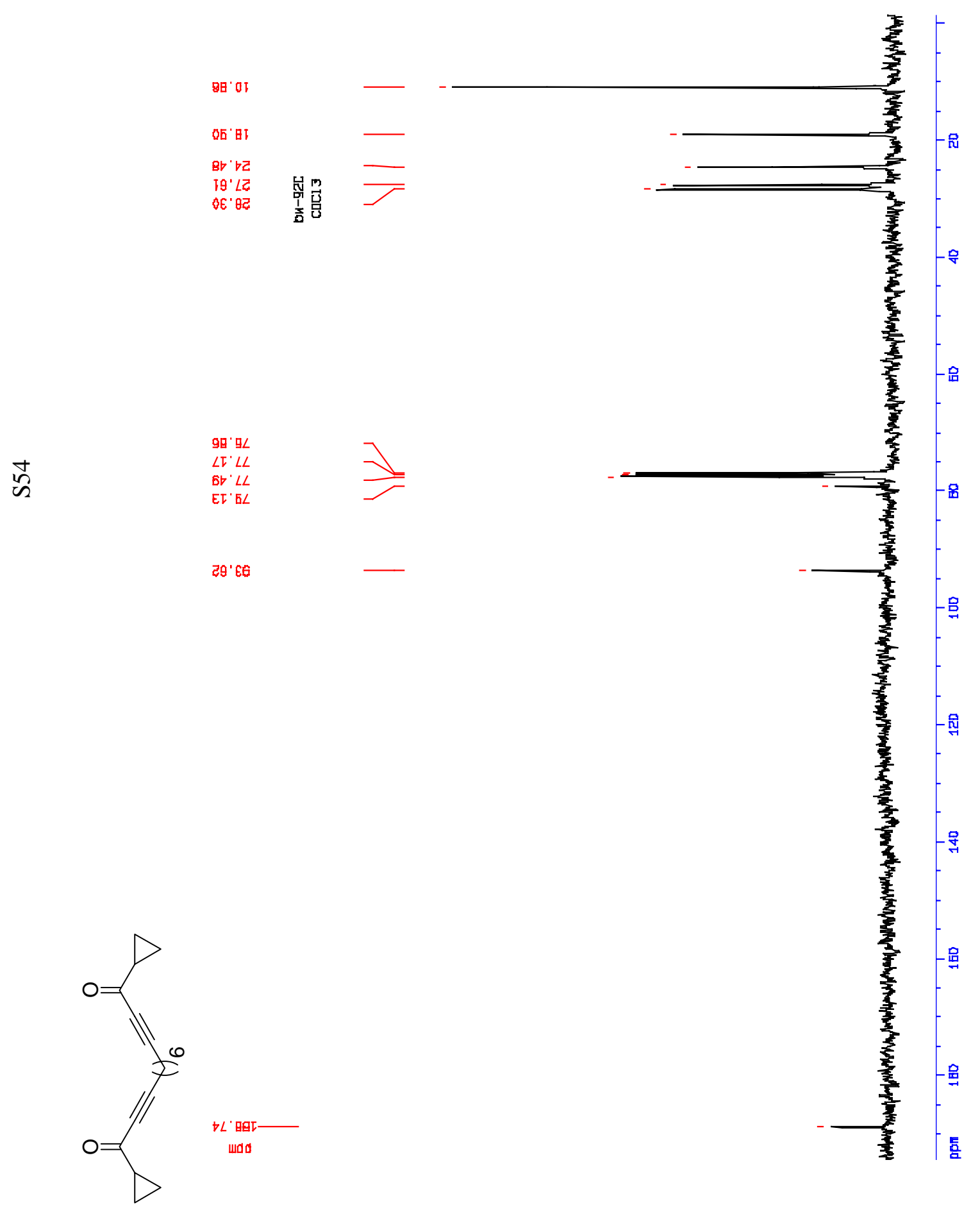




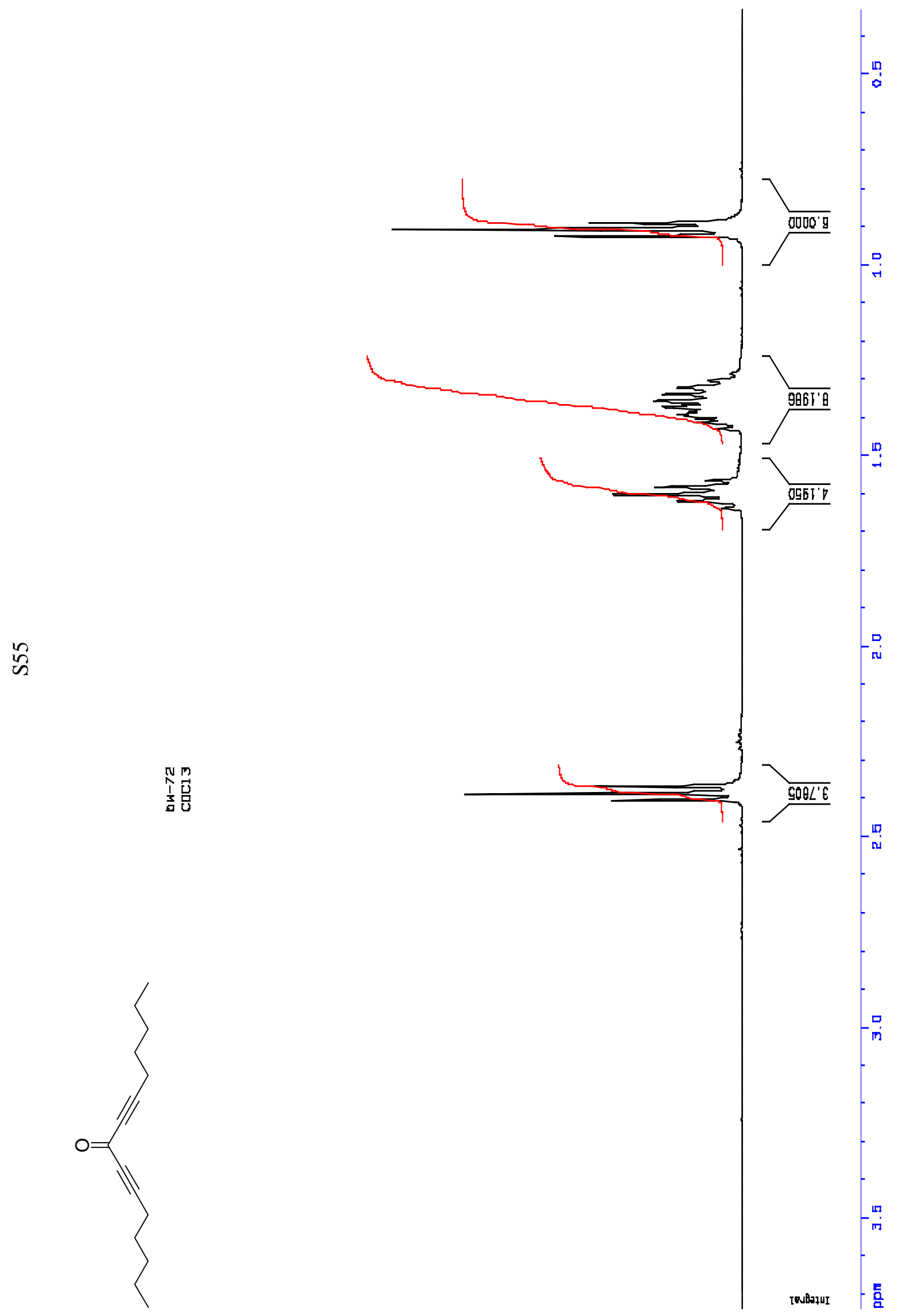



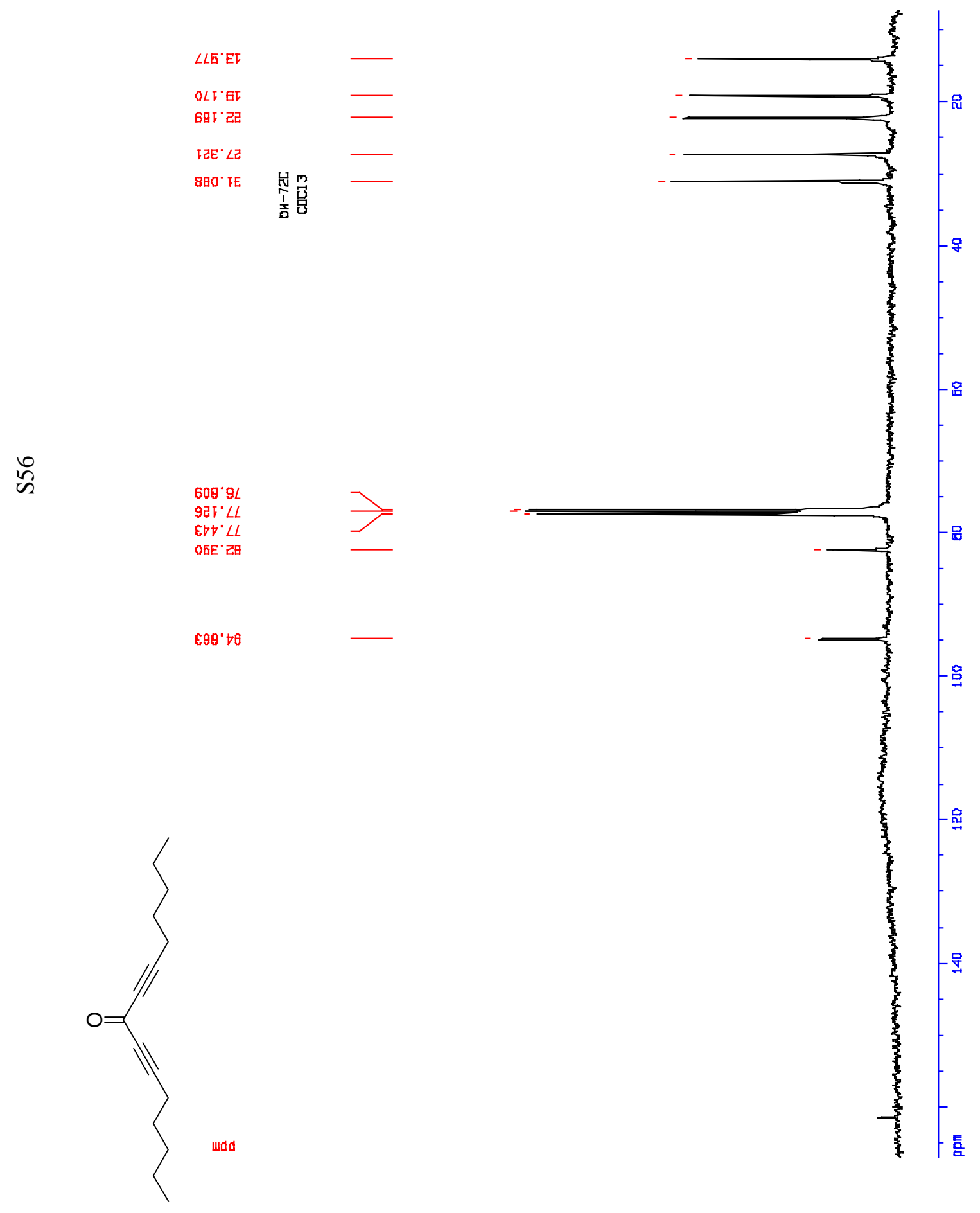